\title{
Mature and immature $\beta$-cells both contribute to islet function and insulin release
}

\section{Daniela Nasteska}

University of Birmingham

\section{Nicholas Fine}

University of Birmingham https://orcid.org/0000-0003-2343-8534

\section{Fiona Ashford}

University of Birmingham

\section{Federica Cuozzo}

University of Birmingham https://orcid.org/0000-0001-8399-1281

\section{Katrina Viloria}

University of Birmingham

\section{Gabrielle Smith}

University of Birmingham

\section{Aisha Dahir}

University of Birmingham

\section{Peter Dawson}

University of Birmingham

\section{Yu-Chiang Lai}

University of Birmingham

\section{Aimée Bastidas-Ponce}

Helmholtz Zentrum München

\section{Mostafa Bakhti}

Helmholtz Zentrum München https://orcid.org/0000-0002-2307-1122

\section{Guy Rutter}

Imperial College London https://orcid.org/0000-0001-6360-0343

\section{Remi Fiancette}

$$
\text { University of Birmingham }
$$

\section{Rita Nano}

IRCCS Ospedale San Raffaele

\section{Lorenzo Piemonti}

Vita-Salute San Raffaele University https://orcid.org/0000-0002-2172-2198

\section{Heiko Lickert}

Helmholtz Zentrum München https://orcid.org/0000-0002-4597-8825 
Weill Cornell Medical College

\section{Ildem Akerman}

University of Birmingham https://orcid.org/0000-0002-9875-1421

David Hodson ( $\nabla$ d.hodson@bham.ac.uk)

University of Birmingham https://orcid.org/0000-0002-8641-8568

\section{Article}

Keywords: $\beta$-cells, insulin release, PDX1, MAFA, diabetes

Posted Date: July 21st, 2020

DOl: https://doi.org/10.21203/rs.3.rs-40718/v1

License: (c) (i) This work is licensed under a Creative Commons Attribution 4.0 International License. Read Full License

Version of Record: A version of this preprint was published at Nature Communications on January 29th, 2021. See the published version at https://doi.org/10.1038/s41467-020-20632-z. 
Daniela Nasteska ${ }^{1,2}$, Nicholas H.F. Fine ${ }^{1,2}$, Fiona B. Ashford ${ }^{1,2}$, Federica Cuozzo ${ }^{1,2}$, Katrina Viloria $^{1,2}$, Gabrielle Smith ${ }^{1,2}$, Aisha Dahir ${ }^{1,2}$, Peter W.J. Dawson ${ }^{3,4}$, Yu-Chiang Lai ${ }^{1,3,4}$, Aimée Bastidas-Ponce ${ }^{4-7}$, Mostafa Bakhti ${ }^{4-6}$, Guy A. Rutter ${ }^{8,9}$, Remi Fiancette ${ }^{10}$, Rita Nano ${ }^{11,12}$, Lorenzo Piemonti ${ }^{11,12}$, Heiko Lickert ${ }^{4-7}$, Qiao Zhou ${ }^{13}$, Ildem Akerman ${ }^{1,2}$, David J. Hodson ${ }^{1,2^{*}}$

${ }^{1}$ Institute of Metabolism and Systems Research (IMSR), and Centre of Membrane Proteins and Receptors (COMPARE), University of Birmingham, Birmingham, B15 2TT, UK

${ }^{2}$ Centre for Endocrinology, Diabetes and Metabolism, Birmingham Health Partners, Birmingham, UK

${ }^{3}$ School of Sport, Exercise and Rehabilitation Science, University of Birmingham, B15 2TT, UK

${ }^{4} \mathrm{MRC}$-Versus Arthritis Centre for Musculoskeletal Ageing Research, University of Birmingham, Edgbaston, B15 2TT, UK

${ }^{4}$ Institute of Diabetes and Regeneration Research, Helmholtz Zentrum München, D-85764 Neuherberg, Germany

${ }^{5}$ German Center for Diabetes Research (DZD), D-85764 Neuherberg, Germany

${ }^{6}$ Institute of Stem Cell Research, Helmholtz Zentrum München, D-85764 Neuherberg, Germany

${ }^{7}$ Technical University of Munich, School of Medicine, Munich, Germany

${ }^{8}$ Section of Cell Biology and Functional Genomics and Pancreatic Islet and Diabetes Consortium, Division of Diabetes, Endocrinology and Metabolism, Imperial College London, London, W12 ONN, UK

${ }^{9}$ Lee Kong Chian School of Medicine, NanYang Technological University, Singapore

${ }^{10}$ Institute of Immunology \& Immunotherapy, College of Medical and Dental Sciences, University of Birmingham, B15 2TT, Birmingham, UK

${ }^{11}$ San Raffaele Diabetes Research Institute, IRCCS Ospedale San Raffaele, Italy

${ }^{12}$ Vita-Salute San Raffaele University, Milan, Italy

${ }^{13}$ Division of Regenerative Medicine, Department of Medicine, Weill Cornell Medical College, New York, USA

${ }^{*}$ Corresponding author: David J. Hodson, d.hodson@bham.ac.uk

Running head: Immature and mature $\beta$-cells are required for insulin release

Key words: $\beta$-cell; islet; heterogeneity; transcriptomics; chemogenetics; DREADD 


\section{ABSTRACT (147 words)}

42 Transcriptionally mature and immature $\beta$-cells co-exist within the adult islet. How such 43 diversity contributes to insulin release remains poorly understood. Here we show that 44 differences in $\beta$-cell maturity, defined using PDX1 and MAFA expression, are required for 45 proper islet operation. Functional mapping of rodent and human islets containing 46 proportionally more mature $\beta$-cells revealed defects in metabolism, ionic fluxes and insulin 47 secretion. At the transcriptomic level, the presence of increased numbers of mature $\beta$-cells led 48 to dysregulation of gene pathways involved in metabolic processes. Using a chemogenetic 49 disruption strategy, the islet signalling network was found to contribute to differences in 50 maturity across $\beta$-cells. During metabolic stress, islet function could be restored by redressing 51 the balance between immature and mature $\beta$-cells. Thus, preserving a balance between 52 immature and mature $\beta$-cells might be important for islet engineering efforts and more broadly 53 the treatment of type 1 and type 2 diabetes.

54 
Type 2 diabetes mellitus (T2DM) occurs when $\beta$-cells are unable to release enough insulin to compensate for insulin resistance. At the cellular level, glucose-regulated insulin secretion depends upon generation of ATP/ADP, closure of ATP-sensitive $\mathrm{K}^{+}\left(\mathrm{K}_{\mathrm{ATP}}\right)$ channels, opening of voltage-dependent $\mathrm{Ca}^{2+}$ channels (VDCC) and exocytosis of insulin granules ${ }^{1}$. At the multicellular level, insulin release is a tightly controlled process, requiring hundreds of $\beta$-cells throughout the islet to coordinate their activities in response to diverse stimuli including glucose, incretins and fatty acids ${ }^{2,3}$.

Our current understanding of the mechanisms underlying insulin release is mainly derived from experiments in single $\beta$-cells or measures averaged across the entire $\beta$-cell complement. However, such studies, which generally view $\beta$-cells as a tightly coupled system, are difficult to reconcile with the known heterogeneous nature of $\beta$-cell identity and function. Based on transcriptomic ${ }^{4,5}$ and protein signatures ${ }^{6}$, marker analyse ${ }^{7-9}$, glucose-responsiveness ${ }^{10,11}$, reporter imaging ${ }^{12-15}$ or single molecule hybridization ${ }^{16}, \beta$-cell subpopulations have been shown to exist with altered maturity states, metabolism, electrical activity, insulin secretion and proliferative capacity (reviewed in ${ }^{17,18}$ ). Of note, $\beta$-cell subpopulations are highly plastic. During aging and T2DM, $\beta$-cells with reduced maturity, metabolism and insulin secretion, but enhanced proliferative capacity, typically increase in proportion in both rodent and human $4,7,8$. At the same time, there is an increase in the number of mature, secretory $\beta$-cells that display poorer proliferative capacity ${ }^{6,7}$. Thus, the adult islet houses highly plastic mature and immature $\beta$-cell subpopulations whose co-existence might be important for balancing renewal with the need for insulin release.

Mature $\beta$-cells are generally thought to contribute the most to islet function, since they comprise $\sim 70-90 \%$ of the $\beta$-cell population, express higher levels of insulin, glucose transporter, glucokinase and maturity genes, and mount normal ATP/ADP and $\mathrm{Ca}^{2+}$ responses to stimulus (reviewed in ${ }^{19}$ ). By contrast, immature $\beta$-cells are in the minority, show poor glucose-responsiveness and are less secretory $4,7,8,14,19$. However, $\beta$-cell subpopulations that disproportionately influence islet responses to glucose have recently been identified in situ and in vivo ${ }^{20-22}$. One of the subpopulations, termed 'hubs', was found to display lowered expression of $\beta$-cell maturity markers and insulin, but increased expression of glucose-sensing enzymes, including glucokinase ${ }^{21,22}$. These studies provide the first glimpse that immature cells with similar characteristics might contribute to the regulation of insulin release across the islet.

We hypothesized that transcriptionally immature $\beta$-cells belong to a highly functional subpopulation, able to overcome their relative deficiencies by interacting with their more mature counterparts to drive insulin release. Using recombinant genetics together with chemogenetic disruption, we therefore set out to alter the balance of immature:mature $\beta$-cells, before determining the effect of this manoeuvre on adult islet function. 


\section{RESULTS}

\section{Generation of islets with proportionally more mature $\beta$-cells}

We first generated and validated a novel overexpression model to alter the balance between immature and mature $\beta$-cells throughout the population. Here, immature $\beta$-cells are operationally defined as expressing low levels of the transcription factors PDX1 and MAFA based upon immunohistochemistry. Islets were transduced with control adenovirus containing PATagRFP ( $\beta$ normal; B-NORM) or a well-characterized polycistronic construct encoding NEUROG3/PDX1/MAFA (Ad-M3C) ( $\beta$ mature; B-MAT). The M3C construct is well-validated ${ }^{23,24}$, a TetO mouse possessing the same construct exists ${ }^{25}$, and driving multiple transcription factors using the same promoter avoids heterogeneous expression profiles. Ad-M3C was able to drive exogenous Neurog3, Pdx1 and Mafa expression (Fig. 1a), expected to occur predominantly in the first two layers of the islet where functional imaging takes place. Native gene expression levels remained unchanged for Neurog 3 and Mafa, but $\sim 25 \%$ lower for Pdx1, consistent with the absence of positive autoregulation seen with $\mathrm{Pdx1}$-fluorophore constructs 26 .

Analyses of individual $\beta$-cells in intact islets showed a non-Gaussian distribution of PDX1 and MAFA protein fluorescence intensities in B-NORM islets, which we arbitrarily define as PDX $1^{\text {LOW/MAFA }}{ }^{\text {LOW }}$ and PDX $1^{\text {HIGH}} / M_{M A F A}{ }^{\text {HIGH }}$ using a $15 \%$ cut-off (i.e. the bins spanning 0-15 normalized PDX1/MAFA intensity units) (Fig. 1b-d). By contrast, there was a significant decrease in the proportion of cells occupying the lowest $15 \%$ of bins for detectable PDX1 and MAFA expression in B-MAT islets (Fig. 1b-d) (Fig. S1 and S2a-c).

Quantification was repeated using DAPI staining for normalization (Fig. S2d and e), or taking into account only INS+ cells (Fig. S2f), with similar results. Analysis of PDX1, MAFA and INS immunoreactivity in B-NORM showed a positive association across hundreds of cells examined, suggesting that PDX $1^{\text {LOW }}$ and MAFA ${ }^{\text {LOW }}$ cells are functionally immature (Fig 1e-g). While very low levels of NEUROG3 could be detected in B-MAT islets (Fig. S2g), a progenitor signature was not detected at the transcriptomic level (see below). A generalized PDX1 overexpression across the $\beta$-cell population was unlikely given that the mean fluorescence intensity was only slightly ( 20\%) increased in B-MAT islets (Fig. S2h-j), consistent with the reported 2-fold increase in PDX1 expression in PDX ${ }^{\text {LOW }}$ cells (Fig. 1b-d) (Fig. S1 and S2a-c). Preferential overexpression in PDX $1^{\text {LOW/MAFA }}{ }^{\text {LOW }}$ (immature) $\beta$-cells was confirmed using Pdx1-BFP reporter islets ${ }^{26}$, which read out endogenous $P d x 1$ levels. Quantification of PDX1 and BFP levels in the same cells revealed a strong positive linear correlation in B-NORM islets. However, the correlation was weaker (and slope less steep) in B-MAT islets due to transition of a subpopulation of BFPLOW cells to a PDX $1^{\mathrm{HIGH}}$ state (Fig. 1h). Supporting this finding, BFP ${ }^{\mathrm{LOW}}$ cells (prior immature cells) adopted a PDX $1^{\mathrm{HIGH}}$ phenotype in B-MAT islets, while BFP ${ }^{\mathrm{HIGH}}$ cells (prior mature) remained PDX $1^{\mathrm{HIGH}}$ (Fig. 1i and j). These changes were in line with the viral transduction efficiency, which was higher in PDX1 $1^{\text {LOW }}$ cells (Fig. S3a and b). While overlap in PDX1 levels in PDX $1^{\mathrm{LOW}}$ and PDX $1^{\mathrm{HIGH}}$ cells in B-NORM islets was observed, this likely reflects variability between experimental replicates, since the values were nonnormalized. We cannot however exclude the presence of MAFA ${ }^{\text {LOW }}$ cells that are not PDX1 $1^{\text {LOW. }}$.

To further understand the sequence of events that occur within the islet following viral transduction, time-course experiments were performed. Notably, a shift in the normalized distribution of PDX1 fluorescence was detected beginning at 24 hrs post-infection, which 
persisted until $120 \mathrm{hrs}$ (Fig. S3c-f). This change was accompanied by a gradual increase in whole islet PDX1 levels (Fig. S3g), suggesting that, at the low titres used here, immature $\beta$ cells are more susceptible to viral transduction, and that overexpression increases over time to maintain the same distribution. These data fit with previous reports showing that, while most $\beta$-cells are infected with adenovirus, transduction efficiency depends on the capacity of the cell to produce a protein ${ }^{27}$. PDX $1^{\text {Low }}$ cells are presumably well-placed to ramp-up de novo protein synthesis, since they are also INS ${ }^{\mathrm{LOW}}$ (Fig. 1e) and thus unconstrained by higher rates of insulin production.

Together, these results show a shift toward proportionally more mature $\beta$-cells in B-MAT islets following overexpression, thus validating the model.

\section{$\alpha-, \beta$ - and $\delta$-cell identity are maintained in B-MAT islets}

Further analyses of B-MAT islets detected no differences in the ratios of $\alpha$-cells or $\delta$-cells with $\beta$-cells (Fig. 1k-n), or numbers of PDX $1^{+}$INS ${ }^{+}$cells (Fig. 10 and $p$ ). Expression levels of the key $\alpha$-, $\beta$ - and $\delta$-cell identity markers Arx, Pax 6 and $N k x 6-1$ (Fig. S4a), respectively, were also unaffected. Moreover, we were unable to observe differences in the numbers of PDX $1^{+} \mathrm{GCG}^{+}$ cells (Fig. 1q) or detect bihormonal cells (Fig. S4b), consistent with the lack of viral transduction in non $\beta$-cells (Fig. S4c). Indeed, we and others have previously shown that, at the titres used here, adenovirus is highly specific for $\beta$-cells due to reduced coxsackie virus receptor expression and low capacity for protein translation in $\alpha$-cells ${ }^{27-30}$. However, we acknowledge that experiments using a nucleus reporter line would be needed to completely exclude transduction in a-cells. A major effect of PDX1 and MAFA overexpression on cell viability was unlikely, since no changes in expression of genes for ER stress or the unfolded protein response (UPR) were detected between B-NORM and B-MAT islets (Fig. S3d), in line with similar ratios of TUNEL $+\beta$-cells (Fig. 1r).

Lastly, no differences in proliferation were observed between B-NORM and B-MAT islets (Fig. 1s). Thus, mild overexpression of NEUROG3, MAFA and PDX1 leads alters the ratio of immature:mature beta cells without inducing a progenitor-like state, or detectable shifts in proliferation andapoptosis or the proportions of islet endocrine cell types. The schematic in Fig. 1 t summarizes the loss of immature $\beta$-cell model.

\section{PDX ${ }^{\text {LOW/MAFA }}{ }^{\text {LOW }} \beta$-cells are transcriptionally less mature}

We next investigated whether PDX $1^{\text {LOW/MAFA }}{ }^{\text {LOW }}$ cells possess a less mature transcriptional signature. Indeed, $\beta$-cell identity and function is maintained by a specific set of transcription factors, which are themselves under the control of a network of $\beta$-cell transcription factors (Fig. 2a) ${ }^{31}$. Networks of transcription factors regulate gene expression through binding to enhancer clusters in a combinatorial manner ${ }^{31}$. Therefore, changes in expression of $\beta$-cell specific transcription factors impact not one, but a network of transcription factors to alter abundance of other key $\beta$-cell genes.

Analysis of published RNA-seq data showed that transcriptional levels of MAFA and PDX1 are highly correlated across islet samples from 64 donors (Fig. 2b), as expected given that they belong to the same co-expression gene network module ${ }^{32}$. This tight correlation was also present for genes located in the same co-regulatory network such as NEUROD1 and NKX61 (Fig. 2c), but not for those regulated by alternative transcriptional networks such, as GAPDH and GLIS3 (Fig. 2c) ${ }^{31}$. Similar relationships were also captured at the single cell level where 
human PDX ${ }^{\text {LOW }} \beta$-cells possess lower RNA abundance of genes present in the same network module, including MAFA, MAFB and NKX6-1 (Fig. 2d) ${ }^{33}$.

Together, these co-expression data place PDX1 and MAFA at the heart of the transcription factor network that regulates $\beta$-cell identity, suggesting that the lower levels of these two key genes also indicate lower expression levels for other key $\beta$-cell transcription factors.

\section{Differences in $\beta$-cell maturity sustain stimulus-secretion coupling}

Islets were subjected to detailed functional mapping to understand how differences in $\beta$-cell maturity might influence function. Multicellular $\mathrm{Ca}^{2+}$ imaging experiments on Fluo8-loaded islets (Fig. $3 \mathrm{a}$ ) revealed reduced $\mathrm{Ca}^{2+}$ responses to glucose and the generic depolarizing stimulus $\mathrm{KCl}$ in B-MAT islets (Fig. 3b-d), which was consistent between individual islet preparations (Fig. S5a and b). Of note, PDX1 expression levels were found to be inversely correlated with $\mathrm{Ca}^{2+}$ amplitude in individual cells of Pdx1-BFP islets, i.e. PDX ${ }^{\text {LOW }}$ cells tended to mount the largest $\mathrm{Ca}^{2+}$ responses to glucose (Fig. 3a, inset). No differences in the proportion of glucose non-responsive cells were detected in B-NORM versus B-MAT islets $(6.2 \pm 1.7 \%$ vs $10.3 \pm 2.4 \%$, B-NORM vs B-MAT, respectively; non-significant) (Fig. 3e). These results were confirmed using the ratiometric $\mathrm{Ca}^{2+}$ probe Fura2 (Fig 3f-h), which again was consistent between mouse/preparation (Fig. S5c and d). Impaired $\mathrm{Ca}^{2+}$ fluxes in B-MAT islets were associated, but not causally-linked, with a decrease in mRNA expression of the L-type $\mathrm{Ca}^{2+}$ channel subunits Cacna1d and Cacnb2, but not Cacna1c (Fig. 3i).

Suggesting a defect in electrical oscillations, $\mathrm{Ca}^{2+}$ pulse duration was decreased in B-MAT versus B-NORM islets (Fig. $3 \mathrm{j}$ and $\mathrm{k}$ ). We therefore explored if the changes in $\mathrm{Ca}^{2+}$ fluxes observed in B-MAT islets were accompanied by defects in metabolism and amplifying signals. Using the biosensor Perceval, a 2-fold decrease in glucose-stimulated ATP/ADP ratios was apparent (Fig. 3l and m). Suggestive of altered glucose-sensing, $\mathrm{Ca}^{2+}$ and ATP/ADP glucose concentration-responses were reduced (Fig. 3p and q). While mRNA and protein expression levels of glucokinase were not significantly different (Fig. $3 n$ and o), we note that this does not necessarily correlate with the activity of the enzyme, which is allosterically regulated by glucokinase regulatory protein ${ }^{34}$. Indicating impaired glucose-dependent amplifying signals, cAMP levels were decreased in response to glucose and forskolin (Fig. $3 \mathrm{r}$ and $\mathrm{s}$ ). No changes in mRNA for the major murine glucose-regulated adenylate cyclase, Adcy ${ }^{35}$, were detected (Fig. 3t). Potentially unifying the abovementioned metabolic and electrical observations, analysis of PDX1 and $\mathrm{Ca}^{2+}$ targets in B-MAT islets revealed changes in expression of both G6pc2 and Ascl1 expression ${ }^{36,37}$ (Fig. 3u).

Thus, islets with proportionally more mature $\beta$-cells display profound defects in metabolism and stimulus-secretion coupling, including ionic and amplifying signals.

\section{Differences in $\beta$-cell maturity sustain islet dynamics and insulin secretion}

Since some $\beta$-cell functional subgroups possess an immature or energetic phenotype, we investigated whether loss-of-immaturity would lead to a decline in these subpopulations shown to drive islet dynamics. Fast $\mathrm{Ca}^{2+}$ recordings $(20 \mathrm{~Hz})$ detected cells whose activity preceded and outlasted that of the rest of the population. These cells, algorithmically-identified as 'hubs', comprise $\sim 1-10 \%$ of the $\beta$-cell population, orchestrate islet responses to glucose and show immature traits (PDX $1^{\text {LOW }}, \mathrm{NKX6}$ - $1^{\text {LOW }}$, INS $\left.{ }^{\mathrm{LOW}}\right)^{21}$. The proportion of hubs was decreased in B-MAT islets (Fig. 4a), most likely due to a reduction in the number of immature cells able to 
act as hubs combined with decreased expression of Gjd2 (Fig. 4b), which encodes the gap junction protein connexin 36 (Cx36). The loss of hubs was associated with a reduction in indices of coordinated $\beta$-cell activity ('connectivity') (Fig. 4c), typified by a shift toward more stochastic $\beta$-cell population responses (Fig. 4d and e) (Movie S1 and S2).

As predicted from the impairments in $\mathrm{Ca}^{2+}$ fluxes, metabolism, amplifying signals and $\beta$-cell$\beta$-cell connectivity, glucose- and Exendin-4-stimulated insulin release was markedly decreased in B-MAT islets (Fig. $4 \mathrm{f}$ and g), despite a 2-fold increase in insulin content (Fig. 4h). Insulin secretion was similar in B-NORM and B-MAT islets when uncorrected for content, suggesting that B-MAT islets release only a fraction of their secretory granule pool in response to glucose (Fig. S5e-f). However, fold-change insulin secretion remained significantly decreased in B-MAT islets (Fig.S5g). Super-resolution imaging revealed no differences in insulin granule density at the membrane (Fig.4i), in line with unchanged expression of mRNA for the exocytotic machinery (e.g. Stx1a, Snap25 and Vamp2) (Fig.4j). Implying the presence of normal insulin gene regulation, Ins 1 and Ins2 mRNA levels were unaffected (Fig. 4k and I). The loss of incretin-responsiveness was surprising given that gut- and islet-derived GLP1 ${ }^{38,39}$ potently upregulates the sensitivity of insulin granules for exocytosis ${ }^{38}$. Further analyses showed a large decrease in glucagon-like peptide-1 receptor (GLP1R) mRNA and protein expression (Fig. 4m and n), which was accompanied by impairments in Exendin-4-stimulated cAMP (Fig. 4o-q) and $\mathrm{Ca}^{2+}$ (Fig. $4 \mathrm{r}$ and s) signals.

As such, differences in $\beta$-cell maturity contribute to islet $\mathrm{Ca}^{2+}$ dynamics and insulin release.

\section{Differences in $\beta$-cell maturity are required for human islet function}

We next examined whether differences in maturity status of individual $\beta$-cells might represent a conserved route for islet function in human islets. As expected, transduction with Ad-M3C ( $\beta$ human mature; B-hMAT) led to increases in exogenous Neurog3, $P d x 1$ and Mafa mRNA levels (Fig. 5a). Endogenous levels of NEUROGN3, MAFA and PDX1 were unchanged (Fig. $5 b)$.

PDX1 fluorescence intensity distribution, visualized using antibodies with cross-reactivity against both human and mouse protein, was bimodal in B-hNORM ( $\beta$ human normal) islets, with peaks corresponding to PDX $1^{\text {LOW }}$ and PDX $1^{\mathrm{HIGH}}$ populations (Fig. $5 \mathrm{c}$ and d), again arbitrarily defined by a $20 \%$ cut-off. A similar distribution of PDX1 fluorescence was detected when normalized to DAPI staining (Fig. S6a and b), or when only PDX1+/INS1+ cells were considered (Fig. S6c). The number of cells occupying the PDX $1^{\text {Low }}$ range (i.e. immature) was decreased in B-hMAT compared to B-hNORM islets (Fig. $5 \mathrm{c}$ and d), suggesting a shift toward a more homogenous distribution of $\beta$-cell maturity. As for mouse islets, PDX1 and INS expression were found to be correlated (Fig. $5 \mathrm{e}$ ). We were unable to extend findings to MAFA and NEUROG3, since attempts at antibody staining were unsuccessful in the isolated islet.

In any case, B-hMAT islets presented with reductions in $\mathrm{Ca}^{2+}$ responses to glucose or glucose $+\mathrm{KCl}$ (Fig. 5f-i), without alterations in the proportion of responsive cells (Fig. 5j), recorded using the genetically-encoded $\mathrm{Ca}^{2+}$ indicator, GCaMP6. These defects in $\mathrm{Ca}^{2+}$ fluxes were associated with significantly lowered expression of mRNA for the $\mathrm{L}$ and $\mathrm{T}$-type $\mathrm{Ca}^{2+}$ channel subunits CACNA1C, CACNA1D and CACNA1G, as well as the $\mathrm{Na}^{+}$channel subunits SCN1B, $S C N 3 A$ and SCN8A (Fig. 5k). Islet $\mathrm{Ca}^{2+}$ dynamics were disrupted in B-hMAT islets in general, with decreases in gap junction protein expression (Fig. $5 \mathrm{l}$ ), proportion of hub cells (Fig. $5 \mathrm{~m}$ ) 
and $\beta$-cell- $\beta$-cell coordination (Fig. $5 \mathrm{n}$ and $\mathrm{o}$ ). Although glucose-stimulated insulin secretion was similar in B-hMAT and B-hNORM islets (Fig. 5p), the former released only a fraction of their granules when corrected for the increase in total insulin (Fig. $5 q$ and $r$ ). Thus, differences in $\beta$-cells maturity similarly contribute to mouse and human islet function (Fig. $5 \mathrm{~s}$ ).

\section{Increases in the proportion of immature $\beta$-cells impairs islet function}

To investigate whether a balance between mature and immature $\beta$-cells is required for normal islet operation, the opposite model was generated by inducing a higher proportion of immature cells across the population. Application of short hairpin RNAs against $P d x 1$ resulted in a leftshift in the distribution of PDX1 protein fluorescence intensities, indicative of loss of PDX1 ${ }^{\mathrm{HIGH}}$ cells (Fig. 6a and b), in-line with downregulation of Pdx1 mRNA (Fig. 6c). MAFA protein fluorescence intensity was also decreased (Fig. 6a and b), supporting the RNA-seq analysis showing that PDX1 and MAFA belong to the same regulatory network. Immunohistochemical analyses showed no changes in the $\alpha$ - to $\beta$-cell ratio, indicating that $\beta$-cells were unlikely to be de-differentiating toward an a-cell phenotype (Fig. 6d). B-IMMAT islets presented with lowered insulin content (Fig. 6e), a tendency toward increased basal hormone levels (Fig. 6f), and absence of glucose-stimulated insulin release that could be restored using Exendin-4 (Fig. $6 f$ and $\mathrm{g}$ ). Similar to overexpression experiments, glucose- and $\mathrm{KCl}$-stimulated $\mathrm{Ca}^{2+}$ fluxes were impaired (Fig. 6h-j), together with decreased expression of the VDCC subunits Cacna1d and Cacnb2 (but not Cacna1c) (Fig. 6k).

Together, these experiments demonstrate that increasing the proportion of either immature or mature $\beta$-cells results in a similar islet phenotype (i.e. perturbed insulin secretion, ionic fluxes and $\beta$-cell population dynamics) (Fig. 6l).

\section{Differences in $\beta$-cell maturity are encoded by the islet context}

Since regulated $\mathrm{Ca}^{2+}$ fluxes are critical for maintaining $\beta$-cell differentiation ${ }^{37}$, we wondered whether immature and mature $\beta$-cells might help maintain their own phenotype in the islet setting due to differences in their $\mathrm{Ca}^{2+}$ signals (i.e. through a feedforward mechanism). To test this, we repeated immunohistochemical analyses in dissociated $\beta$-cells where cell-cell communications are disrupted, and $\mathrm{Ca}^{2+}$ dynamics are less pronounced and more stochastic 21. Unexpectedly, the PDX1 and MAFA intensity distributions were right-shifted in dissociated islets, with $\beta$-cells in the PDX $1^{\text {LOW }}$ and MAFA ${ }^{\text {LOW }}$ range no longer apparent after $24 \mathrm{hr}$ culture (Fig. $7 \mathrm{a}-\mathrm{c}$ ). A PDX $1^{\text {Low }}$ subpopulation could still be detected 3 hours after coverslip attachment (Fig. 7d), and PDX1 frequency distribution was similar in scRNA or sh GJD2-treated islets (Fig. $7 \mathrm{e}$ and $\mathrm{f}$ ). As such, $\beta$-cells likely undergo a gradual adjustment in maturity status following dissociation rather than apoptosis/cell death, these changes occur independently of changes in gap junction signalling (e.g. due to alterations in paracrine input), and should be considered when extrapolating results from studies in dissociated $\beta$-cells.

To further investigate whether $\mathrm{Ca}^{2+}$ dynamics might contribute to $\beta$-cell maturity directly in the islet setting, we turned to a chemogenetic strategy to precisely control membrane potential. Conditional $\beta$-cell silencing was achieved using Ins1Cre animals crossed to a strain harboring stop-floxed alleles for hM4Di, a mutant muscarinic receptor with low affinity for endogenous acetylcholine ${ }^{40}$. Upon administration of designer ligand, the $G_{i}$ pathway is activated specifically in $\beta$-cells, leading to long-lasting electrical silencing via effects on cAMP and $G$ protein-coupled inwardly-rectifying potassium channels ${ }^{40,41}$. We used this manoeuvre to 
generate D-NORM and D-MAT islets, which possess wild-type (control) or hM4Di alleles, respectively.

Specific expression of hM4Di in $\beta$-cells was confirmed via expression of a Citrine reporter (Fig. $7 \mathrm{~g}$ ). We first tested hM4Di functionality using the second-generation hM4Di agonist J60. As expected, J60 silenced $\beta$-cell $\mathrm{Ca}^{2+}$ spiking activity within 15 mins of application to D-MAT but not D-NORM islets (Fig. 7h and i) (Movies S3 and S4). No inhibitory effects of hM4Di-alone were detected, with a small but significant increase in basal $\mathrm{Ca}^{2+}$ levels detected in the presence of the receptor (Fig. 7j). By contrast to J60, the first-generation agonist clozapine $\mathrm{N}$ oxide (CNO) decreased $\mathrm{Ca}^{2+}$ levels (Fig. 7j) and $\mathrm{Ca}^{2+}$ oscillation frequency (Fig. 7k and I) after 3 hours, but did not completely suppress $\beta$-cell activity. We took advantage of this property to disrupt rather than ablate the $\beta$-cell $\mathrm{Ca}^{2+}$ signaling network.

Following treatment of islets with $\mathrm{CNO}$ for 48 hours, immunostaining showed loss of cells in the lowest PDX1 and MAFA fluorescence intensity bins in D-MAT islets (Fig. 7m-0). While washout of CNO for 2 hrs restored baseline $\mathrm{Ca}^{2+}$ levels in D-MAT islets (Fig. 7p), $\mathrm{Ca}^{2+}$ responses to both glucose and $\mathrm{KCl}$ remained markedly impaired (Fig. $7 \mathrm{q}$ and $\mathrm{r}$ ), closely resembling those seen in both B-MAT and B-IMMAT islets. Furthermore, chemogenetic disruption decreased the proportion of cell-cell connectivity and hubs (Fig. 7s and t), which was associated with a shift to more stochastic islet dynamics (Movie S5 and S6), as expected. Gene expression analyses in D-MAT islets showed significant reductions in Cacna1d and Gjd2, with Cacna1c, Cacnb2, Ins1, Ins2, Glp1r and Gck all remaining similar to D-NORM controls (Fig. S7). The phenotype of D-MAT islets was unlikely to be dependent on insulin signaling (or loss thereof), since application of then insulin receptor antagonist S961 to wildtype islets increased the proportion of PDX ${ }^{\mathrm{LOW}}$ rather than PDX $1^{\mathrm{HIGH}} \beta$-cells (Fig. S6d and e). Moreover, selection by cell death was unlikely to feature in D-MAT islets, since a reduction (but not ablation) in $\mathrm{Ca}^{2+}$ signaling would be expected to alleviate cell stress ${ }^{42}$.

These chemogenetic experiments suggest that either: 1) differences in $\beta$-cell maturity are maintained via $\mathrm{Ca}^{2+}$ signaling patterns encoded by the islet context; or 2 ) less mature $\beta$-cells within the islet represent a ER-stressed or transitory subpopulation, which recovers its identity when rested ${ }^{42,43}$ (Fig. $7 u$ ).

\section{Differences in $\beta$-cell maturity influence downstream gene expression}

To define the transcriptional profile of islets in which immature $\beta$-cells are lost, we performed differential gene expression analysis (DGE) on control and B-MAT mouse islets. To increase $\beta$-cell maturity throughout the islet, we developed a doxycycline-inducible mouse model for the cistronic expression of PDX1, MAFA and NEUROG3. This was generated by crossing RIP7rtTA mice with those harbouring NEUROG3/PDX1/MAFA/mCherry under the control of a tetracycline response element (Tet-MAT) (Fig. 8a). As expected, Tet-MAT islets displayed increased expression of $P d x 1$, Mafa and Neurog3 in comparison to control islets (Tet-NORM) (Fig. 8b). This was accompanied by loss of immature $\beta$-cells (PDX1 $1^{\text {LOW }}$ ) (Fig. $8 \mathrm{c}$ and d), as well as impaired $\mathrm{Ca}^{2+}$ fluxes (Fig. 8e-g), without evidence of a generalized PDX1 overexpression (fluorescence intensity $=11044 \pm 1837 \mathrm{AU}$ versus $12679 \pm 1813 \mathrm{AU}$, TetNORM versus Tet-MAT, respectively; non-significant), Thus, we were able to confirm results in a third independent model, further demonstrating the robustness of the adenoviral transduction model. 
Doxycycline-treated islets from Tet-NORM and Tet-MAT mice were then subjected to transcriptomic profiling using RNA-seq. Differential gene expression analysis (DGE) revealed 83 genes whose expression was significantly altered between Tet-NORM and Tet-MAT islets (at adjusted p-value < 0.05) (Fig. 8h). The majority (94\%) of these genes were upregulated in Tet-MAT islets (Fig. 8h). Gene annotation analysis (DAVID) ${ }^{44}$ revealed that significantly upregulated genes were enriched for gene ontology clusters related to $\beta$-cell function and identity (Fig. 8i and j), confirming the validity of the model at the transcriptomic level. Gene set enrichment analysis (GSEA) also revealed upregulation of other molecular pathways such as metabolic processes linked to glucose and carbohydrate derivatives (Fig. 8k). Closer inspection of the significantly upregulated genes revealed a number of candidates that might impact insulin secretion including Ucn3, G6pc2, Cox6a2, Rgs4 and Pkib ${ }^{45-48}$, confirmed using RT-qPCR (Fig. 8I). Taken together, these results show that increasing the proportion of mature $\beta$-cells in the islet leads to upregulation of key $\beta$-cell identity markers, but also results in differential regulation of pathways, such as those involved in cellular nutrient metabolism.

\section{Restoring the balance between immature and mature $\beta$-cells is protective}

A decrease in the expression of $\beta$-cell identity makers such as NKX6-1, PDX1 and MAFA occurs during metabolic stress ${ }^{49,50}$. This may alter the balance between immature and mature $\beta$-cells, with consequences for normal islet function. We therefore examined whether restoring the balance between immature and mature $\beta$-cells would prevent islet failure in response to

373 lipotoxic insult.

Islets treated for 48 hours with high concentration of the fatty acid palmitate showed a left-shift in the PDX1 fluorescence intensity distribution, primarily due to loss of PDX $1^{\mathrm{HIGH}} \beta$-cells (Fig. 9a). Transduction with Ad-M3C reversed this loss (Fig. 9b and c), with PDX1 expression levels being indistinguishable from BSA-controls. Functional assessment of palmitate-treated islets revealed $\sim 50 \%$ lowered $\mathrm{Ca}^{2+}$ fluxes in response to both glucose and $\mathrm{KCl}$ (Fig. 9d-f). Pertinently, these deficits could be prevented using Ad-M3C (Fig. 9d-f). From this, it can be inferred that re-establishing the balance between PDX $1^{\text {LOW }}$ and PDX $1^{\mathrm{HIGH}} \beta$-cells, and thus restoring differences in $\beta$-cell maturity, protects against islet failure during metabolic stress. 
384 It is becoming increasingly apparent that $\beta$-cells can be grouped into subpopulations according to their transcriptomic and protein signatures. In particular, the existence of immature $\beta$-cells in the normal adult islet poses a conundrum, since this subpopulation is generally considered to be poorly functional when viewed in isolation $4,7,8,14$. Despite this, no previous studies have imposed changes on $\beta$-cell maturity while examining functional outcomes. Using multiple models, we show here that differences in $\beta$-cell maturity are needed across the population for proper islet function. An increase in the proportion of mature $\beta$-cells is associated with islet failure due to impaired ionic fluxes, metabolism and cell-cell connectivity (schematic in Fig. $9 \mathrm{~g}$ ). Furthermore, redressing the balance between immature and mature $\beta$-cells restores islet function under conditions of metabolic stress. Thus, our studies provide direct evidence that both immature and mature $\beta$-cells are required for proper islets function and insulin release.

Islets with an increased proportion of mature $\beta$-cells displayed a large reduction in $\beta$-cell- $\beta$ cell connectivity. This was associated with a decreased number of hubs, immature and energetic cells previously shown to coordinate glucose responsiveness ${ }^{21}$. Indeed, $\beta$-cells in B-MAT islets responded more stochastically to glucose, closely resembling the responses seen in islets from ob/ob or $\mathrm{C} \times 36^{-/}$animals ${ }^{51-53}$, as well as following silencing of hubs and their associated cell clusters ${ }^{21}$, or uncoupling of $\beta$-cells following dissociation ${ }^{21}$. How might immature $\beta$-cells affect $\beta$-cell- $\beta$-cell coordination so profoundly? We speculate that these cells might be gap junction-coupled as a network within the islet, since mRNA for Cx36 decreased $\sim 50 \%$ following their loss, although we acknowledge that dual patch recordings of PDX 1 Low cells would be needed to provide definitive evidence for this. Together with the tendency of PDX $1^{\text {LOW }}$ cells to mount higher amplitude $\mathrm{Ca}^{2+}$ rises, such preferential communication could allow a subset of $\beta$-cells to regulate excitability in neighboring $\beta$-cells, as shown by recent modelling approaches ${ }^{54}$. Alternatively, increases in the proportion of mature $\beta$-cells might perturb islet function by influencing gene expression or paracrine circuits such as those mediated by somatostatin and GABA. Nonetheless, these results obtained using three different models (viral, DREADD and doxycycline-inducible) confirm our previous optogenetic findings on hub cells ${ }^{21}$, and suggest that a continuum of immature $\beta$-cells exists with shared phenotypic and functional features.

While raw insulin secretion was unchanged in B-MAT versus B-NORM islets, the proportion of total insulin secreted was reduced. This secretory defect is likely due to a combination of factors reported here, including: 1) reduced glucose-stimulated metabolism (ATP/ADP); 2) decreased $\mathrm{Ca}^{2+}$ influx, which was refractory to generic depolarizing stimulus; 3 ) defective $\beta$ cell- $\beta$-cell coordination; and 4) impaired glucose-induced amplifying signals (cAMP), which could not be restored with incretin mimetic or forskolin. Insulin granule density at the membrane and exocytotic marker gene expression were both unchanged.

A feature of B-MAT islets was downregulated expression of genes encoding $\mathrm{Ca}^{2+}$ channels. Given that PDX1 and MAFA are required for $\beta$-cell $\mathrm{Ca}^{2+}$ fluxes, what are the mechanisms involved? One possibility is that $\mathrm{Ca}^{2+}$ channel expression is higher in immature $\beta$-cells due to a fine poise between transcription factor expression and regulation of downstream gene targets ("Goldilocks effect"). Indeed, recent studies have shown that patients with a stabilising MAFA missense mutation show reduced insulin secretion ${ }^{55}$, suggestive of defects in stimulussecretion coupling. In addition, metabolism was altered in B-MAT islets, yet Cox6a2, which encodes an electron transport chain subunit, was upregulated. Unusually, however, Cox6a2 
is an ADP-binding subunit of respiratory chain complex IV, previously shown to upregulate uncoupling protein 2 expression ${ }^{45}$. Therefore, overexpression of Cox6a2 would be expected to dissociate mitochondrial oxidative metabolism from ATP/ADP generation, as shown by our imaging data. Moreover, the decrease in ATP/ADP and $\mathrm{Ca}^{2+}$ responses to glucose detected in B-MAT islets is largely consistent with previous observations showing that cells with immature traits (hubs) ${ }^{21,22}$ are metabolically-adapted, and that cells with low exocytosis $\left(R B P 4^{+}\right)^{5}$ still possess normal $\mathrm{Ca}^{2+}$ currents. Lastly, imaging of PDX ${ }^{\mathrm{LOW}}$ cells, triaged by expression of the BFP reporter, revealed an inverse association between PDX1 levels and $\mathrm{Ca}^{2+}$ amplitude when viewed in the islet context.

Supporting a critical role for cell-cell interactions in driving a diverse profile of $\beta$-cell maturity, experiments in dissociated islets revealed a decrease in the proportion of PDX $1^{\text {LOW/MAFA }}{ }^{\text {LOW }}$ cells. The intra-islet mechanisms that support heterogeneity in $\beta$-cell maturity (and ergo the existence of PDX1 $1^{\text {LOW/MAFA }}{ }^{\text {LOW }}$ cells) likely include $\mathrm{Ca}^{2+}$ signaling dynamics and depolarization status, since PDX1 ${ }^{\mathrm{LOW}} / \mathrm{MAFA}{ }^{\mathrm{LOW}}$ cells were also reduced in chemogenetic experiments in which $\beta$-cells were conditionally perturbed. Mechanistically, $\mathrm{Ca}^{2+}$ fluxes have been shown to suppress $\mathrm{Ca}^{2+}$-regulated genes to impair $\beta$-cell identity ${ }^{37}$. Our results suggest that cells with lower levels of PDX1 and MAFA might be more sensitive to this phenomenon, since their phenotype tends to be lost when $\mathrm{Ca}^{2+}$ dynamics are dampened in the normal islet. Following chemogenetic silencing, loss-of-immature $\beta$-cells was associated with impaired $\mathrm{Ca}^{2+}$ responses to both glucose and $\mathrm{KCl}$, as for the overexpression models. By contrast, $\mathrm{Ca}^{2+}$ responses to $\mathrm{KCl}$ remain intact in $\mathrm{K}_{\mathrm{ATP}}$ gain-of-function (GOF) islets, despite similar levels of $\beta$-cell hyperpolarization ${ }^{56,57}$. This difference is likely due to changes in voltage-dependent $\mathrm{Ca}^{2+}$ channel function in D-MAT islets, which presented with decreased expression of the $\mathrm{Ca}^{2+}$ channel subunit Cacna1d. It will be interesting to explore whether immature $\beta$-cells are lost in other models where depolarization status can be controlled (e.g. using $\mathrm{K}_{\mathrm{ATP}} \mathrm{GOF}$ or optogenetics).

There are a number of limitations with the present study that should be noted. Firstly, while transition of PDX1/MAFA ${ }^{\mathrm{LOW}}$-> PDX1/MAFA ${ }^{\mathrm{HIGH}} \beta$-cells (and thus an increase in the proportion of mature $\beta$-cells) can be statistically inferred post-transduction, we cannot exclude a more widespread overexpression that also encompasses PDX1/MAFA ${ }^{\mathrm{HIGH}} \beta$-cells. Secondly, impaired $\beta$-cell function in B-MAT islets might stem from loss of transcriptional dynamics. For example PDX1/MAFA ${ }^{\text {LOW }}$-> PDX1/MAFA ${ }^{\mathrm{HIGH}}$ cells might transition over the hours timescale 9,58 , and clamping this using overexpression approaches might constrain insulin release. Thirdly, we cannot exclude that PDX1/MAFA ${ }^{\text {LOW }} \rightarrow$ PDX1/MAFA $^{\mathrm{HIGH}}$ cells become senescent or apoptotic, although neither of these possibilities are supported by our transcriptomic analyses. Also, we only looked at islets from 8-12 week-old animals and further studies are required across lifespan, as well as in response to metabolic stressors, especially since senescent $\beta$-cells possess transcriptomic signatures of immature cells ${ }^{13}$. Fourthly, NEUROG3 was mildly overexpressed, which could feasibly lead to a progenitor-like $\beta$-cell state. We think that this is unlikely, as NEUROG3 protein was only weakly detectable, NEUROG3 exists in a dephosphorylated form in the adult islet where it helps to maintain a differentiated state ${ }^{59,60}$, and results were replicated in a chemogenetic model that does not possess NEUROG3 activity. In addition, the transcriptomic profile of B-MAT islets did not reveal enrichment for progenitor signatures and classically-defined $\beta$-cell identity was apparently normal.

472 Lastly, we acknowledge a number of potential limitations with the overexpression system, 473 quantification and imaging approaches used here: 1) generalized transcription factor 
474 overexpression, especially that involving NEUROG3, might lead to impaired islet function and 475 insulin secretion; 2) underestimation of overexpression skewed toward the highest 476 PDX1/MAFA signal intensity bins cannot be excluded (i.e. it might be more difficult to detect 477 overexpression in a cell that already has high levels); 3) the imaging approaches used here 478 could suffer from technical noise, decreasing our ability to accurately quantify PDX1 and 479 MAFA; and 4) exogenous PDX1 might possess different activity or affect different targets 480 compared to endogenous PDX1. In addition, we cannot exclude that intercellular feedback is 481 present whereby when more cells express PDX1 and MAFA, those expressing the highest 482 levels make less, as suggested by the QRT-PCR analyses of endogenous Pdx1 levels. 483 Further studies using novel surface markers and lineage labels, together with scRNA-seq or 484 spatial transcriptomics, will be needed to categorically confirm overexpression specifically in 485 immature $\beta$-cells in the intact tissue.

486 In summary, we have performed an in-depth functional interrogation of islets in which 487 proportionally more $\beta$-cells have been made mature in terms of PDX1 and MAFA expression 488 levels. These studies suggest that proper islet function is dependent on the co-existence of 489 immature and mature $\beta$-cells in the tissue context. Findings from single-cell screening studies 490 or studies in dissociated cells should thus be interpreted carefully in light of differences 491 imparted by the tissue context. Importantly, recreating these subtle differences in $\beta$-cell 492 maturity might be pre-requisite for engineering more robust islets from stem cells, as well as 493 preserving insulin release during diabetes and other states of metabolic stress. 
Wild type CD1, Ins1Cre ${ }^{\text {Thor }}$ knock-in (IMSR Cat\# JAX:026801, RRID:IMSR_JAX:026801), Ins1CreERT knock-in (IMSR Cat\# JAX:026802, RRID:IMSR_JAX:026802) ${ }^{61}$ or Pdx1-BFP fusion mice ${ }^{26}$ were used as tissue donors for overexpression experiments with adenovirus containing a polycistronic construct for CMV-NEUROG3/PDX1/MAFA/mCherry (Ad-M3C) 23,24,62. Pdx1-BFP animals contain blue fluorescent protein (BFP) fused to the open reading frame (ORF) of PDX1 in which the STOP codon in exon 2 has been deleted. Pdx1-BFP mice are viable and fertile without signs of MODY4, and BFP fluorescence reflects endogenous PDX1 levels ${ }^{26}$.

To allow identification of non- $\beta$-cells, Ins 1 Cre ${ }^{\text {Thor }}$ animals were crossed with the R26 $6^{\text {TmG }}$

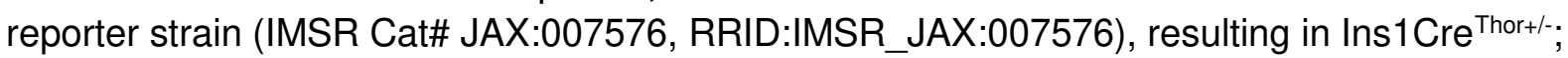
R26 ${ }^{\mathrm{mTmG}-\mathrm{fl} / \text { - }}$ animals harboring Cre-dependent excision of tdTomato.

Chemogenetic constructs were conditionally expressed in $\beta$-cells by crossing Ins1Cre animals ${ }^{61}$ with those possessing flox'd alleles for the mutant muscarinic receptor hM4Di (IMSR Cat\# JAX:026219, RRID:IMSR_JAX:026219) ${ }^{63}$. The presence of Cre was accounted for by using Ins1Cre ${ }^{\text {Thor+/-; }}$ hM4Di-DREADD ${ }^{\mathrm{fl} /-}$ (D-MAT) and Ins1Cre ${ }^{\text {Thor+/-; }}$,hM4Di-DREADD ${ }^{-/-}$(D-NORM) littermates.

To achieve conditional overexpression of $\mathrm{M} 3 \mathrm{C}$, mice harboring the tetracycline trans-activator under the control of the Ins2 promoter (RIP7rtTA) ${ }^{64}$ were crossed with animals engineered to possess $\mathrm{M} 3 \mathrm{C}$ upstream of a tetracycline response element (M3C-TetON) ${ }^{25}$. Littermate controls contained the RIP7rtTA allele, given previously reported issue with Ins2 constructs (RIP7rtTA $^{+--} ;$TetO-M3C $^{+/-}$and RIP7rtTA ${ }^{+/-}$TetO-M3C ${ }^{-/-}$, termed Tet-MAT and Tet-NORM, respectively). 64

Male and female 6-12 week-old animals were maintained in a specific pathogen free facility, with free access to food and water. Animal studies were regulated by the Animals (Scientific Procedures) Act 1986 of the U.K., and approval was granted by the University of Birmingham's Animal Welfare and Ethical Review Body.

\section{Human donors}

Human islets were obtained from Canada (Alberta Diabetes Institute, IsletCore) and Italy (San Raffaele, Milan), with necessary local and national ethical permissions, including consent from the next of kin. Studies with human tissue were approved by the University of Birmingham Ethics Committee, as well as the National Research Ethics Committee (REC reference 16/NE/0107, Newcastle and North Tyneside, U.K.). Donor characteristics are reported in Table S1.

\section{Islet isolation}

Mice were euthanized by cervical dislocation before inflation of the pancreas via injection of collagenase solution ( $1 \mathrm{mg} / \mathrm{ml}$; Serva NB8) into the bile duct. Pancreata were then digested for 12 mins at $37^{\circ} \mathrm{C}$ in a water bath before purification of islets using a Histopaque or Ficoll gradient. Islets were hand-picked and cultured $\left(5 \% \mathrm{CO}_{2}, 37^{\circ} \mathrm{C}\right)$ in RPMI medium containing $10 \%$ FCS, 100 units $/ \mathrm{mL}$ penicillin, and $100 \mu \mathrm{g} / \mathrm{mL}$ streptomycin. 


\section{Human Islet Culture}

Human islets were cultured $\left(5 \% \mathrm{CO}_{2}, 37^{\circ} \mathrm{C}\right)$ in: CMRL supplemented with $10 \% \mathrm{FCS}, 100$ units $/ \mathrm{mL}$ penicillin, $100 \mu \mathrm{g} / \mathrm{mL}$ streptomycin, $0.25 \mu \mathrm{g} / \mathrm{mL}$ fungizone and $5.5 \mathrm{mmol} / \mathrm{L}$ D-glucose and low glucose DMEM supplemented with $10 \% \mathrm{FCS}, 100 \mathrm{units} / \mathrm{mL}$ penicillin and $100 \mu \mathrm{g} / \mathrm{mL}$ streptomycin. For donor details, see Table S1.

\section{Loss of immature and mature $\beta$-cells}

WT islets were transduced for 48-72 hours with Ad-M3C construct ${ }^{65}$. Ad-PATagRFP ${ }^{21}$ was used to confirm absence of off-target effects. For knockdown of PDX1, mCherry-tagged short hairpin RNA against $P d x 1$ (shPdx1) or scrambled control (scRNA) were delivered using adenovirus (Vector Biolabs Cat\# shADV-268353 and 1122). Expression levels were verified with RT-qPCR using SYBR Green or TaqMan chemistry with primers and probes against viral and native Neurog3, $P d x 1$ and Mafa ${ }^{24,65}$. Additionally, experiments were repeated using islets isolated from Pdx1-BFP fusion mice ${ }^{26}$. Islets from RIP7rtTa ${ }^{+/-} ; \mathrm{M} 3 \mathrm{C}-\mathrm{TetON}^{+/-}$and RIP7rtTa ${ }^{+/-}$ ;M3C-TetON ${ }^{-1-}$ mice were incubated with doxycycline $100 \mathrm{ng} / \mathrm{ml}$ for 48 hours to induce transgene expression.

\section{Gene expression-mRNA levels}

Quantitative real-time PCR (RT-qPCR) was performed on an Applied Biosystems 7500 and QuantStudio 5 instruments using PowerUp SYBR Green Master Mix (Thermo Fisher Scientific Cat\# A25742), or Taqman Fast Advanced Master Mix (Thermo Fisher Scientific Cat\#4444557) and fold-change in mRNA expression was calculated compared with Actb/Gapdh/Ppia by using the $2^{-\Delta \Delta \mathrm{Ct}}$ method. Gap junction knock down was achieved using adenoviral particles harboring either Gjd2 shRNA or scrambled control (Vector Biolabs), as previously described ${ }^{21}$. For primer and probe details, see Table S2.

\section{Immunostaining}

Islets were incubated overnight at $4^{\circ} \mathrm{C}$ with primary antibodies against MAFA (Bethyl Cat\# IHC-00352, RRID:AB_1279486), PDX1 (DSHB Cat\# F6A11, RRID:AB_1157904 and Abcam Cat\# ab47308, RRID:AB_777178), NEUROG3 (DSHB Cat\# F25A1B3) insulin (Cell Signaling Technology Cat\# 3014, RRID:AB_2126503), glucagon (Sigma-Aldrich Cat\# G2654, RRID:AB_259852), somatostatin (Thermo Fisher Scientific Cat\# 14-9751-80, RRID:AB_2572981), glucokinase (Santa Cruz Biotechnology Cat\# sc-7908, RRID:AB_2107620), GLP1R (DSHB Cat\# Mab 7F38, RRID:AB_2618101) and GFP (Aves Lab Cat\# 1020), before washing and application of either Alexa/DyLight 488 (Thermo Fisher Scientific Cat\# A-11029, RRID:AB_2534088 and Thermo Fisher Scientific Cat\# SA5-10038, RRID:AB_2556618), Alexa 568 (Thermo Fisher Scientific Cat\# A10042, RRID:AB_2534017) and Alexa/DyLight 633 (Thermo Fisher Scientific Cat\# A-21052, RRID:AB_2535719 and Thermo Fisher Scientific Cat\# 35513, RRID:AB_1965952) secondary antibodies. To avoid cross-reactivity between antibodies from the same species, sequential staining and reblocking was performed. Samples were mounted on coverslips containing VECTASHIELD HardSet with DAPI (Vector Laboratories Cat\# H-1500).

Imaging was performed using Zeiss LSM780/LSM880 confocal microscopes equipped with $25 x$ / 0.8 / water, 40x / 1.2 / water and 100x / 1.46 / oil objectives. Super-resolution imaging was performed using the Airyscan module of the LSM880 ( 140 nm). Excitation was delivered 
using $\lambda=405 \mathrm{~nm}, 488 \mathrm{~nm}, 561 \mathrm{~nm}$ and $633 \mathrm{~nm}$ laser lines. Signals were detected at $\lambda=428$ $481 \mathrm{~nm}$ (DAPI), $\lambda=498-551 \mathrm{~nm}$ (Alexa/DyLight 488), $\lambda=577-621 \mathrm{~nm}$ (Alexa568) and $\lambda=641$ $739 \mathrm{~nm}$ (Alexa/Dylight 633) using highly-sensitive GaAsP spectral detectors. A subset of experiments was performed using a Leica TCS SP5 confocal equipped with a $63 x$ / 1.3 / glycerol objective and HyD detectors. Quantification of PDX1 and MAFA staining was performed using a custom routine in ImageJ. Briefly, Gaussian filtered images were subjected to an auto-threshold and binarization step to create a mask, which was then used to identify mean pixel intensity in each $\mathrm{PDX} 1^{+}$or $\mathrm{MAFA}^{+}$cell before construction of a frequency distribution. Glucokinase, insulin, glucagon and somatostatin were quantified using corrected total cell fluorescence (CTCF), according to the following equation: CTCF = integrated density - (area of ROI x mean fluorescence of background). Images were de-noised using a Gaussian smoothing procedure, and linear adjustments to brightness and contrast were made for presentation purposes.

\section{Live imaging}

For $\mathrm{Ca}^{2+}$ imaging, islets were loaded with Fluo8 (AAT Bioquest Cat\# 21082-AAT) or Fura2 (HelloBio HB0780-1mg), or transduced with GCaMP6 ${ }^{m}$, before imaging using a Crest X-Light spinning disk system coupled to a Nikon Ti-E base and $10 \times / 0.4 /$ air or $25 \times / 0.8 /$ air objective. In Fluo8 experiments, excitation was delivered at $\lambda=458-482 \mathrm{~nm}$ using a Lumencor Spectra $X$ light engine, with emitted signals detected at $\lambda=500-550 \mathrm{~nm}$ using a Photometrics Delta Evolve EM-CCD. For experiments with the ratiometric $\mathrm{Ca}^{2+}$ indicator, Fura2, excitation was delivered at $\lambda=340 \mathrm{~nm}$ and $\lambda=385 \mathrm{~nm}$ using a FuraLED system, with emitted signals detected at $\lambda=470-550 \mathrm{~nm}$.

ATP/ADP imaging was performed as for Fluo8, except islets were infected with adenovirus harboring the ATP/ADP sensor, Perceval ${ }^{66}$, for 48 hours. For cAMP imaging, islets were infected with adenovirus harboring Epac2-camps (a kind gift from Prof. Dermot Cooper, Cambridge). Excitation was delivered at $\lambda=430-450 \mathrm{~nm}$ and emission detected at $\lambda=460$ 500 and $\lambda=520-550 \mathrm{~nm}$ for Cerulean and Citrine, respectively. Fura2 and Epac2-camps intensity were calculated as the ratio of $340 / 385$ or Cerulean/Citrine, respectively. Traces were presented as raw or $F / F_{\text {min }}$ where $F=$ fluorescence at any timepoint and $F_{\min }=$ minimum fluorescence.

Ins1Cre;R26 ${ }^{\mathrm{mTmG}}$ islets were transduced with Ad-M3C before live imaging using a Zeiss LSM780 meta-confocal microscope, as above. mGFP, tdTomato and mCherry were excited with $\lambda=488 \mathrm{~nm}, 561 \mathrm{~nm}$ and $594 \mathrm{~nm}$ laser lines. Excitation was collected at $\lambda=498-551 \mathrm{~nm}$ (mGFP), $\lambda=573-590 \mathrm{~nm}$ (tdTomato) and $\lambda=603-691 \mathrm{~nm}$ (mCherry).

In all cases, HEPES-bicarbonate buffer was used, containing (in mmol/L) $120 \mathrm{NaCl}, 4.8 \mathrm{KCl}$, $24 \mathrm{NaHCO}_{3}, 0.5 \mathrm{Na}_{2} \mathrm{HPO}_{4}, 5 \mathrm{HEPES}, 2.5 \mathrm{CaCl}_{2}, 1.2 \mathrm{MgCl}_{2}$, and 3-17 D-glucose.

\section{Western blotting}

Samples were collected in urea Laemmli sample buffer $(0.2 \mathrm{M}$ Tris- $\mathrm{HCl}, \mathrm{pH} 6.8,40 \%$ glycerol, $8 \%$ SDS, 5\% B-ME, 6M Urea, $0.005 \%$ Bromophenol Blue) and sonicated ( $2 \times 5$ seconds at $20 \mathrm{kHz})$. Proteins were separated by SDS-PAGE (10\% Acrylamide Bis-Tris Gel) with MOPSSDS running buffer and transferred on to PVDF membranes. Membranes were blocked with TBS-T buffer (Tris-Buffered Saline containing 0.1\% Tween-20) containing 5\% (w/v) non-fat skimmed milk powder for 1 hour at room temperature. Membranes were then incubated in 
antibodies against PDX1 (lowa DSHB Cat\#F6A11, RRID:AB_1157904) and GAPDH (Cell Signaling Technology Cat\# 5174, RRID:AB_10622025), diluted in TBS-T containing 3\% (w/v) bovine serum albumin (BSA) overnight at $4^{\circ} \mathrm{C}$. Membranes were washed $3 \times 10$ mins in TBS$T$ followed by incubation in horseradish peroxidase-conjugated (HRP-conjugated) secondary antibodies in TBS-T for $1 \mathrm{~h}$ at room temperature. Membranes were washed for a further $3 \times 10$ mins in TBS-T. ECL western blotting detection reagent (Millipore Cat\# WBKLS0500) was used as per manufacturer's instructions to expose images followed by capture on G-Box (SynGene Chemi XR5).

\section{Insulin secretion measures}

Mouse: batches of 10 mouse islets were acclimatized in low protein-bind $1.5 \mathrm{ml}$ Eppendorf tubes containing $0.5 \mathrm{ml}$ HEPES-bicarbonate buffer supplemented with $3 \mathrm{mM}$ glucose and $0.1 \%$ BSA. Buffer was then removed before addition of either $3 \mathrm{mM}$ glucose, $16.7 \mathrm{mM}$ glucose or $16.7 \mathrm{mM}$ glucose + $20 \mathrm{nM}$ Exendin-4 (AnaSpec Cat\# ANA24463), and incubation for 30 min at $37^{\circ} \mathrm{C}$. Human: batches of 15 human islets were stimulated with $3 \mathrm{mM}$, glucose, 16.7 $\mathrm{mM}$ glucose or $16.7 \mathrm{mM}$ glucose $+20 \mathrm{nM}$ Exendin-4 according to IsletCore protocols 10 ("Static Glucose-stimulated Insulin Secretion (GSIS) Protocol - Human Islets V.2"). Total insulin was extracted using acid ethanol and insulin concentration determined using an ultrasensitive HTRF assay (Cisbio Cat\# 62IN2PEG) according to the manufacturer's instructions. In all cases, values are normalized against total insulin for each individual experiment to account for differences in $\beta$-cell proportion with treatment and islet size.

\section{Chemogenetics}

The h4MDi ligands JHU37160 (J60) (Hello Bio Cat\# HB6261) and clozapine N-oxide (CNO) (Tocris Cat\# 4936/10) were applied to islets at $1 \mu \mathrm{M}$ for the indicated time points. While P450 converts CNO into clozapine, which promiscuously binds endogenous receptors in vivo ${ }^{67}$, this is not expected to be an issue in vitro. In any case, CNO was present under all conditions examined to account for off-target effects. For assessment of intraislet insulin signaling, control islets were treated with $50 \mathrm{nM}$ insulin receptor antagonist S961 (Phoenix Pharmaceuticals, Cat\# 051-56) for 48h.

\section{Next generation sequencing}

Sequencing libraries were prepared using RNA (RIN >7) with the Lexogen Quantseq3 FWD kit (Lexogen Cat\# 015.24). Libraries were sequenced using HiSeq2000 across a single flowcell generating 75bp long single ended reads (Illumina Cat\# 20024904). All samples were prepared and sequenced as a single pool. Trimmomatic software (v0.32) and bbduk.sh script (Bbmap suite) was used to trim the ILLUMINA adapters, polyA tails and low-quality bases from reads. Trimmed reads were then uniquely aligned to the human genome (hg38) using STAR (v2.5.2b) and the Gencode (v28, Ensembl release 92) annotation as the reference for splice junctions. Between 4-6M mapped reads per sample were quantified using HT-seq (v0.9.1) using Gencode (v28) genes (-intersection-nonempty flag).

\section{Correlation and wavelet analyses}

659 Detection of superconnected islet regions was performed using matrix binarization analyses developed in-house, as previously described ${ }^{68}$. Briefly, cells were identified using a region of 
decomposition to remove noise and baseline trends, and a $20 \%$ threshold imposed to binarize cells according to activity status. Co-activity between all cell pair combinations was assessed using the equation $C_{i j}=T_{i j} / \sqrt{ } T_{i} T_{j}$ where $C$ is a correlation coefficient, $T_{i}$ and $T_{j}$ is the period spent $\mathrm{ON}$ for each cell, and $\mathrm{T}_{\mathrm{ij}}$ is the period both cells spend $\mathrm{ON}$ together. Significance was calculated versus the randomized dataset for each cell pair using a permutation step for each binarized data row. This analysis allows identification of cells whose activity repetitively spans that of the rest of the population. Superconnected cells or hubs were defined as cells possessing $60-100 \%$ of the correlated links and plotted on functional connectivity maps using the Euclidean coordinates.

Wavelet analysis was used to determine the time-localized $\mathrm{Ca}^{2+}$ oscillation frequency. Spectra were extracted from $\mathrm{Ca}^{2+}$ traces with a univariate bias-corrected wavelet transform ("biwavelet" package in $\mathrm{R}$ ), which prevents compression of power as period lengthens. Period was then depicted against time, with a color ramp representing frequency power.

\section{Differential gene expression analyses}

Differential gene expression was obtained using DEseq2 with age- and sex-matched paired Tet-NORM $(n=5)$ and Tet-MAT samples $(n=5)$. Differentially expressed genes between control and Tet-MAT islets at adjusted $p$-value $<0.05$ were annotated using DAVID BP_FAT ${ }^{44}$, with high stringency for clustering.

Gene set enrichment analysis (GSEA) was used to interrogate specific gene sets against expression data. GSEA calculates an Enrichment Score (ES) by scanning a ranked-ordered list of genes (according to significance of differential expression (-log10 p-value)), increasing a running-sum statistic when a gene is in the gene set and decreasing it when it is not. The top of this list (red) contains genes upregulated in Tet-MAT islets while the bottom of the list (blue) represents downregulated genes. Each time a gene from the interrogated gene set is found along the list, a vertical black bar is plotted ("hit"). If the "hits" accumulate at the bottom of the list, then this gene set is enriched in downregulated genes (and vice versa). If interrogated genes are distributed homogenously across the rank-ordered list of genes, then that gene set is not enriched in any of the gene expression profiles. We converted human gene sets into homologous mouse gene sets using homologous gene database from MGI.

\section{Statistical analyses}

All analyses were conducted using GraphPad Prism, Igor Pro, R Project or MATLAB software. Unpaired or paired Student's t-test was used for pairwise comparisons. Multiple interactions were determined using normal or repeated measures ANOVA followed by Bonferroni, Sidak or Tukey posthoc testing (accounting for degrees of freedom). Straight lines were fitted with linear regression whilst a polynomial trend was used for multiple regression. Goodness of fit was calculated using $\mathrm{R}^{2}$.

\section{Data availability}

The datasets generated during and/or analysed during the current study are available from the corresponding author on reasonable request.

Raw read files and processed data files for RNA-seq can be found at the NCBI Gene Expression Omnibus (GEO) database (GSE133798). Scripts and other bioinformatics 
704 https://github.com/iakerman/Quantseq. 
707 1. Rutter, G.A., Pullen, T.J., Hodson, D.J. \& Martinez-Sanchez, A. Pancreatic beta-cell

2. Benninger, R.K. \& Piston, D.W. Cellular communication and heterogeneity in pancreatic islet insulin secretion dynamics. Trends Endocrinol Metab 25, 399-406 (2014).

3. Frank, J.A. et al. Optical tools for understanding the complexity of $\beta$-cell signalling and insulin release. Nature Reviews Endocrinology (2018).

4. Dorrell, C. et al. Human islets contain four distinct subtypes of $\beta$ cells. Nature Communications 7, 11756 (2016).

5. Camunas-Soler, J. et al. Patch-Seq Links Single-Cell Transcriptomes to Human Islet Dysfunction in Diabetes. Cell Metabolism 31, 1017-1031.e4 (2020).

6. Wang, Yue J. et al. Single-Cell Mass Cytometry Analysis of the Human Endocrine Pancreas. Cell Metabolism 24, 616-626 (2016).

7. Bader, E. et al. Identification of proliferative and mature beta-cells in the islets of Langerhans. Nature 535, 430-4 (2016).

8. van der Meulen, T. et al. Virgin Beta Cells Persist throughout Life at a Neogenic Niche within Pancreatic Islets. Cell Metab 25, 911-926 e6 (2017).

9. Szabat, M., Luciani, D.S., Piret, J.M. \& Johnson, J.D. Maturation of adult beta-cells revealed using a Pdx1/insulin dual-reporter lentivirus. Endocrinology 150, 1627-35 (2009).

10. Salomon, D. \& Meda, P. Heterogeneity and contact-dependent regulation of hormone secretion by individual B cells. Experimental Cell Research 162, 507-20 (1986).

11. Hiriart, M. \& Ramirez-Medeles, M.C. Functional Subpopulations of Individual Pancreatic B-Cells in Culture. Endocrinology 128, 3193-3198 (1991).

12. Singh, S.P. et al. Different developmental histories of beta-cells generate functional and proliferative heterogeneity during islet growth. Nat Commun 8, 664 (2017).

13. Aguayo-Mazzucato, C. et al. $\beta$ Cell Aging Markers Have Heterogeneous Distribution and Are Induced by Insulin Resistance. Cell Metabolism 25, 898-910.e5 (2017).

14. Rui, J. et al. $\beta$ Cells that Resist Immunological Attack Develop during Progression of Autoimmune Diabetes in NOD Mice. Cell Metabolism 25, 727-738 (2017).

15. Katsuta, H. et al. Subpopulations of GFP-marked mouse pancreatic beta-cells differ in size, granularity, and insulin secretion. Endocrinology 153, 5180-7 (2012).

16. Farack, L. et al. Transcriptional Heterogeneity of Beta Cells in the Intact Pancreas. Dev Cell 48, 115-125 e4 (2019).

17. Roscioni, S.S., Migliorini, A., Gegg, M. \& Lickert, H. Impact of islet architecture on betacell heterogeneity, plasticity and function. Nat Rev Endocrinol 12, 695-709 (2016).

18. Gutierrez, G.D., Gromada, J. \& Sussel, L. Heterogeneity of the Pancreatic Beta Cell. Front Genet 8, 22 (2017).

19. Benninger, R.K.P. \& Hodson, D.J. New Understanding of $\beta$-Cell Heterogeneity and In Situ Islet Function. Diabetes 67, 537-547 (2018).

20. Westacott, M.J., Ludin, N.W.F. \& Benninger, R.K.P. Spatially Organized beta-Cell Subpopulations Control Electrical Dynamics across Islets of Langerhans. Biophys $J$ 113, 1093-1108 (2017).

21. Johnston, Natalie R. et al. Beta Cell Hubs Dictate Pancreatic Islet Responses to Glucose. Cell Metabolism 24, 389-401 (2016).

22. Salem, V. et al. Leader $\beta$ cells coordinate Ca2+ dynamics across pancreatic islets in vivo. Nature Metabolism, 615-629 (2019).

23. $\mathrm{Li}, \mathrm{W}$. et al. Long-term persistence and development of induced pancreatic beta cells generated by lineage conversion of acinar cells. Nat Biotechnol 32, 1223-30 (2014).

24. Yamada, T. et al. Reprogramming Mouse Cells With a Pancreatic Duct Phenotype to Insulin-Producing beta-Like Cells. Endocrinology 156, 2029-38 (2015). 
25. Ariyachet, C. et al. Reprogrammed Stomach Tissue as a Renewable Source of Functional beta Cells for Blood Glucose Regulation. Cell Stem Cell 18, 410-21 (2016).

26. Bastidas-Ponce, $\mathrm{A}$. et al. Foxa2 and $\mathrm{Pdx} 1$ cooperatively regulate postnatal maturation of pancreatic beta-cells. Mol Metab 6, 524-534 (2017).

27. Marroqui, L. et al. Differential cell autonomous responses determine the outcome of coxsackievirus infections in murine pancreatic $\alpha$ and $\beta$ cells. eLife 4(2015).

28. Hodson, D.J. et al. ADCY5 couples glucose to insulin secretion in human islets. Diabetes 63, 3009-3021 (2014).

29. Hodson, D.J. et al. Incretin-modulated beta cell energetics in intact islets of Langerhans. Molecular Endocrinology 28, 860-871 (2014).

30. Wideman, R.D. et al. Improving function and survival of pancreatic islets by endogenous production of glucagon-like peptide 1 (GLP-1). Proceedings of the National Academy of Sciences of the United States of America 103, 13468-73 (2006).

31. Pasquali, L. et al. Pancreatic islet enhancer clusters enriched in type 2 diabetes riskassociated variants. Nature Genetics 46, 136-143 (2014).

32. Akerman, I. et al. Human Pancreatic beta Cell IncRNAs Control Cell-Specific Regulatory Networks. Cell Metab 25, 400-411 (2017).

33. Segerstolpe, Å. et al. Single-Cell Transcriptome Profiling of Human Pancreatic Islets in Health and Type 2 Diabetes. Cell Metabolism 24, 593-607 (2016).

34. Choi, J.M., Seo, M.H., Kyeong, H.H., Kim, E. \& Kim, H.S. Molecular basis for the role of glucokinase regulatory protein as the allosteric switch for glucokinase. Proceedings of the National Academy of Sciences 110, 10171-10176 (2013).

35. Raoux, M. et al. Multilevel control of glucose homeostasis by adenylyl cyclase 8 . Diabetologia 58, 749-57 (2015).

36. Pound, L.D. et al. G6PC2: a negative regulator of basal glucose-stimulated insulin secretion. Diabetes 62, 1547-56 (2013).

37. Stancill, J.S. et al. Chronic $\beta$-Cell Depolarization Impairs $\beta$-Cell Identity by Disrupting a Network of Ca2+-Regulated Genes. Diabetes 66, 2175-2187 (2017).

38. Leech, C.A. et al. Molecular physiology of glucagon-like peptide-1 insulin secretagogue action in pancreatic beta cells. Progress in Biophysics and Molecular Biology 107, 236-47 (2011).

39. Chambers, A.P. et al. The Role of Pancreatic Preproglucagon in Glucose Homeostasis in Mice. Cell Metabolism 25, 927-934.e3 (2017).

40. Roth, B.L. DREADDs for Neuroscientists. Neuron 89, 683-94 (2016).

41. Zhu, H. \& Roth, B.L. Silencing synapses with DREADDs. Neuron 82, 723-5 (2014).

42. Xin, Y. et al. Pseudotime Ordering of Single Human beta-Cells Reveals States of Insulin Production and Unfolded Protein Response. Diabetes (2018).

43. Szabat, M. et al. Reduced Insulin Production Relieves Endoplasmic Reticulum Stress and Induces $\beta$ Cell Proliferation. Cell Metabolism 23, 179-193 (2016).

44. Huang, D.W., Sherman, B.T. \& Lempicki, R.A. Bioinformatics enrichment tools: paths toward the comprehensive functional analysis of large gene lists. Nucleic Acids Research 37, 1-13 (2009).

45. Dzeja, P. et al. Mice Deficient in the Respiratory Chain Gene Cox6a2 Are Protected against High-Fat Diet-Induced Obesity and Insulin Resistance. PLoS ONE 8, e56719 (2013).

46. Ruiz de Azua, I. et al. RGS4 is a negative regulator of insulin release from pancreatic $\beta$-cells in vitro and in vivo. Proceedings of the National Academy of Sciences 107, 7999-8004 (2010).

47. Blanchet, E. et al. Feedback Inhibition of CREB Signaling Promotes Beta Cell Dysfunction in Insulin Resistance. Cell Reports 10, 1149-1157 (2015).

48. Kulkarni, R.N. et al. $\beta$-cell-specific deletion of the lgf1 receptor leads to hyperinsulinemia and glucose intolerance but does not alter $\beta$-cell mass. Nature Genetics 31, 111-115 (2002). 
49. Talchai, C., Xuan, S., Lin, H.V., Sussel, L. \& Accili, D. Pancreatic beta cell dedifferentiation as a mechanism of diabetic beta cell failure. Cell 150, 1223-34 (2012).

50. Guo, S. et al. Inactivation of specific beta cell transcription factors in type 2 diabetes. J Clin Invest 123, 3305-16 (2013).

51. Ravier, M.A., Sehlin, J. \& Henquin, J.C. Disorganization of cytoplasmic Ca(2+) oscillations and pulsatile insulin secretion in islets from ob/ obmice. Diabetologia 45, 1154-63 (2002).

52. Head, W.S. et al. Connexin-36 gap junctions regulate in vivo first- and second-phase insulin secretion dynamics and glucose tolerance in the conscious mouse. Diabetes 61, 1700-7 (2012).

53. Ravier, M.A. et al. Loss of connexin36 channels alters beta-cell coupling, islet synchronization of glucose-induced $\mathrm{Ca} 2+$ and insulin oscillations, and basal insulin release. Diabetes 54, 1798-807 (2005).

54. Lei, C.-L. et al. Beta-cell hubs maintain Ca2+ oscillations in human and mouse islet simulations. Islets 10, 151-167 (2018).

55. lacovazzo, D. et al. MAFA missense mutation causes familial insulinomatosis and diabetes mellitus. Proceedings of the National Academy of Sciences 115, 1027-1032 (2018).

56. Remedi, M.S. et al. Secondary Consequences of $\beta$ Cell Inexcitability: Identification and Prevention in a Murine Model of KATP-Induced Neonatal Diabetes Mellitus. Cell Metabolism 9, 140-151 (2009).

57. Remedi, M.S., Friedman, J.B. \& Nichols, C.G. Diabetes induced by gain-of-function mutations in the Kir6.1 subunit of the KATP channel. The Journal of General Physiology 149, 75-84 (2017).

58. Modi, H. et al. (2019).

59. Azzarelli, R. et al. Multi-site Neurogenin3 Phosphorylation Controls Pancreatic Endocrine Differentiation. Developmental Cell 41, 274-286.e5 (2017).

60. Wang, S. et al. Sustained Neurog3 expression in hormone-expressing islet cells is required for endocrine maturation and function. Proceedings of the National Academy of Sciences 106, 9715-9720 (2009).

61. Thorens, B. et al. Ins1 knock-in mice for beta cell-specific gene recombination. Diabetologia 58, 558-565 (2014).

62. Lew, V.L. \& Bookchin, R.M. Osmotic effects of protein polymerization: analysis of volume changes in sickle cell anemia red cells following deoxy-hemoglobin $S$ polymerization. J Membr Biol 122, 55-67 (1991).

63. Zhu, H. et al. Cre-dependent DREADD (Designer Receptors Exclusively Activated by Designer Drugs) mice. Genesis 54, 439-46 (2016).

64. Pullen, T.J. et al. Overexpression of Monocarboxylate Transporter-1 (Slc16a1) in Mouse Pancreatic beta-Cells Leads to Relative Hyperinsulinism During Exercise. Diabetes 61, 1719-25 (2012).

65. Zhou, Y. et al. TCF7L2 is a master regulator of insulin production and processing. Human Molecular Genetics (2014).

66. Berg, J., Hung, Y.P. \& Yellen, G. A genetically encoded fluorescent reporter of ATP:ADP ratio. Nat Methods 6, 161-6 (2009).

67. Gomez, J.L. et al. Chemogenetics revealed: DREADD occupancy and activation via converted clozapine. Science 357, 503-507 (2017).

68. Hodson, D.J. et al. Existence of long-lasting experience-dependent plasticity in endocrine cell networks. Nature Communications 3, 605 (2012). 


\section{ACKNOWLEDGEMENTS}

We thank Dr. Jocelyn E. Manning Fox and Prof. Patrick E. MacDonald for provision of human islets via the Alberta Diabetes Institute IsletCore at the University of Alberta in Edmonton with the assistance of the Human Organ Procurement and Exchange (HOPE) program, Trillium Gift of Life Network (TGLN) and other Canadian organ procurement organizations. We are grateful to the European Consortium for Islet Transplantation (ECIT), which was supported by JDRF award 31-2008-416 (ECIT Islet for Basic Research program). D.J.H. was supported by a Diabetes UK R.D. Lawrence (12/0004431) Fellowship, a Wellcome Trust Institutional Support Award, and MRC (MR/N00275X/1 and MR/S025618/1) and Diabetes UK (17/0005681) Project Grants. This project has received funding from the European Research Council (ERC) under the European Union's Horizon 2020 research and innovation programme (Starting Grant 715884 to D.J.H.). G.A.R. was supported by Wellcome Trust Senior Investigator (WT098424AIA) and Investigator (212625/Z/18/Z) Awards, MRC Programme grants (MR/R022259/1, MR/J0003042/1, MR/L020149/1) and Experimental Challenge Grant (DIVA, MR/L02036X/1), MRC (MR/N00275X/1), Diabetes UK (BDA/11/0004210, BDA/15/0005275, BDA 16/0005485) and Imperial Confidence in Concept (ICiC) grants. This project has received funding from the European Union's Horizon 2020 research and innovation programme via the Innovative Medicines Initiative 2 Joint Undertaking under grant agreement No 115881 (RHAPSODY) to G.A.R. L.P. provided human islets through collaboration with the Diabetes Research Institute, IRCCS San Raffaele Scientific Institute (Milan), within the European Consortium for Islet Transplantation islet distribution program for basic research supported by JDRF (1-RSC-2014-90-I-X).

\section{CONTRIBUTIONS}

D.N. and D.J.H. devised the studies. D.N., N.H.F.F., F.B.A., F.C., K.V., P.D., Y-C.L, M.B., A.BP, R.F., H.L., I.A. and D.J.H. performed experiments and analyzed data. G.S., A.D. and I.A. provided bioinformatics and analyzed data. G.A.R. provided mice, constructs and discussed data. R.N. and L.P. isolated and provided human islets. Q.Z. provided constructs and mice. D.J.H. supervised the work. D.N. and D.J.H. wrote the paper with input from all the authors.

\section{COMPETING INTERESTS}

G.A.R. has received grant funding from Servier and is a consultant for Sun Pharma. All other authors declare no competing interests. 
FIGURE 1
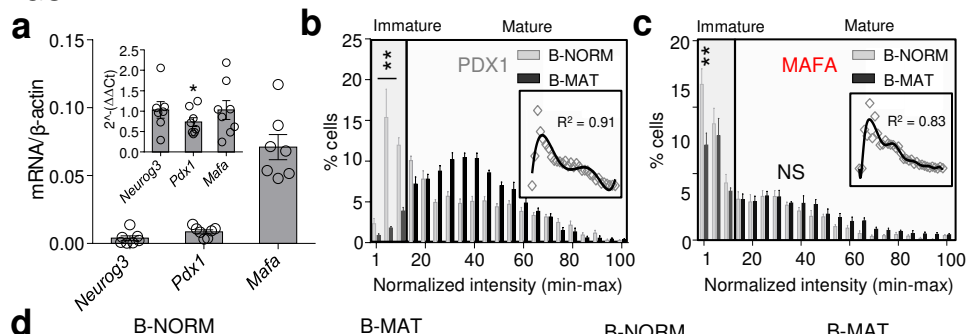

d
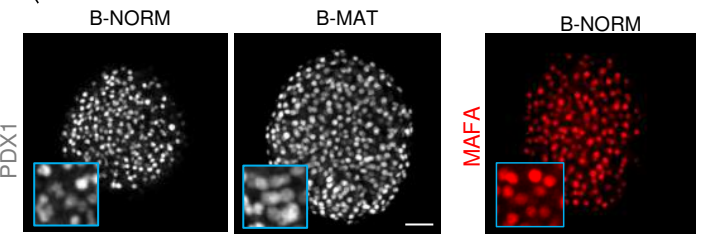

B-MAT
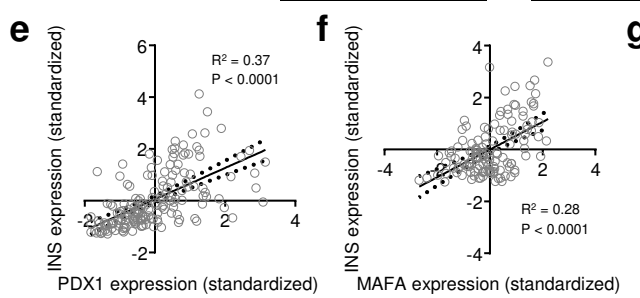

g

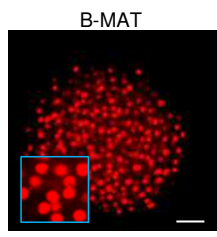

h
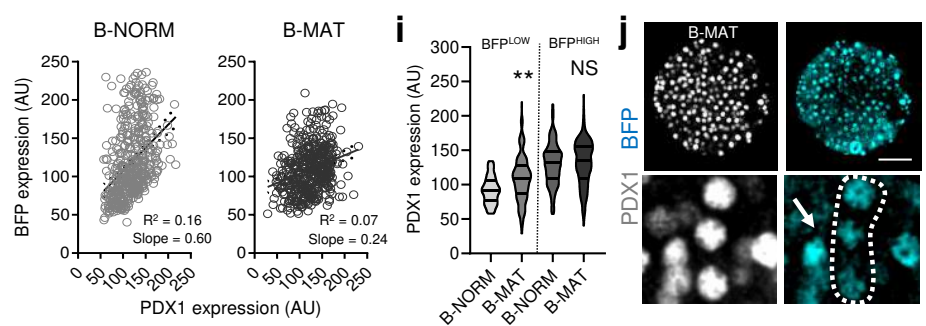

k

B-NORM

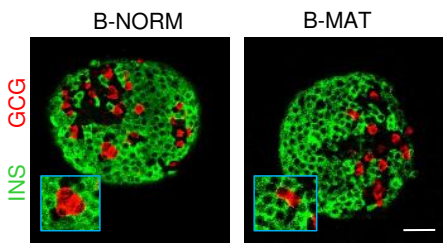

I B-NORM
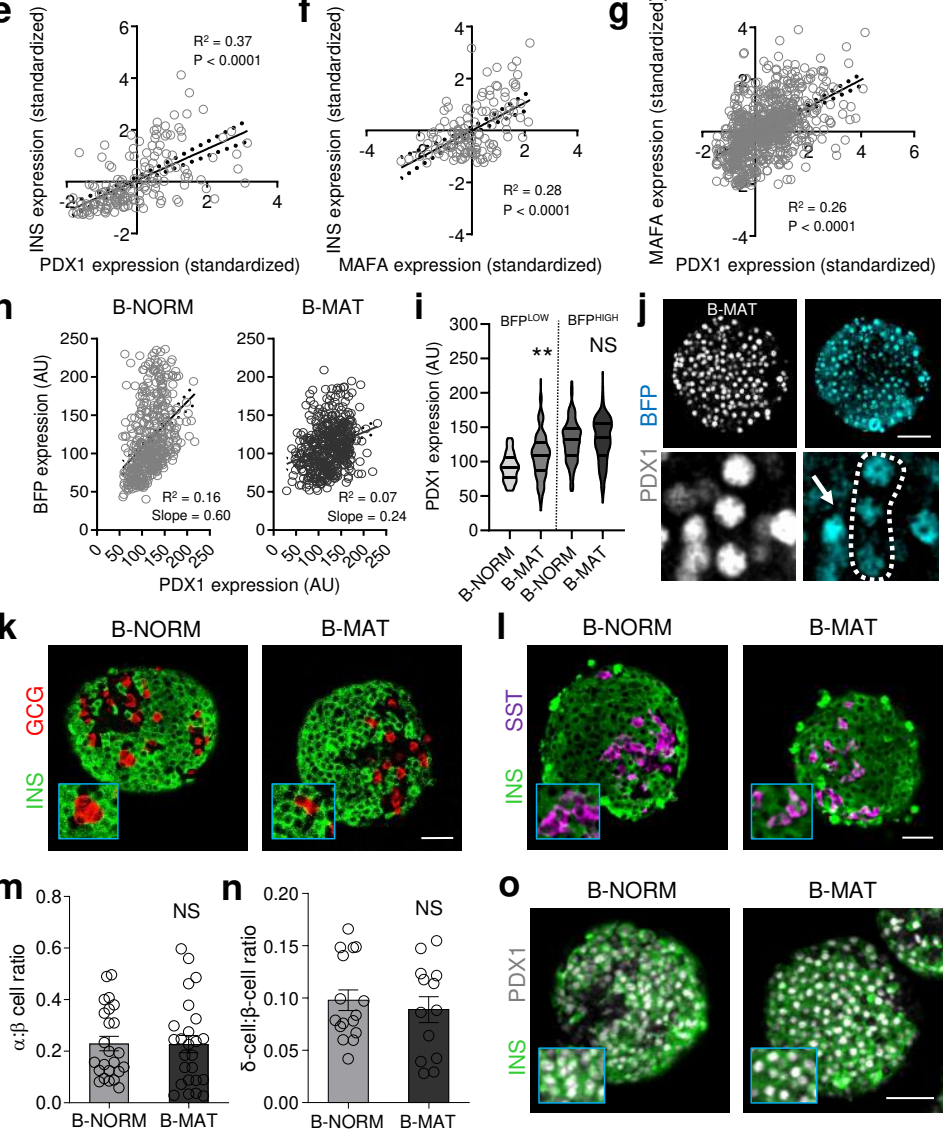

n 0.207 NS

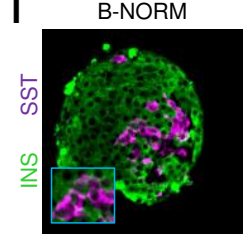

B-MAT

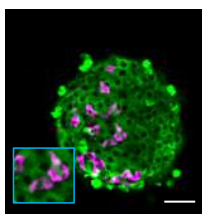

O B-NORM

B-MAT
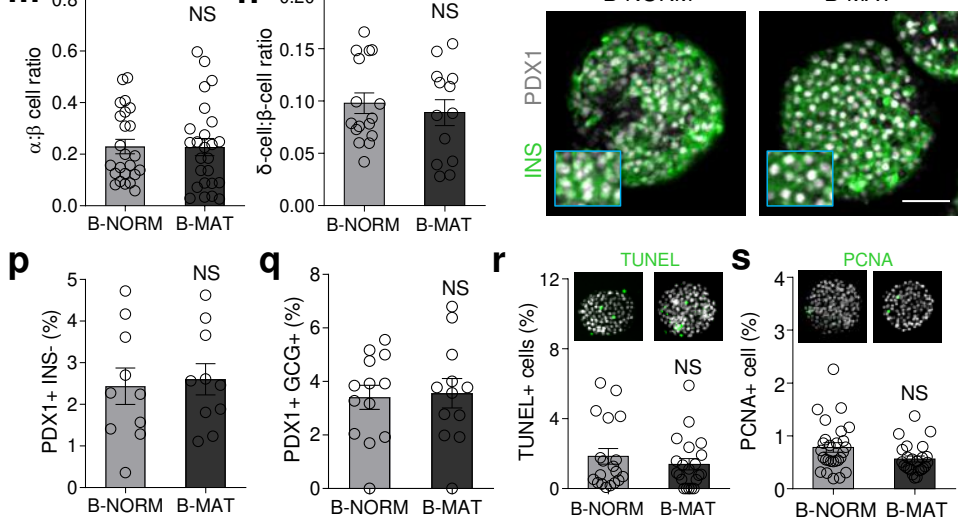

B-NORM B-MAT

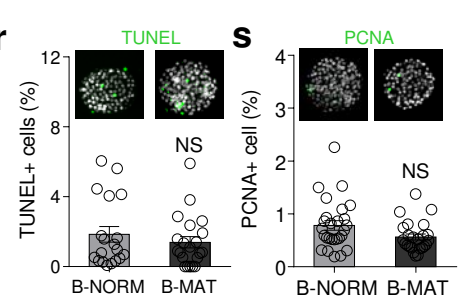

t
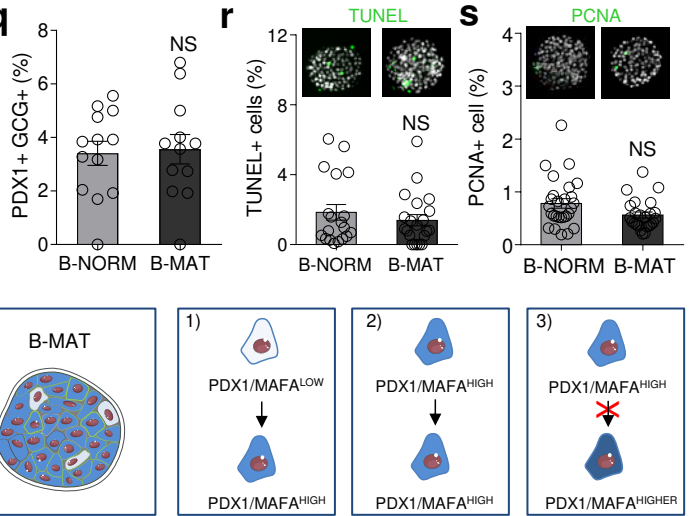
Figure 1: Generating islets with proportionally more mature $\boldsymbol{\beta}$-cells. a mRNA expression of adenoviral Neurog3, $P d x 1$ and Mafa in mouse islets, detected using primers specific to transduced genes and expressed as mRNA/ $\beta$-actin. No changes in endogenous Neurog 3 and Mafa mRNA are detected, while a slight but significant reduction in $P d x 1$ mRNA is present (graph is inset and expressed as $2^{\wedge}-(\Delta \Delta \mathrm{Ct})(\mathrm{n}=5-8$ animals; paired t-test).b Islets transduced with Ad-M3C ( $\beta$-cell mature; B-MAT) lose $\beta$-cells occupying the bottom 15 percentile for PDX1 expression compared to controls ( $\beta$-cell normal; B-NORM) (inset shows the non-normalized B-NORM distribution fitted with a polynomial) $(n=6-7$ islets/3 animals; two-way ANOVA) $(F=$ 18.75, DF $=20$ ). c As for $(\mathbf{b})$, but showing the frequency distribution for MAFA expression ( $\mathrm{n}$ $=8$ islets $/ 3$ animals; two-way ANOVA) $(F=3.03$, $D F=20)$. $\mathbf{d}$ Representative images showing more homogenous PDX1/MAFA fluorescence throughout the $\beta$-cell population in B-MAT islets (scale bar $=60 \mu \mathrm{m}$ ) (See Fig. S1 for NEUROG3 expression). e-g INS-PDX1 (e), INS-MAFA (f) and MAFA-PDX1 $(\mathbf{g})$ are positively correlated in individual cells in B-NORM islets $(n=137-$ 984 cells, linear regression). $\mathbf{h}$ PDX1 and BFP are linearly correlated in Pdx1-BFP islets, and this association is lost following transduction with Ad-M3C (B-MAT). i BFPLOW cells (prior immature) become PDX $1^{\text {HIGH }}$ in B-MAT islets, while BFP ${ }^{\mathrm{HIGH}}$ cells (prior mature) remain $\mathrm{PDX} 1^{\mathrm{HIGH}}$. j Representative images from Pdx1-BFP islets showing cells that underwent $\mathrm{PDX} 1{ }^{\mathrm{LOW}} \rightarrow \mathrm{PDX} 1^{\mathrm{HIGH}}$ conversion following transduction with Ad-M3C (arrow shows a cell that remained $\left.\mathrm{PDX} 1^{\mathrm{HIGH}}\right)($ scale bar $=50 \mu \mathrm{m})(\mathrm{n}=5-6$ islets $/ 3$ animals; two-way ANOVA) $(\mathrm{F}=2.80$, $D F=18) . \mathbf{k}-\mathbf{q}$ No differences are detected in the ratios of $\alpha$ - to $\beta$-cells $(23-25$ islets/3-4 animals) and $\delta$ - to $\beta$-cells (18-20 islets/3 animals) (k-n), or the proportion of PDX1 positive, but INS negative or GLU positive cells (o-q) (10-13 islets/4 animals) in B-NORM versus B-MAT islets (unpaired t-test) (scale bar $=40 \mu \mathrm{m})$. r Quantification of TUNEL+ cells shows no difference in B-NORM versus B-MAT islets ( $n=18-21$ islets/4 animals; unpaired t-test) (representative images shown above the corresponding bar). $\mathbf{s}$ Cell proliferation, measured using proliferating cell nuclear antigen (PCNA), is similarly low in B-NORM and B-MAT islets ( $n=24-27$ islets $/ 4$ animals; unpaired t-test) (representative images shown above the corresponding bar). $t$ Schematic showing the proposed fate of immature (LOW) and mature (HIGH) $\beta$-cells in BMAT islets. Transition to high protein content tends to occur in the relatively immature cells (1), whereas the more mature cells remain largely unaffected (2), with protein levels never surpassing those in B-NORM islets (3). Bar graphs show the mean \pm SEM. Violin plot shows median and interquartile range. ${ }^{*} \mathrm{P}<0.05,{ }^{* *} \mathrm{P}<0.01$ and $\mathrm{NS}$, non-significant. BFP-blue fluorescent protein; INS-insulin; GLU-glucagon; TUNEL- terminal deoxynucleotidyl transferase dUTP nick end labeling. 
FIGURE 2

a

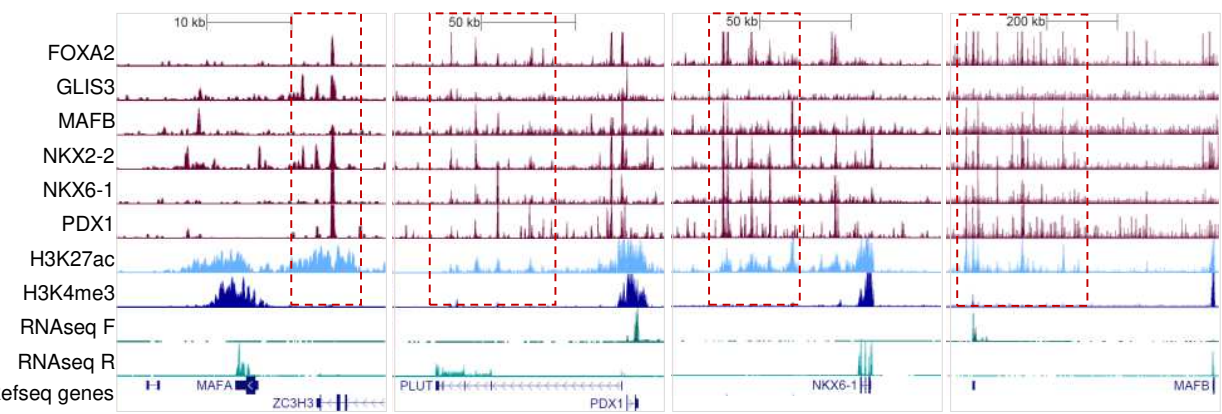

b

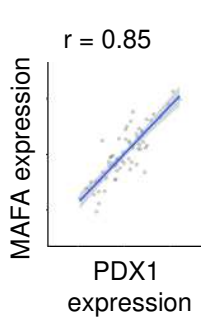

C
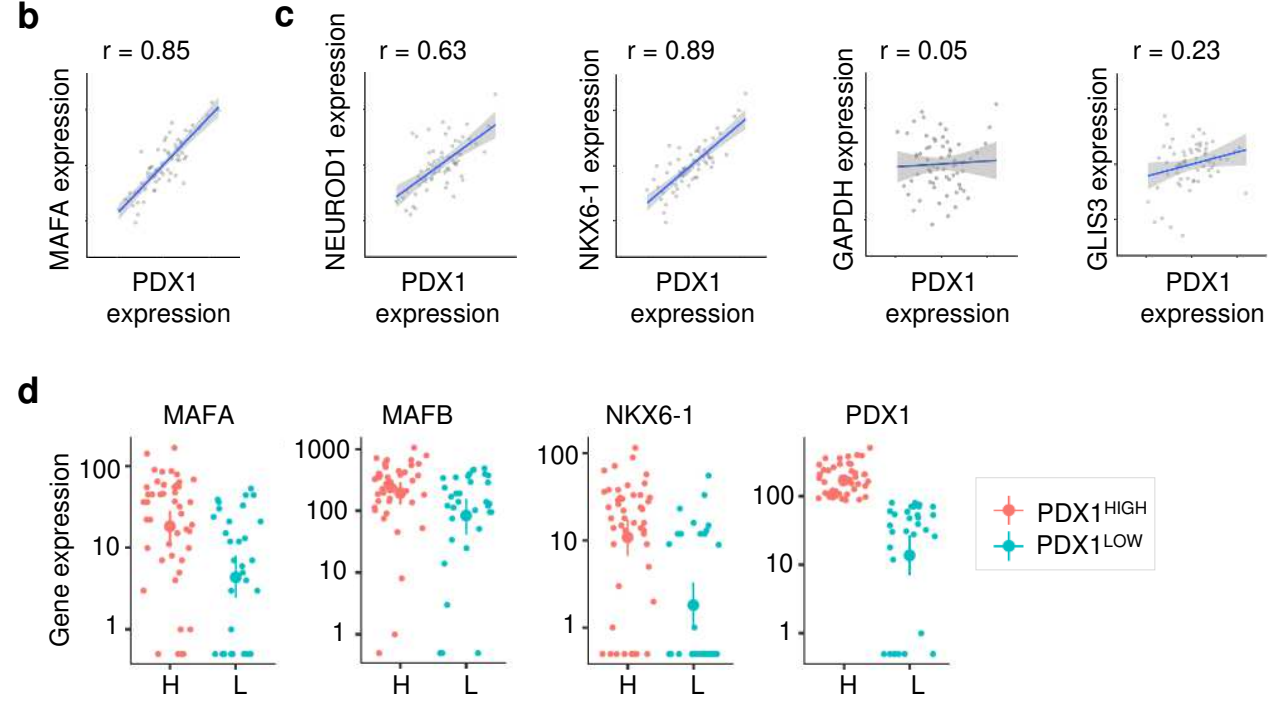

PDX1

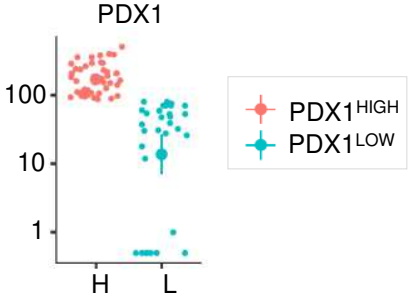

Figure 2: PDX1 ${ }^{\text {LOW/MAFA }}{ }^{\text {LOW }}$ cells are transcriptionally immature. a Binding of multiple transcription factors to enhancer clusters (boxed in red) regulates expression of key $\beta$-cell transcription factors in human islets. For reference, RNA-seq, H3K27ac (enhancer mark) and H3K4me3 (promoter mark) are also shown. All scales are set to 20 RPKM for ChIP-seq ${ }^{32}$ and 20 or 60 RPKM for RNA-seq (TF strand to 60, other to 20). b Expression of MAFA and PDX1 correlate over 64 human islet samples. The axes represent normalized expression values (-3 to 3 ) for each gene used for the co-expression network analysis ${ }^{31}$. $\mathbf{c}$ Correlation of expression of mRNA levels for PDX1 and NEUROD1, NKX6-1, GAPDH and GLIS3 across 64 human islet samples. The axes represent normalized expression values (-3 to 3 ) for each gene used for the co-expression network analysis ${ }^{31}$. $\mathbf{d}$ Single cell gene expression levels for MAFA, MAFB and NKX6-1 in cells with high and low mRNA levels for PDX1. Analysis was performed using monocle, the y-axis representing gene expression levels in log10 scale. Datasets were obtained from ${ }^{31,33}$. 
FIGURE 3

a

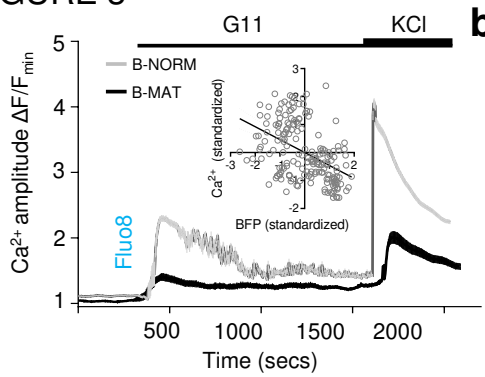

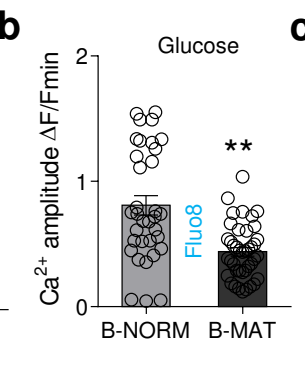
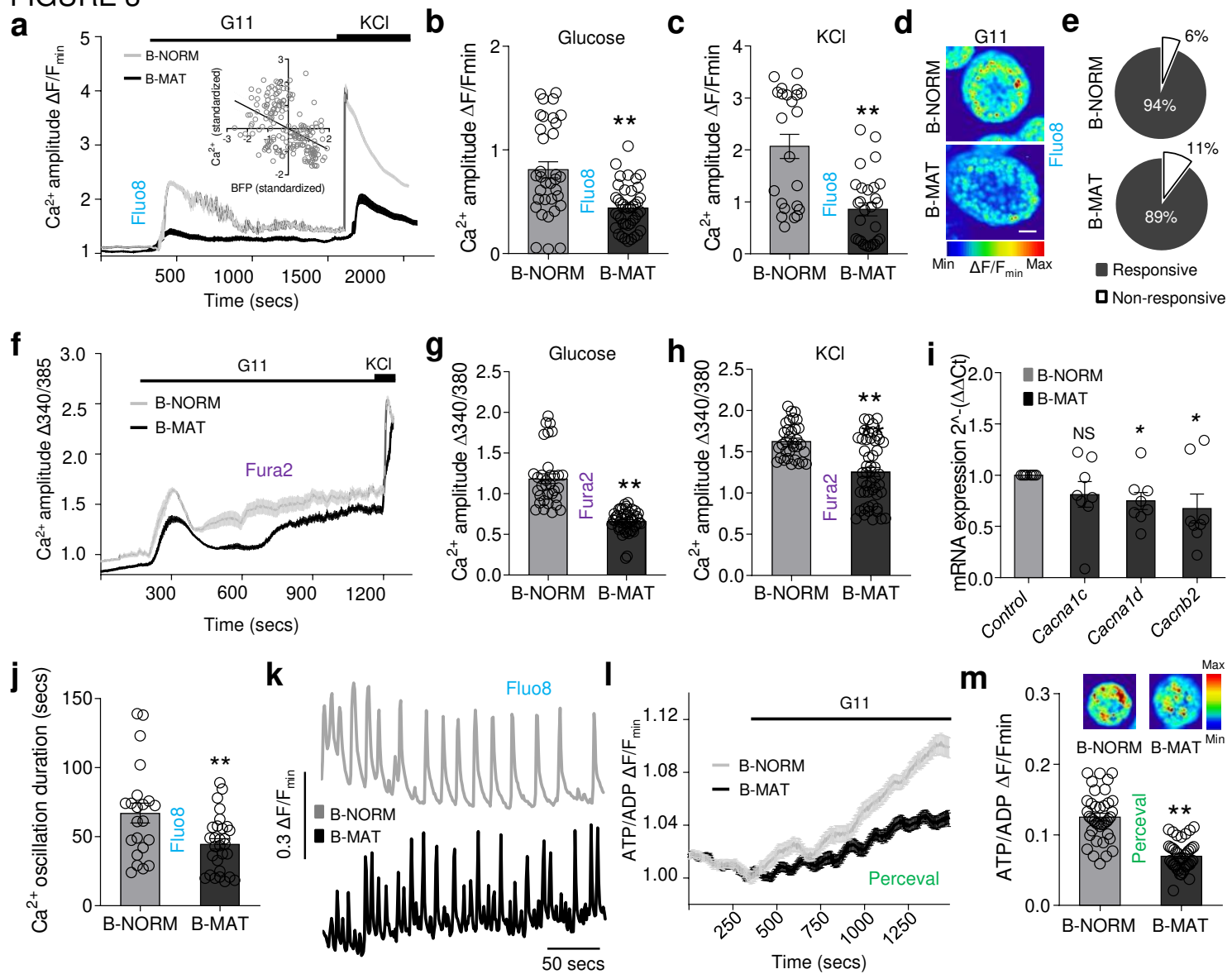

I
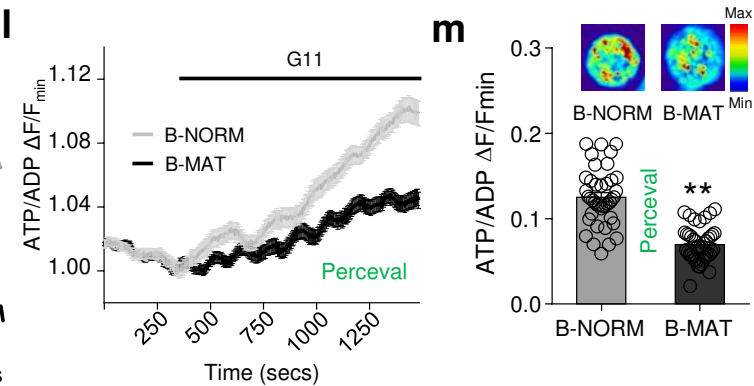

n
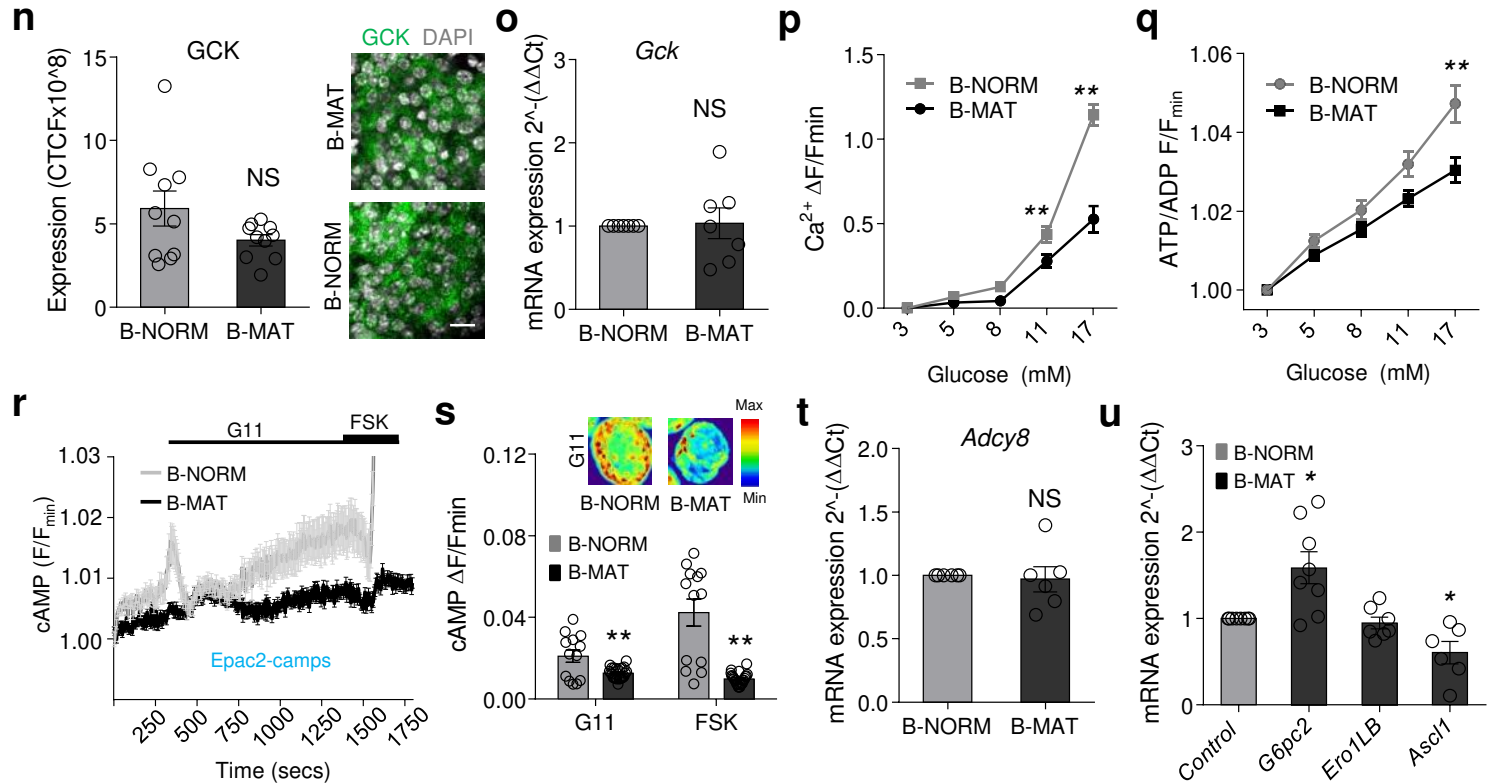

Figure 3: Differences in $\beta$-cell maturity contribute to islet signalling. a-c $\mathrm{Ca}^{2+}$ fluxes (a) in response to glucose (b) or glucose $+\mathrm{KCl}(\mathbf{c})$ are significantly impaired in B-MAT islets. Inset shows inverse linear correlation between $\mathrm{Ca}^{2+}$ amplitude and BFP expression in individual $\beta$ cells in Pdx1-BFP islets in response to $17 \mathrm{mM}$ glucose (G11, $11 \mathrm{mM}$ glucose; $\mathrm{KCl}, 10 \mathrm{mM})$ (B-NORM/B-MAT: $n=34-43$ islets/4-5 animals; unpaired t-test) (Pdx1-BFP; $n=6$ islets/3 animals; $\left.R^{2}=0.21, P<0.0001\right)$. $\mathbf{d}$ Representative images showing loss of glucose-stimulated $\mathrm{Ca}^{2+}$ rises in B-MAT but not B-NORM islets (scale bar $=40 \mu \mathrm{m}$ ). e No differences in the proportion (\%) of glucose-responsive $\beta$-cells are detected in B-MAT islets $(n=34-43$ islets $/ 4$ - 
5 animals; unpaired t-test). f-h As for (a-c), but instead using the ratiometric $\mathrm{Ca}^{2+}$ indicator Fura2 to account for any effects on basal $\mathrm{Ca}^{2+}$ levels. $(n=33-50$ islets/4 animals; unpaired $t-$ test). $\mathbf{i}$ Expression of genes encoding the VDCC subunits CACNA1D and CACNB2 is reduced in B-MAT islets ( $n=8-10$ animals; paired t-test). $\mathbf{j}$, $\mathbf{k}$ B-MAT islets show a reduction in $\mathrm{Ca}^{2+}$ pulse duration, as shown by summary bar graph (j) and representative traces $(\mathbf{k})(n=8-15$ islets/4 animals; unpaired t-test). I, $\mathbf{m}$ ATP/ADP ratios (I) recorded using the recombinant probe Perceval are $\sim 50 \%$ reduced in B-MAT islets. Representative images $(\mathbf{m})$ of glucosestimulated ATP/ADP rises are displayed above the corresponding bar $(n=40$ islets $/ 4$ animals; unpaired t-test). $\mathbf{n}$, o Glucokinase (GCK) protein expression ( $\mathbf{n})$ tends to be reduced in B-MAT islets ( $n=10$ islets/2 animals; paired t-test), although Gck mRNA levels are normal $(\mathbf{o})(n=7$ animals; paired t-test) (scale bar $=15 \mu \mathrm{m})$. p, $\mathbf{q} \mathrm{Ca}^{2+}(\mathbf{p})$ and $\operatorname{ATP} / \operatorname{ADP}(\mathbf{q})$ responses to increasing glucose concentration are decreased in B-MAT islets $\left(\mathrm{Ca}^{2+}: \mathrm{n}=11-24\right.$ islets $/ 5$ animals; two-way ANOVA $F=20.36$, $D F=4)(A T P / A D P: ~ n=37-38$ islets $/ 5$ animals, two-way ANOVA; $F=6.10$, DF $=4)$. $r$, $\mathbf{s}$ Mean traces $(\mathbf{r})$ and bar graph $(\mathbf{s})$ showing that cAMP levels in response to glucose and forskolin (FSK, $100 \mu \mathrm{M}$ ) are reduced in B-MAT islets. Representative images of glucose-stimulated cAMP rises are displayed above the corresponding bar ( $\mathrm{n}=13-24$ islets; unpaired t-test). $\mathbf{t}$ Expression of Adcy8 remains unchanged in B-MAT islets ( $\mathrm{n}=6$ animals; paired t-test). $\mathbf{u}$ The $P d x 1$ target genes $G 6 p c 2$ and Ascl1 are up- and down-regulated, respectively, in B-MAT islets (expression of Ero $1 L B$ is unchanged) ( $\mathrm{n}=6-8$ animals; paired t-test). Bar graphs and traces show the mean \pm SEM. ${ }^{*} \mathrm{P}<0.05,{ }^{* \star} \mathrm{P}<0.01$ and NS, non-significant. CTCF-corrected total cell fluorescence. 
FIGURE 4
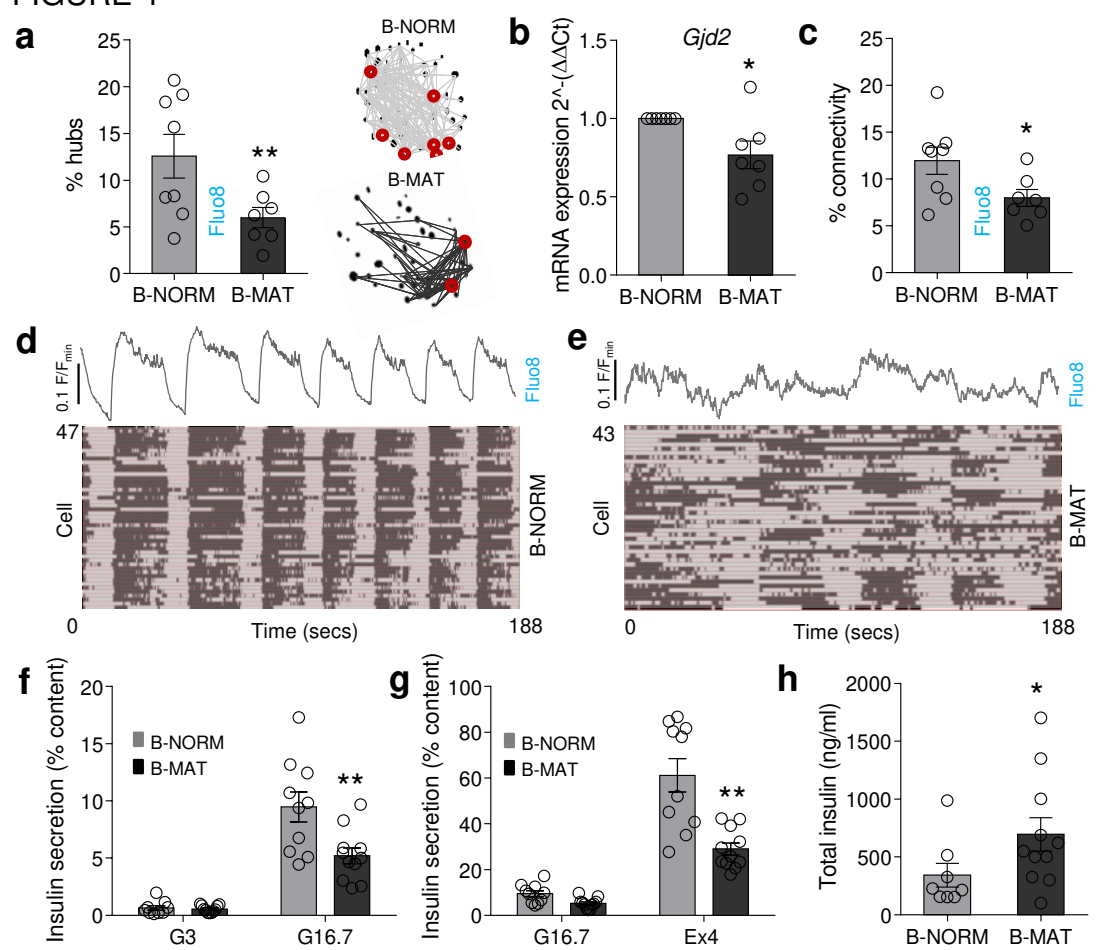

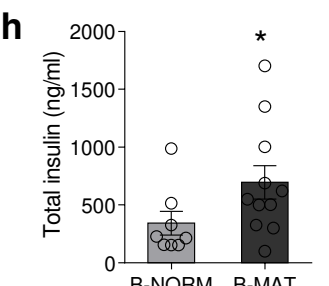
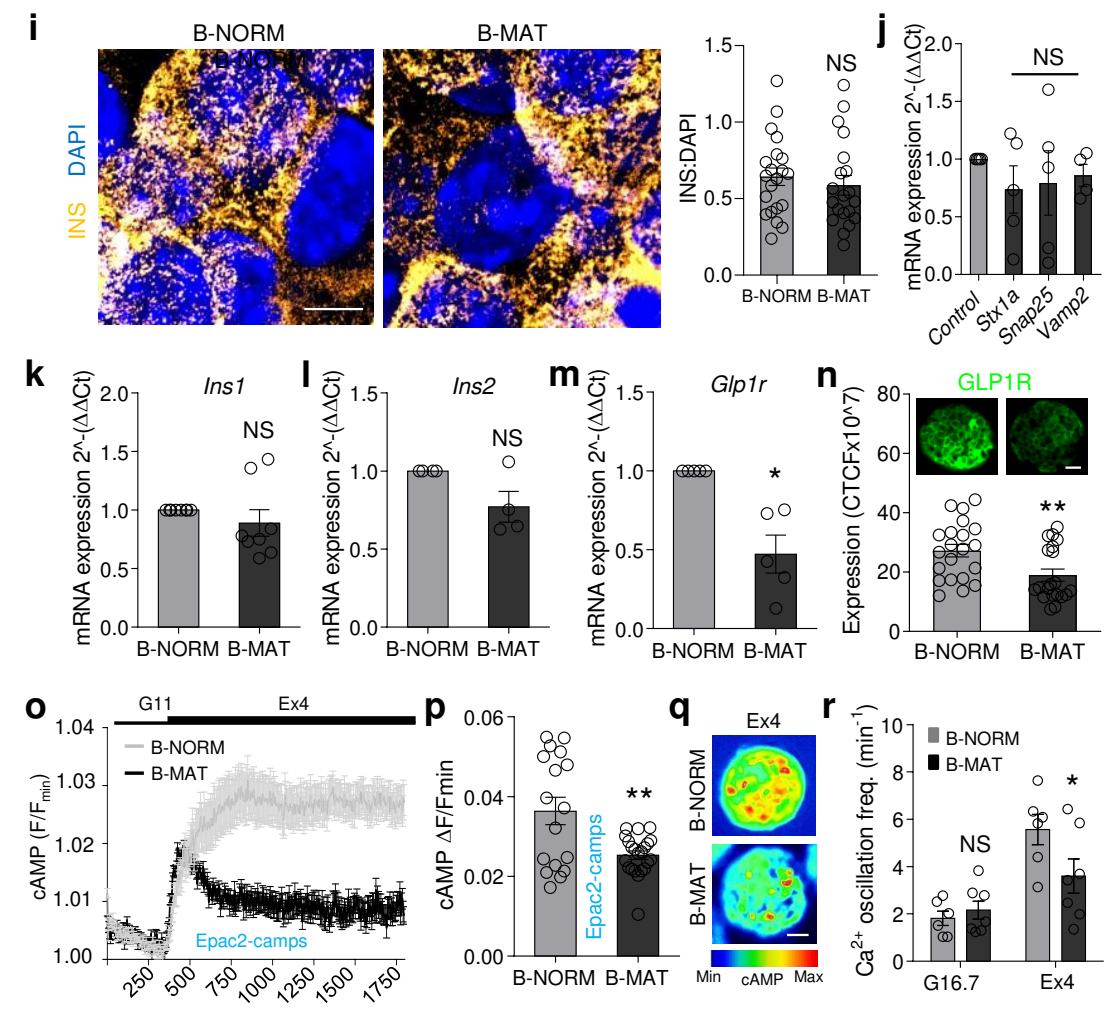

s
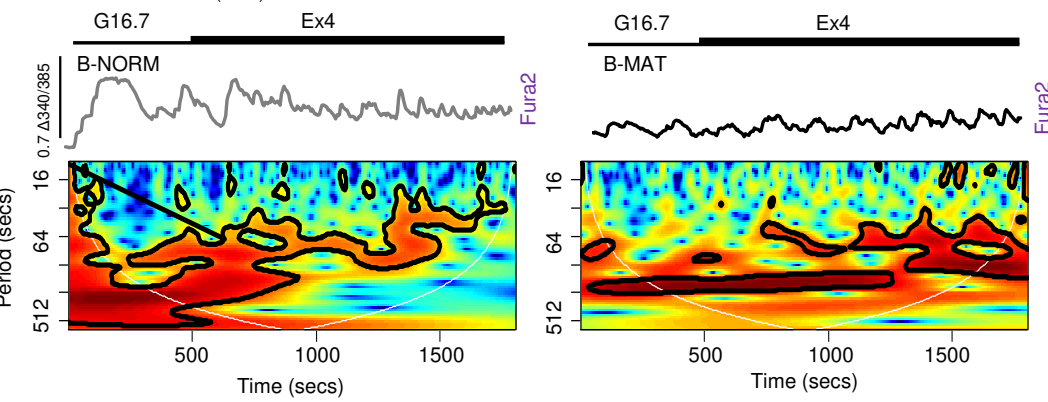
Figure 4: Both immature and mature $\beta$-cells are required for islet dynamics and insulin secretion. a-c Hub cell proportion (circled in red) (a) ( $\mathrm{n}=7-8$ islets/3 animals; unpaired t-test), mRNA for Gjd2 (b) ( $\mathrm{n}=7$ animals; paired t-test) and coordinated $\beta$-cell- $\beta$-cell activity (connectivity) (c) ( $n=7-8$ islets/3 animals; unpaired t-test) are all decreased in B-MAT islets. $\mathbf{d}, \mathbf{e}$ Raster plots showing $\beta$-cell activity profiles across the population, which is coordinated in B-NORM islets (d), but more stochastic in B-MAT islets (e). $\mathbf{f}$ - $h$ Loss of immature $\beta$-cells leads to reductions in glucose (f)- and Exendin-4 (g)-stimulated insulin secretion $(n=10-11$ replicates/4 animals; two-way ANOVA) $(G 16.7: F=7.89, D F=1)(E x 4: F=13.40, D F=1)$, despite an increase in insulin content (h) (\% insulin content = secreted insulin / total insulin) ( $n=8-10$ replicates $/ 4$ animals; unpaired t-test). Note that all samples were run together, but due to the relative magnitude of the Exendin-4 response, the results are displayed separately with the same high glucose state (G3, 3 mM glucose; G16.7, $16.7 \mathrm{mM}$ glucose; Ex4, $20 \mathrm{nM}$ Exendin-4). i Representative super-resolution images and summary bar graph showing absence of changes in insulin granule density at the membrane (normalized to DAPI) in BMAT islets (scale bar $=6 \mu \mathrm{m})(\mathrm{n}=12$ islets/6 animals; unpaired t-test). $\mathrm{j}$ No differences in expression of Stx1a, Snap25 and Vamp2 are detected in B-MAT islets ( $n=5-6$ animals; paired t-test). $\mathbf{k}, \mathbf{I}$ Ins 1 ( $\mathbf{k}$ ) and Ins2 (I) mRNA levels are unchanged in B-MAT islets ( $\mathrm{n}=4-8$ animals; paired t-test). $\mathbf{m}, \mathbf{n}$ GLP1R mRNA ( $\mathbf{m})(\mathrm{n}=5$ animals, paired t-test) and protein $(\mathbf{n})(\mathrm{n}=20-21$ islets/4 animals, unpaired t-test) expression are markedly reduced in B-MAT islets (representative images shown above bar graph, scale bar $=25 \mu \mathrm{m}$ ). 0-q Maximal Exendin-4stimulated cAMP rises are blunted in B-MAT islets, shown by mean traces (o), summary bar graph $(\mathbf{p})$ and representative images (scale bar $=25 \mu \mathrm{m})(\mathbf{q})(n=17-22$ islets/2 animals; unpaired t-test) (G11, $11 \mathrm{mM}$ glucose; Ex4, $20 \mathrm{nM}$ Exendin-4). r, s Exendin-4 increases $\mathrm{Ca}^{2+}$ spiking frequency in B-NORM islets which is blunted in B-MAT islets (r), confirmed using wavelet analysis of the dominant frequencies (s) (mean wave shown) $(n=6-7$ islets/3 animals; two-way ANOVA) $(F=4.40, D F=1)(G 16.7,16.7 \mathrm{mM}$ glucose; Ex4, $20 \mathrm{nM}$ Exendin-4). Bar graphs and traces show the mean $\pm \mathrm{SEM}$. ${ }^{*} \mathrm{P}<0.05,{ }^{*} \mathrm{P}<0.01$ and NS, non-significant. 


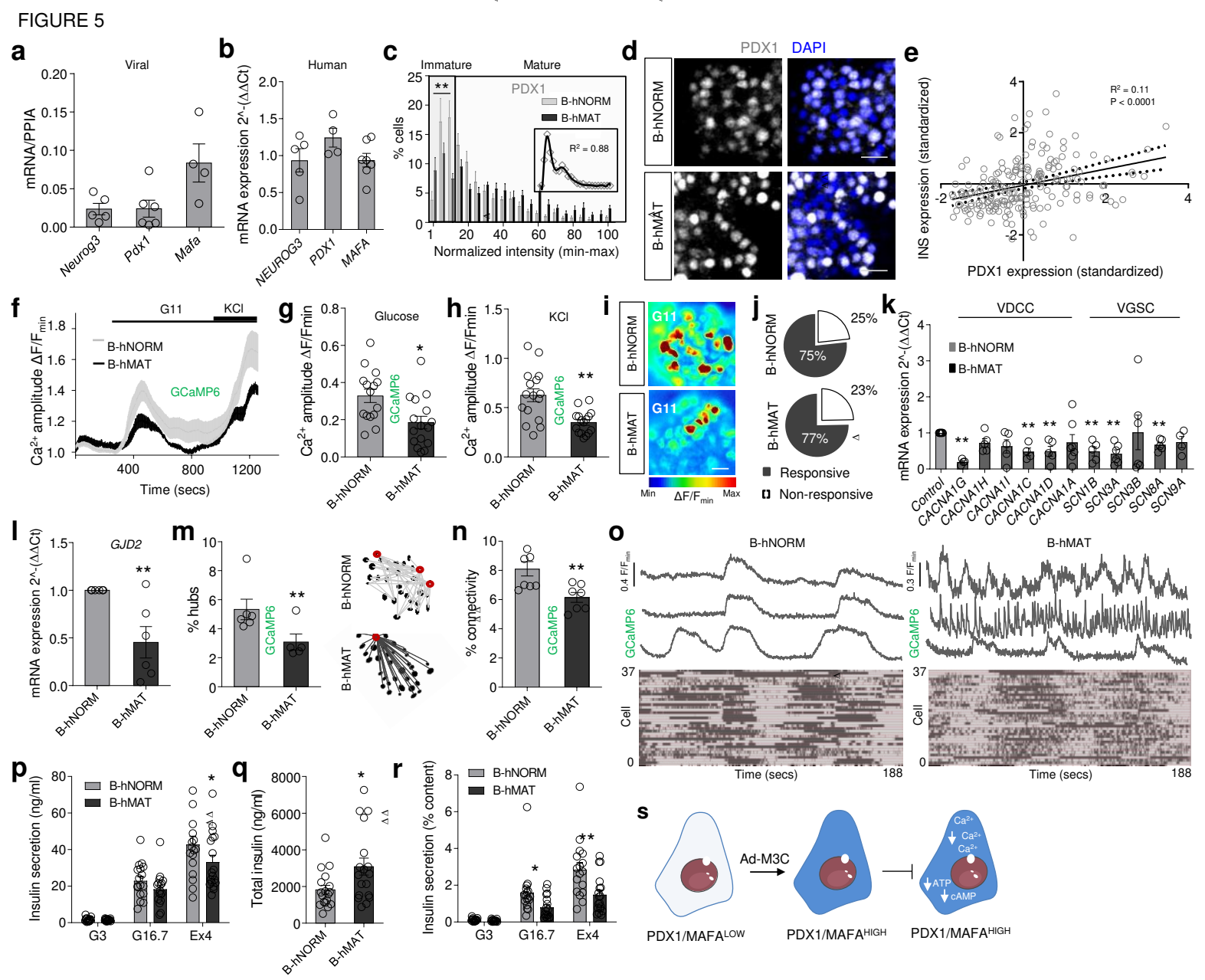

1008
Figure 5: Differences in $\beta$-cell maturity contribute to human islet function. $\mathbf{a}, \mathbf{b} \mathrm{Ad}-\mathrm{M} 3 \mathrm{C}$ increases exogenous Neurog3, $P d x 1$ and MafA expression (a), while no differences are detected in native NEUROG3, PDX1 and MAFA expression (b) ( $\mathrm{n}=4-8$ donors). c, Ad-M3C increases the proportion of cells expressing high PDX1 levels (B-hMAT) (inset is the nonnormalized B-hNORM distribution fitted with a polynomial) ( $n=13$ islets/4 donors; two-way ANOVA) $(F=4.14, D F=20)$. $d$ Representative images showing loss of PDX1 ${ }^{\text {LOW }}$ cells in $B-$ hMAT islets (detected using a PDX1 antibody with reactivity against mouse and human protein) (scale bar $=42.5 \mu \mathrm{m}$ ). e PDX1 and INS1 are positively correlated in individual cells from B-hNORM islets ( $n=220$ cells). $\mathbf{f}-\mathbf{h ~} \mathrm{Ca}^{2+}$ traces $(\mathbf{f})$ showing decreased responsiveness to glucose $(\mathbf{g})$ and $\mathrm{KCl}(\mathbf{h})$ in B-hMAT islets ( $\mathrm{n}=16$ islets/3 donors; unpaired t-test). $\mathbf{i}, \mathbf{j}$ as for (f-h), but representative images (scale bar $=25 \mu \mathrm{m}$ ) showing loss of glucose-stimulated $\mathrm{Ca}^{2+}$ rises in B-hMAT but not B-hNORM islets (i), despite no differences in the proportion of responsive cells (j) ( $\mathrm{n}=16$ islets/3 donors; unpaired t-test). $\mathbf{k}$ The VDCC and $\mathrm{Na}^{+}$channel subunits CACNA1G, CACNA1C, CACNA1D, SCN1B, SCN3A and SCN8A are all downregulated in B-hMAT islets ( $n=4-6$ donors; paired t-test). I-o GJD2 expression (I) is decreased in B-hMAT islets ( $n=6$ donors; paired $t$-test), which is associated with a decrease in the number of hubs (circled in red) $(\mathbf{m})$ and coordinated $\beta$-cell- $\beta$-cell activity (connectivity) ( $\mathbf{n}$ and $\mathbf{o})$ (representative traces are from 'connected' cells) ( $n=7-8$ islets/3 donors unpaired t-test). $\mathbf{p}$-r Non-normalized Insulin secretion is similar in B-hMAT and B-hNORM islets (p), although B-hMAT islets only release a fraction of their total insulin ( $\mathbf{q}$ and $\mathbf{r}$ ) (\% insulin content = secreted insulin / total insulin) ( $n=17-18$ replicates $/ 5$ donors; unpaired $t$-test and two-way ANOVA). s Schematic showing proposed changes occurring in $\beta$-cells in B-hMAT islets. Bar graphs and traces show the mean \pm SEM. ${ }^{*} \mathrm{P}<0.05$, ${ }^{*} \mathrm{P}<0.01$ and $\mathrm{NS}$, non-significant. GCaMP6-genetically-encoded $\mathrm{Ca}^{2+}$ indicator; VDCC-voltage-dependent $\mathrm{Ca}^{2+}$ channels; 
1033 VGSC-voltage-gated $\mathrm{Na}^{+}$channels; GJD2-Gap junction delta-2 protein encoding Connexin103436. 
FIGURE 6
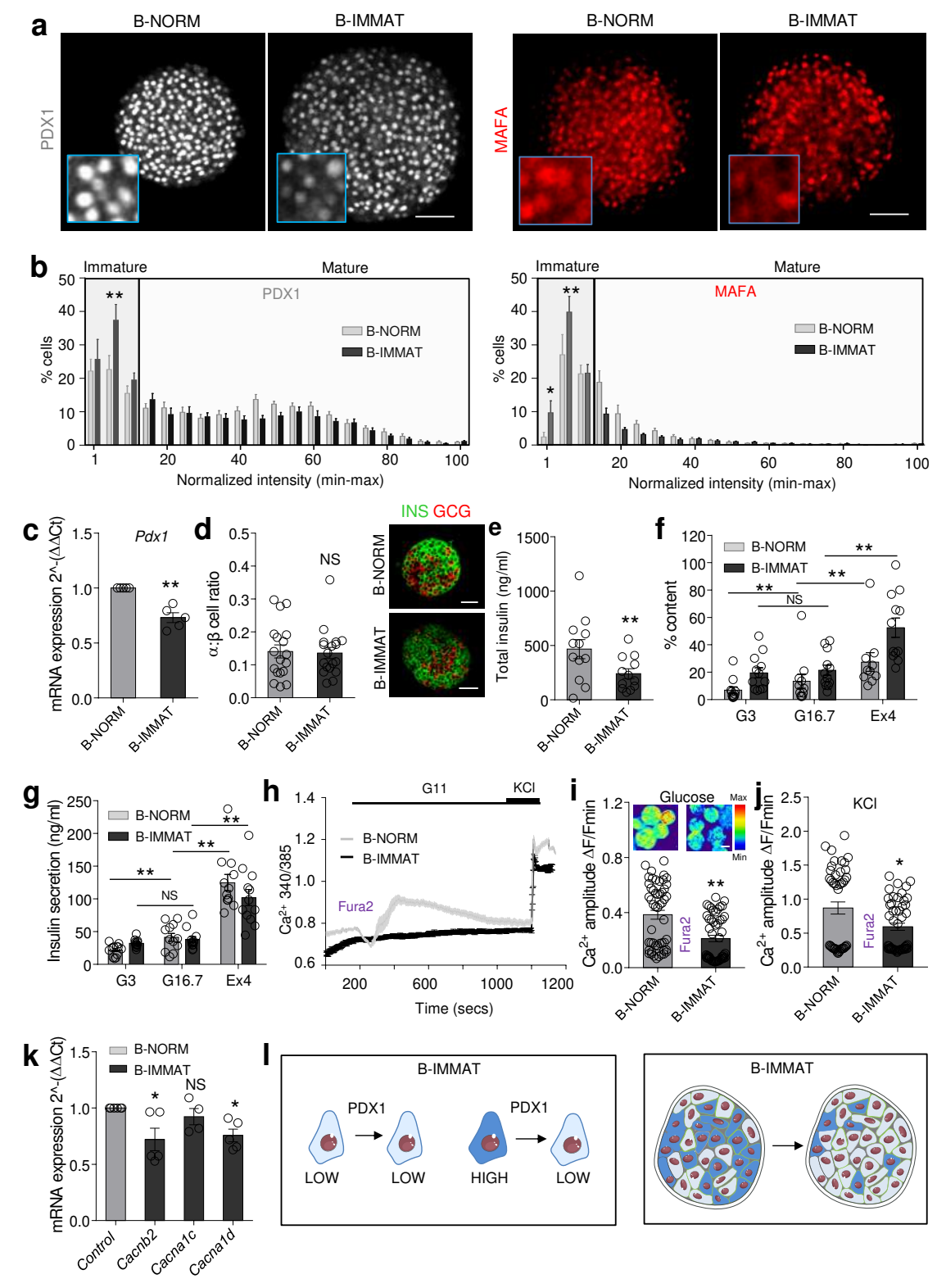

Figure 6: A proportional increase in immature $\beta$-cells impairs islet function. a $\operatorname{sh} P d x 1$ increases the proportion of $\beta$-cells in the islet with low levels of PDX1 and MAFA ( $\beta$-cell immature; B-IMMAT) (scale bar $=60 \mu \mathrm{m}$ ). b Quantification of PDX1 and MAFA expression intensity shows an increase in $\beta$-cells occupying the bottom 15 percentile in B-IMMAT islets $(n=13-14$ islets/3 animals; two-way ANOVA) (PDX1: $F=2.38, D F=20)$ (MAFA: $F=3.20$, DF $=20)$. c RT-qPCR showing a decrease in Pdx1 expression levels in B-IMMAT islets $(n=5$; paired t-test). $\mathbf{d}$ Induction of homogenous $\beta$-cell immaturity does not alter the $\alpha$ - to $\beta$-cell ratio (scale bar $=42.5 \mu \mathrm{m})(\mathrm{n}=18$ islets $/ 2-3$ animals; unpaired t-test). e-g B-IMMAT islets display decreased insulin content (e), increased basal insulin release and absence of significant glucose-stimulated insulin secretion ( $\mathbf{f}$ and $\mathbf{g})(\mathrm{n}=10-12$ replicates/4 animals; t-test and oneway ANOVA) (G3, 3 mM glucose; G16.7, 16.7 mM glucose; Ex4, 20 nM Exendin-4). h-j Ca ${ }^{2+}$ traces $(\mathbf{h})$ and bar graphs (i and $\mathbf{j})$ showing impaired responses to glucose and glucose $+\mathrm{KCl}$ in B-IMMAT islets ( $n=49-51$ islets/4-5 animals; unpaired t-test) (representative images shown above bar graph, scale bar $=75 \mu \mathrm{m}$ ). $\mathbf{k}$ mRNA for the L-type VDCC subunits Cacnb2 and Cacna1d are significantly downregulated in B-IMMAT islets ( $n=5-6$; paired t-test). I Schematic showing the proposed changes in B-IMMAT islets. Bar graphs and traces show the mean \pm SEM. ${ }^{*} \mathrm{P}<0.05,{ }^{* *} \mathrm{P}<0.01$ and NS, non-significant. 
FIGURE 7
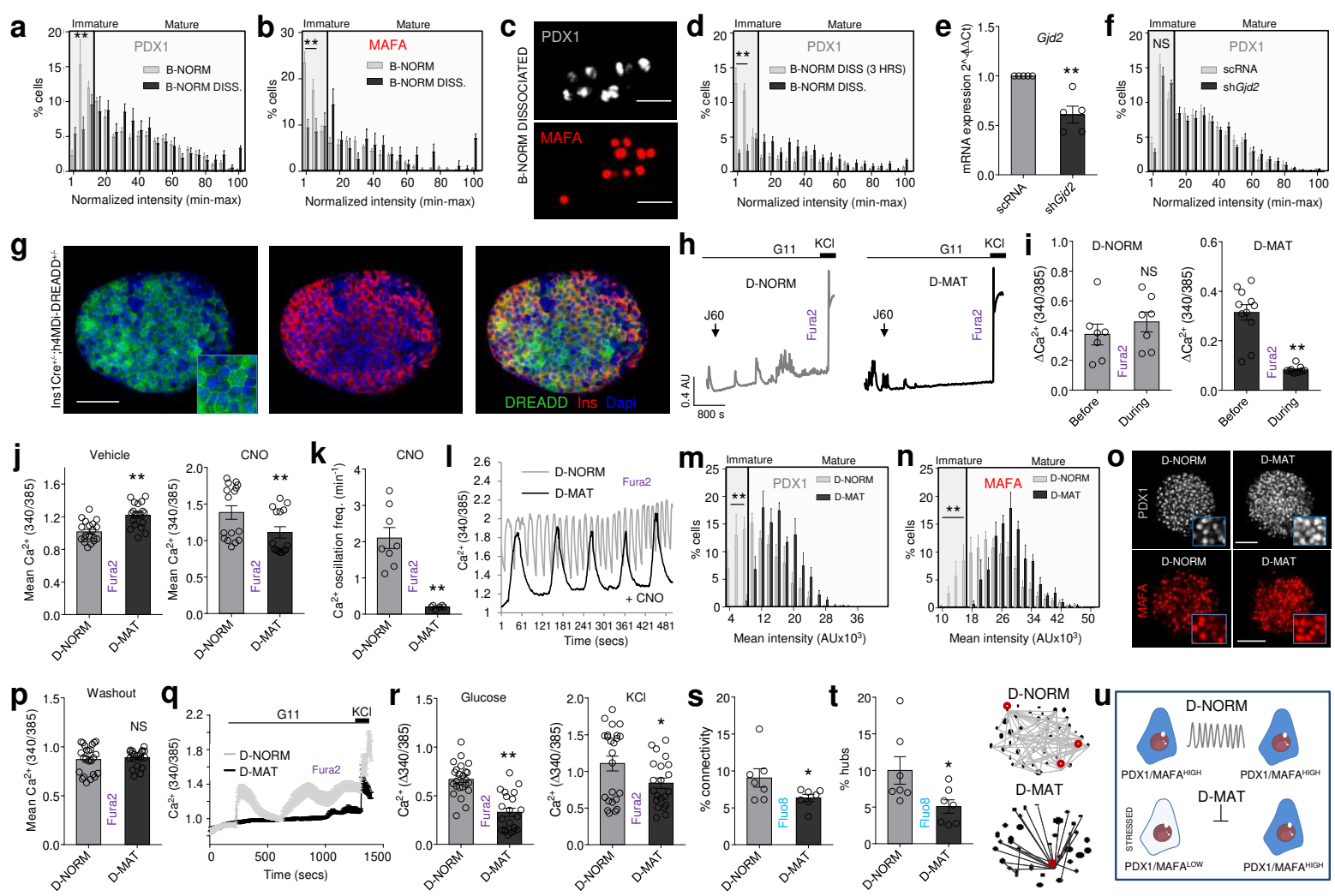

Figure 7: Differences in $\beta$-cell maturity are encoded by islet signaling patterns. $\mathbf{a}, \mathbf{b}$ Dissociation of islets into single $\beta$-cells (B-NORM DISS.) leads to loss of cells occupying the bottom 15 percentile for PDX1 (a) and MAFA (b) expression (B-NORM data from Fig. $1 \mathrm{~b}$ and $C$ are superimposed for comparison purposes) ( $n=6-11$ islets/4 animals; two-way ANOVA) (PDX1: $F=7.23, \mathrm{DF}=19)(\mathrm{MAFA}: \mathrm{F}=4.69, \mathrm{DF}=20)(\mathrm{scale}$ bar $=42.5 \mu \mathrm{m})$. c Representative images showing a decrease in the proportion of PDX1/MAFA ${ }^{\text {LOW }} \beta$-cells following dissociation of islets, as indicated by increased PDX1/MAFA fluorescence intensity throughout the $\beta$-cell population. d Immature $\beta$-cells (PDX $1^{\text {LOW }}$ ) are still present 3 hours following dissociation of islets into single cells $(n=80$ islets $/ 10$ coverslips; two-way ANOVA) (PDX1: $F=9.54, D F=$ 40) (MAFA: $F=5.22$, DF $=20)$. e Gjd2 expression is decreased in islets treated with shGjd2 versus scRNA controls ( $n=5$ animals; paired t-test). $f$ Relatively immature $\beta$-cells (PDX $\left.1^{\text {LOW }}\right)$ are still present in scRNA- and shGjd2-treated islets $(n=8-9$ islets/2-3 animals; two-way ANOVA) $(F=12.85$, $D F=20)$. $g$ The inhibitory DREADDs, h4MDi, are conditionally expressed in the membrane of $\beta$-cells following Cre-mediated recombination (D-MAT) ( $n=3$ islets) (scale bar $=85 \mu \mathrm{m}$ ). $\mathbf{h}$, i Representative $\mathrm{Ca}^{2+}$ traces (h) and analysis (i) showing complete silencing of $\beta$-cell activity in D-MAT but not D-NORM (control) islets following application of the designer ligand $\mathrm{J} 60$ ( $n=7-11$ islets/3 animals; unpaired t-test). $\mathbf{j}$, Clozapine-N-oxide (CNO) decreases intracellular $\mathrm{Ca}^{2+}$ levels in D-MAT islets following 3 hours incubation compared to vehicle control (DMSO) ( $n=16$ islets/5 animals; Mann-Whitney $U$ test). $\mathbf{k}$, I CNO decreases $\mathrm{Ca}^{2+}$ oscillation frequency $(\mathbf{k})$ in D-MAT islets following 3 hours incubation, also shown by representative traces (I) ( $n=6-8$ islets/2 animals; unpaired t-test). $\mathbf{m}, \mathbf{n}$ Incubation of D-MAT islets with $\mathrm{CNO}$ for 48 hours induces loss of $\beta$-cells occupying the bottom 15 percentile for PDX1 $(\mathbf{m})$ and MAFA $(\mathbf{n})$ expression $(n=8-9$ islets/3-4 animals; two-way ANOVA) (PDX1: $F$ $=5.34, \mathrm{DF}=20)$ (MAFA: $F=4.63$, $\mathrm{DF}=20$ ). o Representative images showing loss of PDX1/MAFA ${ }^{\text {LOW }}$ cells in in D-MAT islets (scale bar $\left.=60 \mu \mathrm{m}\right)$. $\mathbf{p}$ Intracellular $\mathrm{Ca}^{2+}$ levels are restored in 48 hours CNO-treated islets following a 2 hour washout period $(n=21-24$ islets $/ 3$ 1081 animals; unpaired t-test). $\mathbf{q}-\mathbf{r} \mathrm{Ca}^{2+}$ traces $(\mathbf{q})$ showing defective responses to $11 \mathrm{mM}$ glucose $(\mathrm{G} 11)$ and $\mathrm{KCl}(10 \mathrm{mM})(\mathbf{r})$ in D-MAT islets, even following removal of CNO for 2 hours ( $\mathrm{n}=21$ - 
24 islets/3 animals; unpaired t-test). s, t D-MAT islets display more stochastic $\mathrm{Ca}^{2+}$ responses (s) (decreased connectivity), which is associated with loss of hubs (circled in red) (t) ( $n=7$ islets/4 animals; unpaired t-test). u Schematic showing effects of altering $\mathrm{Ca}^{2+}$ signaling patterns on immature and mature $\beta$-cells. Bar graphs and traces show the mean \pm SEM. ${ }^{\star} \mathrm{P}<0.05,{ }^{* \star} \mathrm{P}<0.01$ and NS, non-significant. 
FIGURE 8

a

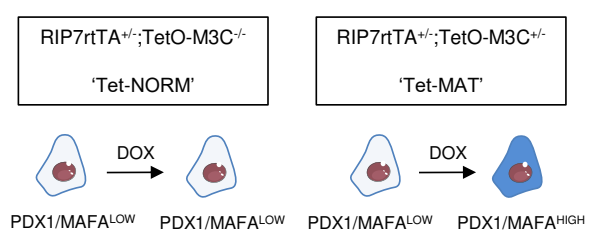

b

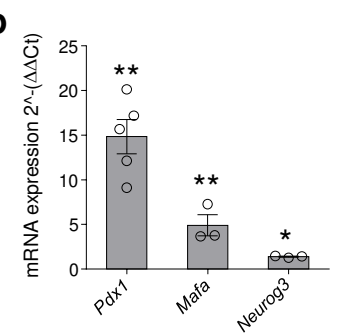

C
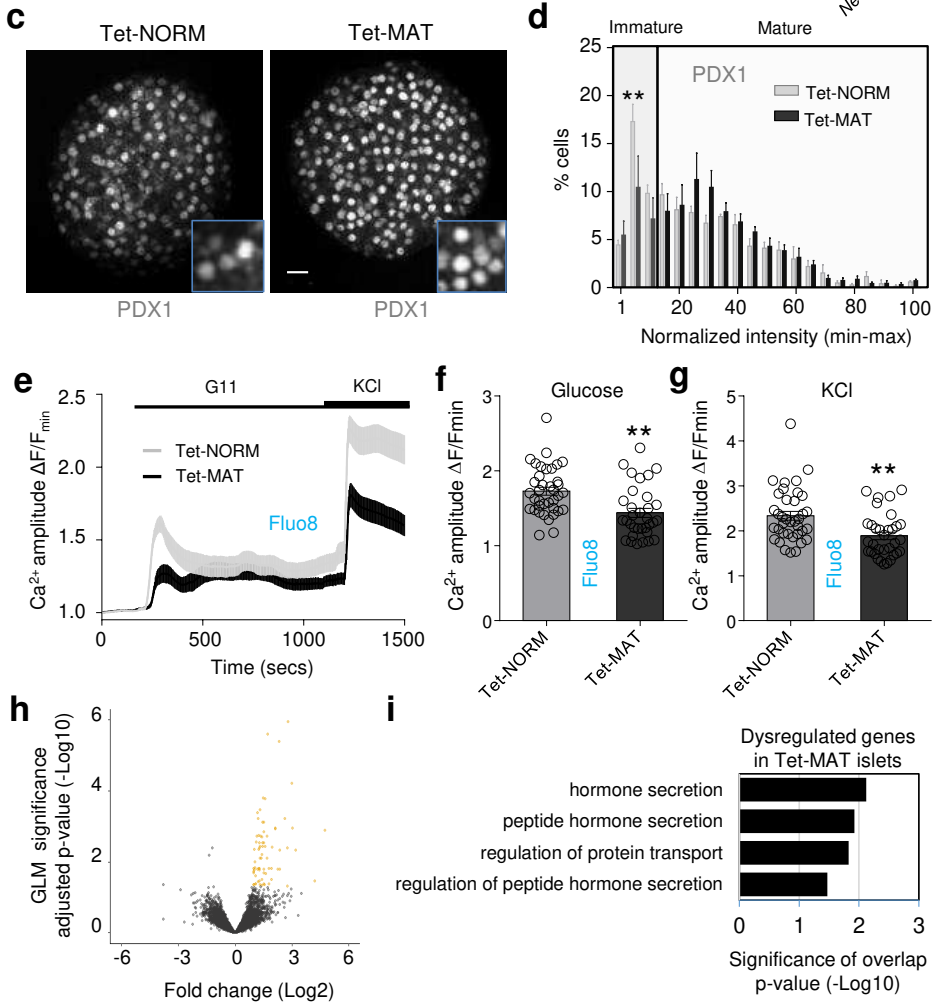

i

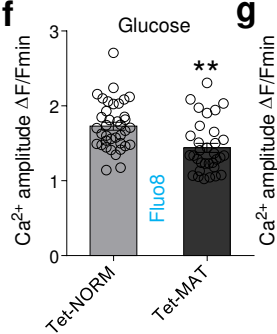

$\mathrm{KCl}$
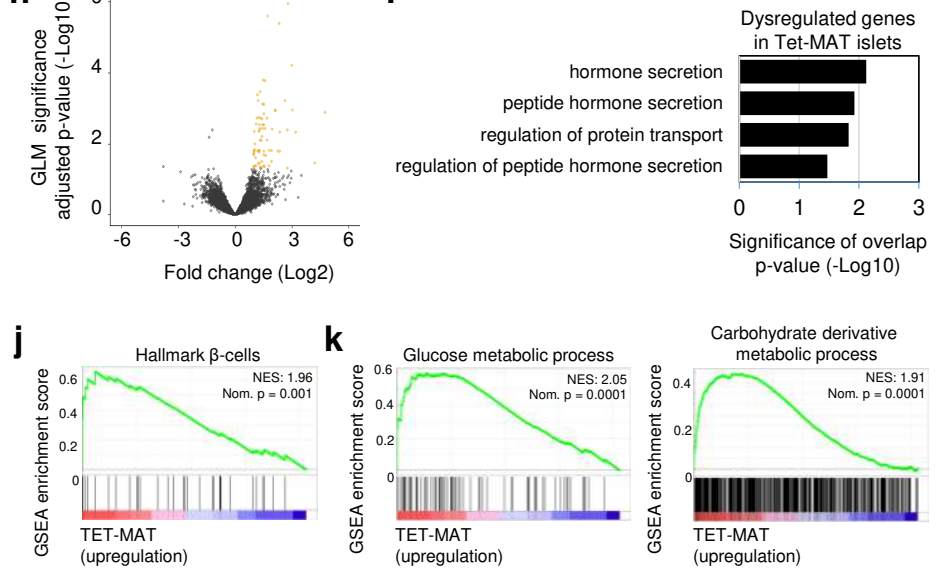

I
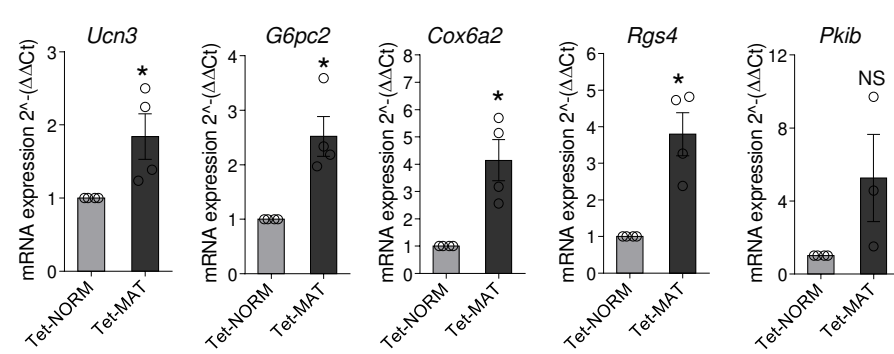

Figure 8: Differences in $\beta$-cell maturity influence islet gene expression. a Recombination of RIP7rtTA and TetO/M3C mice allows doxycycline-inducible changes in $\beta$-cell maturity in Tet-MAT but not Tet-NORM (control) islets. b Pdx1, Mafa and Neurog3 expression increases following incubation of Tet-MAT islets with $100 \mathrm{ng} / \mathrm{ml}$ doxycycline for 48 hours $(\mathrm{n}=3-5$ animals; paired t-test). $\mathbf{c}, \mathbf{d}$ A significant decrease in the number of relatively immature $\beta$-cells (PDX ${ }^{\text {LOW }}$ ) is seen in doxycycline-treated Tet-MAT islets, as shown by representative images (c), as well as the loss of cells in the lowest fluorescence intensity bins (d) (two-way ANOVA; 
$\mathrm{n}=6$ islets $/ 3$ animals $)$ (scale bar $=20 \mu \mathrm{m})(\mathrm{F}=41368, \mathrm{DF}=20)$. e- $\mathrm{g}$ Mean traces $(\mathbf{e})$ and bar graphs (f and $\mathbf{g}$ ) showing impaired glucose- and $\mathrm{KCl}$-stimulated $\mathrm{Ca}^{2+}$ rises in Tet-MAT but not Tet-NORM islets $(n=33-37$ islets $/ 4$ animals; unpaired t-test). $\mathbf{h}$ Volcano plot of differential gene expression between Tet-NORM and Tet-MAT islets. Fold-change (Log2, $x$-axis) gene expression is plotted against adjusted $p$-value for differential gene expression (normalized by GLM, -Log10, y-axis). Colored dots represent Ensembl genes that are differentially regulated at an adjusted $p$-value $<0.05$ ( $n=5$ animals). i Gene ontology analysis of differentially regulated genes in Tet-MAT islets. A set of 83 genes were functionally annotated using DAVID (adjusted p-value of $<0.05$ ). j Gene set enrichment analysis (GSEA) suggests that genes belonging to the gene set "hallmark $\beta$-cells" are upregulated in Tet-MAT islets. Normalized enrichment score (NES) and nominal p-value is presented in the top left corner of the graph. k GSEA analysis shows enrichment of genes belonging to glucose and carbohydrate derivative metabolic processes amongst the upregulated genes in Tet-MAT islets. I RT-qPCR analyses confirming upregulation of Ucn3, G6pc2, Cox6a2 and Rgs4 but not Pkib in Tet-MAT islets $\left(n=3-4\right.$ animals; paired t-tes). Bar graphs and traces show the mean $\pm S E M$. ${ }^{*} P<0.05$, ${ }^{* *} \mathrm{P}<0.01$ and NS, non-significant. 
FIGURE 9

a

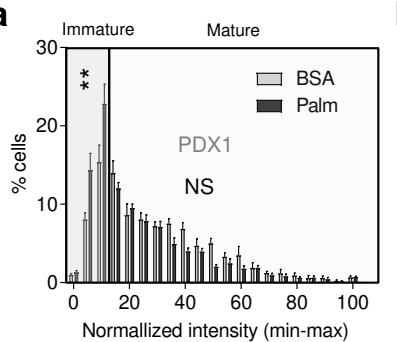

b
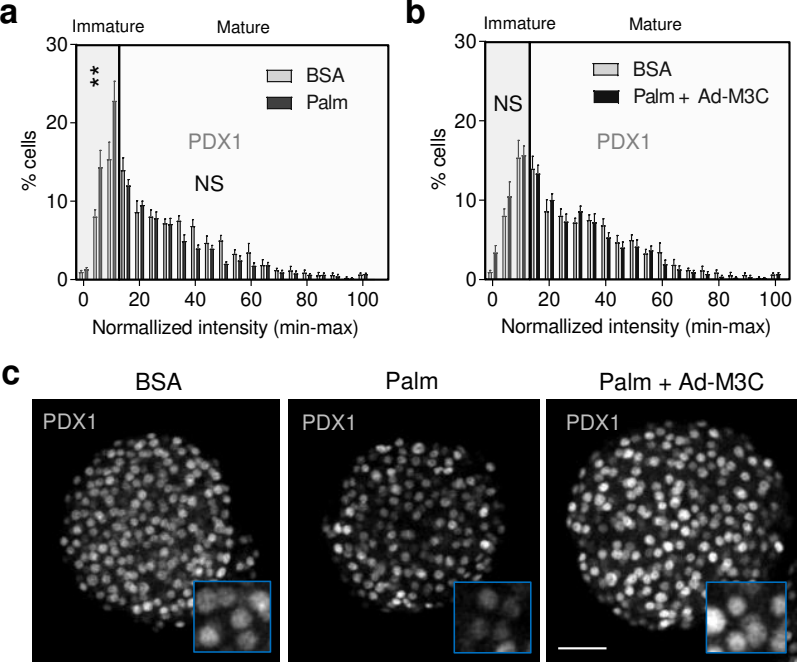

Palm + Ad-M3C
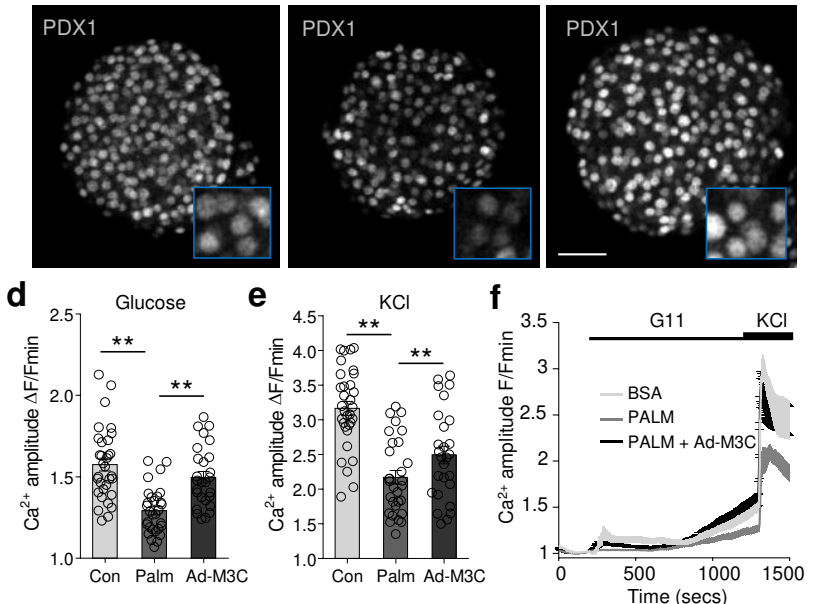

g
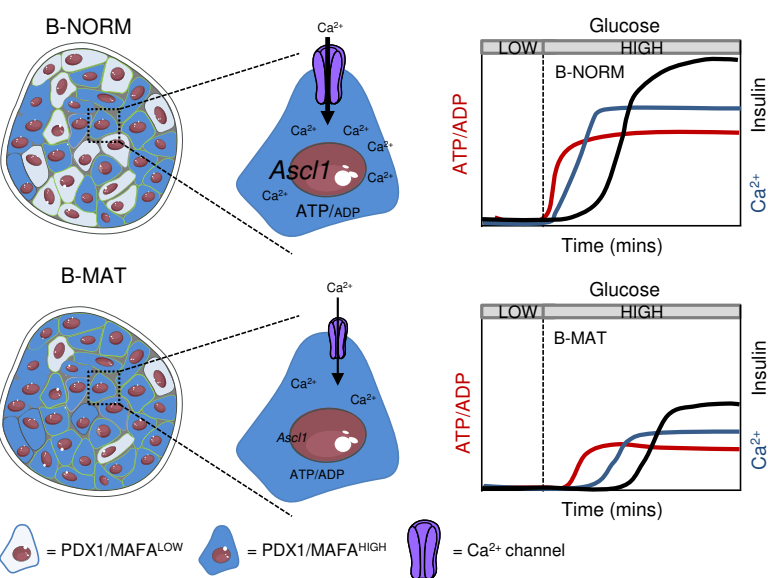

$=\mathrm{Ca}^{2+}$ channel

Figure 9: Maintaining immature-mature $\beta$-cell balance protects against islet failure. a-c A significant decrease in the proportion of PDX $1^{\mathrm{HIGH}} \beta$-cells is detected in palmitate-treated islets (a), and this can be reversed using $\operatorname{Ad}-\mathrm{M} 3 \mathrm{C}(\mathbf{b})$, as shown by representative images (c) $(n=7$ islets/4 animals; two-way ANOVA) (Palm: $F=4.28, D F=20)(P a l m+A d-M 3 C: F=0.90$, $\mathrm{DF}=20$ ) (BSA, bovine serum albumin; Palm, $0.5 \mathrm{mM}$ palmitate for 48 hours; Ad-M3C, CMVNEUROG3/PDX1/MAFA/mCherry) (scale bar $=42.5 \mu \mathrm{m}$ ). Note that the same BSA-only (control) PDX1 fluorescence intensity distribution is shown in both graphs (a) and (b) to allow cross-comparison (the experiments were performed in parallel). $\mathbf{d}-\mathbf{f} \mathrm{Ca}^{2+}$ responses to glucose (d) and $\mathrm{KCl}(\mathbf{e})$ are blunted in palmitate-treated, but not palmitate + Ad-M3C-treated islets (one-way ANOVA; $n=27-32$ islets $/ 4$ animals $(\mathrm{G} 11: \mathrm{F}=18.80$, $\mathrm{DF}=2)(\mathrm{KCl}: \mathrm{F}=23.13$, $\mathrm{DF}=$ 2 ), as shown by mean traces (f). $\mathbf{g}$ Schematic showing that a decrease in the proportion of PDX1 ${ }^{\text {LOW/MAFA }}{ }^{\text {LOW }} \beta$-cells leads to altered islet $\mathrm{Ca}^{2+}$ fluxes, decreased expression of $\mathrm{Ca}^{2+}$ dependent genes such as Ascl1, and broader changes to $\beta$-cell function including impaired ATP/ADP and insulin responses to glucose. Bar graphs and traces show the mean \pm SEM. ${ }^{*} \mathrm{P}<0.05,{ }^{* *} \mathrm{P}<0.01$ and NS, non-significant. 


\section{Figures}
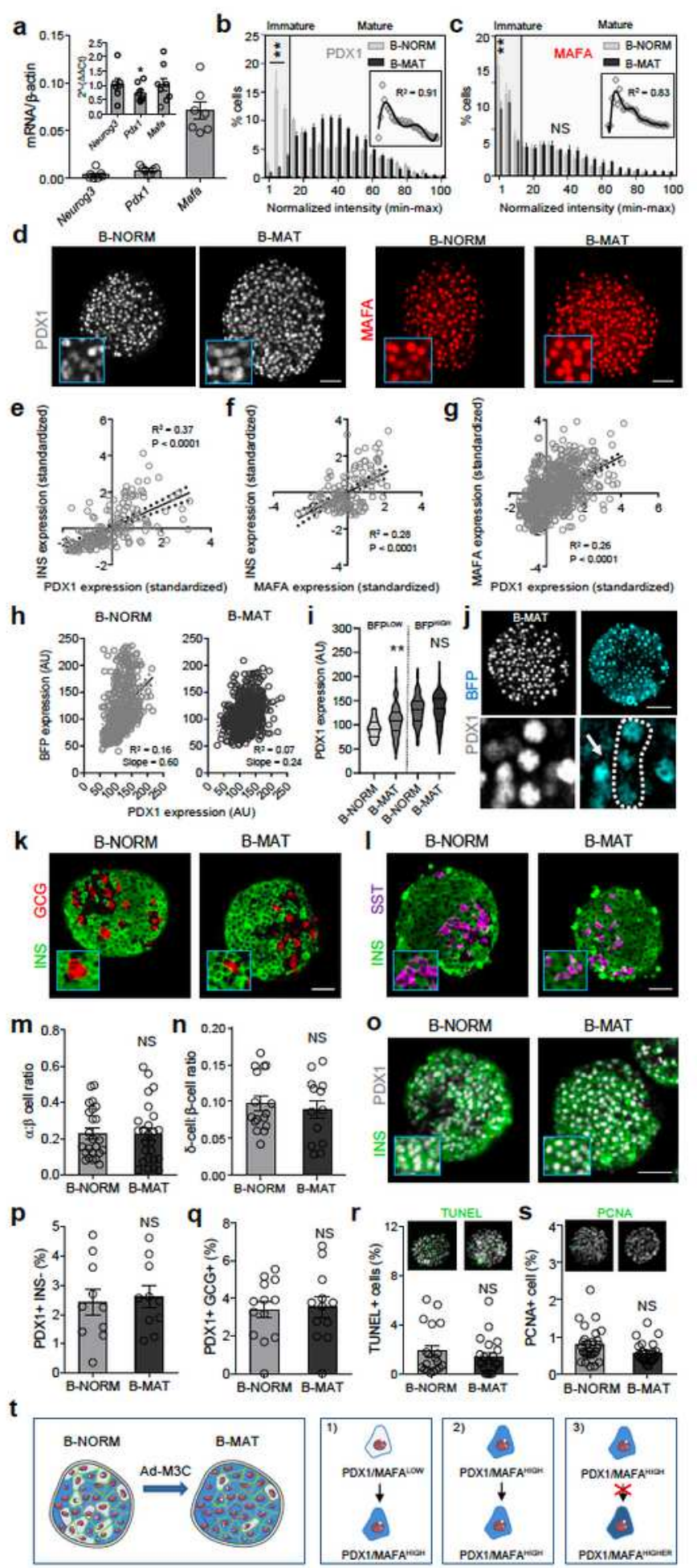

\section{Figure 1}

Generating islets with proportionally more mature $\beta$-cells. a mRNA expression of adenoviral Neurog3, $\mathrm{Pdx} 1$ and Mafa in mouse islets, detected using primers specific to transduced genes and expressed as mRNA/ $\beta$-actin. No changes in endogenous Neurog3 and Mafa mRNA are detected, while a slight but 
significant reduction in $\mathrm{Pdx} 1 \mathrm{mRNA}$ is present (graph is inset and expressed as $2^{\wedge}-(\Delta \Delta \mathrm{Ct})(\mathrm{n}=5-8$ animals; paired t-test).b Islets transduced with Ad-M3C ( $\beta$-cell mature; B-MAT) lose $\beta$-cells occupying the bottom 15 percentile for PDX1 expression compared to controls ( $\beta$-cell normal; B-NORM) (inset shows the non-normalized B-NORM distribution fitted with a polynomial) $(n=6-7$ islets $/ 3$ animals; two-way ANOVA) $(F=18.75, D F=20)$. c As for $(b)$, but showing the frequency distribution for MAFA expression $(n=8$ islets/3 animals; two-way ANOVA) $(F=3.03, D F=20)$. d Representative images showingmore homogenous PDX1/MAFA fluorescence throughout the $\beta$-cell population in B-MAT islets(scale bar $=60$ $\mu \mathrm{m}$ ) (See Fig. 11 for NEUROG3 expression). e-g INS-PDX1 (e), INS-MAFA(f)and MAFA-PDX1 (g) are positively correlated in individual cells in B-NORM islets $(n=137-984$ cells, linear regression). $h$ PDX1 and BFP are linearly correlated in Pdx1-BFP islets, andthis association is lost following transduction with AdM3C (B-MAT). i BFPLOW cells (priorimmature) become PDX1HIGH in B-MAT islets, while BFPHIGH cells (prior mature) remainPDX1HIGH. j Representative images from Pdx1-BFP islets showing cells that underwentPDX1LOW -> PDX1HIGH conversion following transduction with Ad-M3C (arrow shows a cell thatremained PDX1HIGH) (scale bar $=50 \mu \mathrm{m})(\mathrm{n}=5-6$ islets $/ 3$ animals; two-way ANOVA) $(\mathrm{F}=2.80, \mathrm{DF}=$ 18). $k$-q No differences are detected in the ratios of $a$ - to $\beta$-cells (23-25 islets $/ 3-4$ animals)and $\delta$ - to $\beta$-cells (18-20 islets/3 animals) ( $k-n$ ), or the proportion of PDX1 positive, but INSnegative or GLU positive cells (oq) (10-13 islets/4 animals) in B-NORM versus B-MAT islets(unpaired t-test) (scale bar $=40 \mu \mathrm{m}) . \mathrm{r}$ Quantification of TUNEL+ cells shows no difference inB-NORM versus B-MAT islets ( $n=18-21$ islets/4 animals; unpaired t-test) (representativeimages shown above the corresponding bar). s Cell proliferation, measured using proliferatingcell nuclear antigen (PCNA), is similarly low in B-NORM and B-MAT islets ( $\mathrm{n}$ = 24-27 islets/4animals; unpaired t-test) (representative images shown above the corresponding bar). tSchematic showing the proposed fate of immature (LOW) and mature (HIGH) $\beta$-cells in B-MAT islets. Transition to high protein content tends to occur in the relatively immature cells(1), whereas the more mature cells remain largely unaffected (2), with protein levels neversurpassing those in B-NORM islets (3). Bar graphs show the mean \pm SEM. Violin plot showsmedian and interquartile range. ${ }^{*} P<0.05,{ }^{*} P<0.01$ and NS, non-significant. BFP-bluefluorescent protein; INS-insulin; GLU-glucagon; TUNEL- terminal deoxynucleotidyltransferase dUTP nick end labeling. 
a

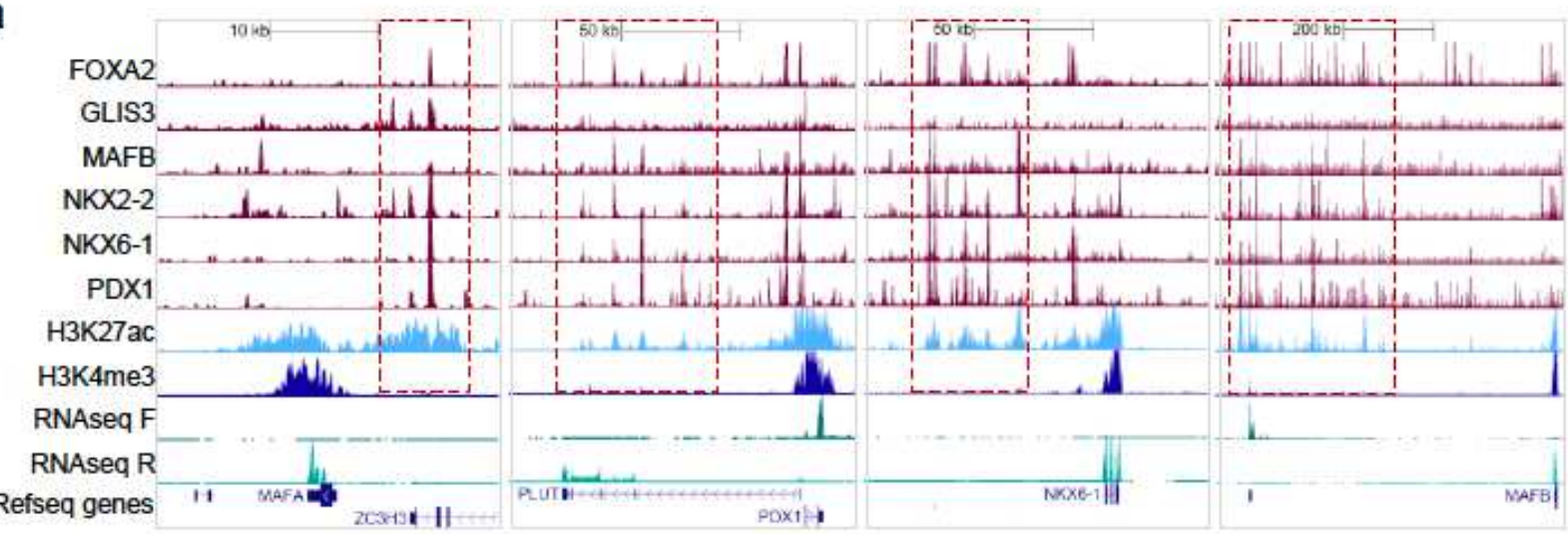

b

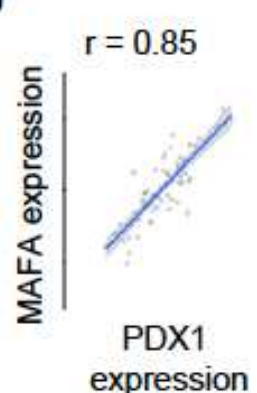

C
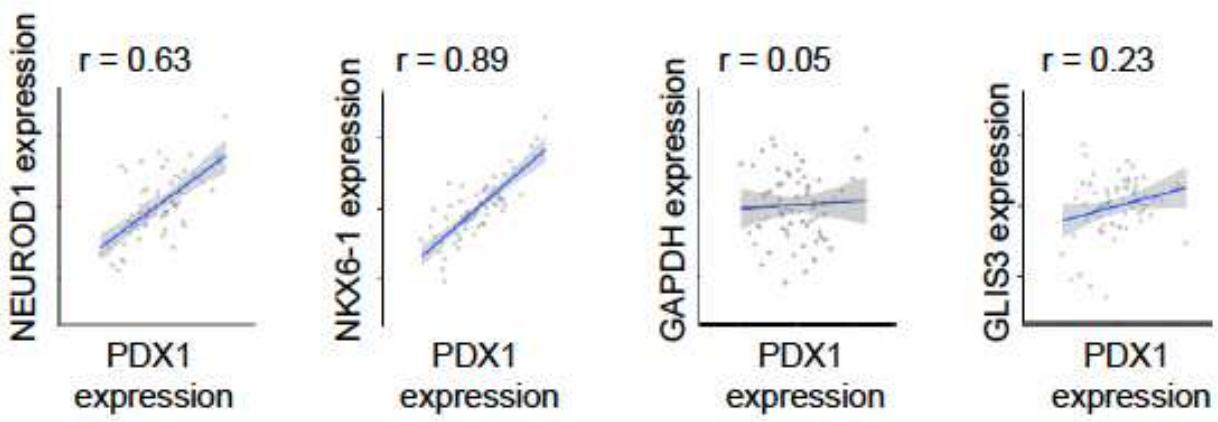

d
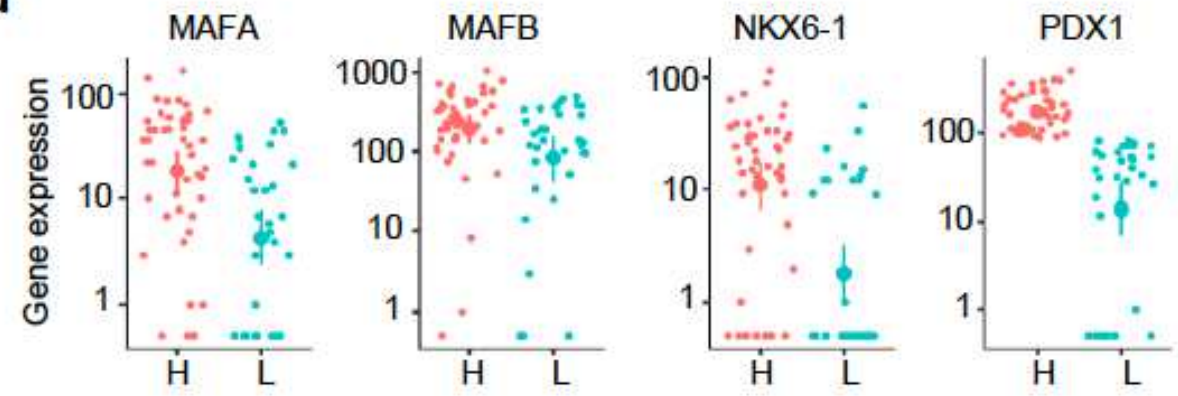

\section{Figure 2}

PDX1LOW/MAFALOW cells are transcriptionally immature. a Binding of multiple transcription factors to enhancer clusters (boxed in red) regulates expression of key $\beta$-cell transcription factors in human islets. For reference, RNA-seq, H3K27ac (enhancer mark) and H3K4me3 (promoter mark) are also shown. All scales are set to 20 RPKM for ChIP-seq32 and 20 or 60 RPKM for RNA-seq (TF strand to 60, other to 20). b Expression of MAFA and PDX1 correlate over 64 human islet samples. The axes represent normalized expression values (-3 to 3) for each gene used for the co-expression network analysis 31. c Correlation of expression of mRNA levels for PDX1 and NEUROD1, NKX6-1, GAPDH and GLIS3 across 64 human islet samples. The axes represent normalized expression values (-3 to 3) for each gene used for the coexpression network analysis 31. d Single cell gene expression levels for MAFA, MAFB and NKX6-1 in cells with high and low mRNA levels for PDX1. Analysis was performed using monocle, the y-axis representing gene expression levels in log10 scale. Datasets were obtained from 31,33. 

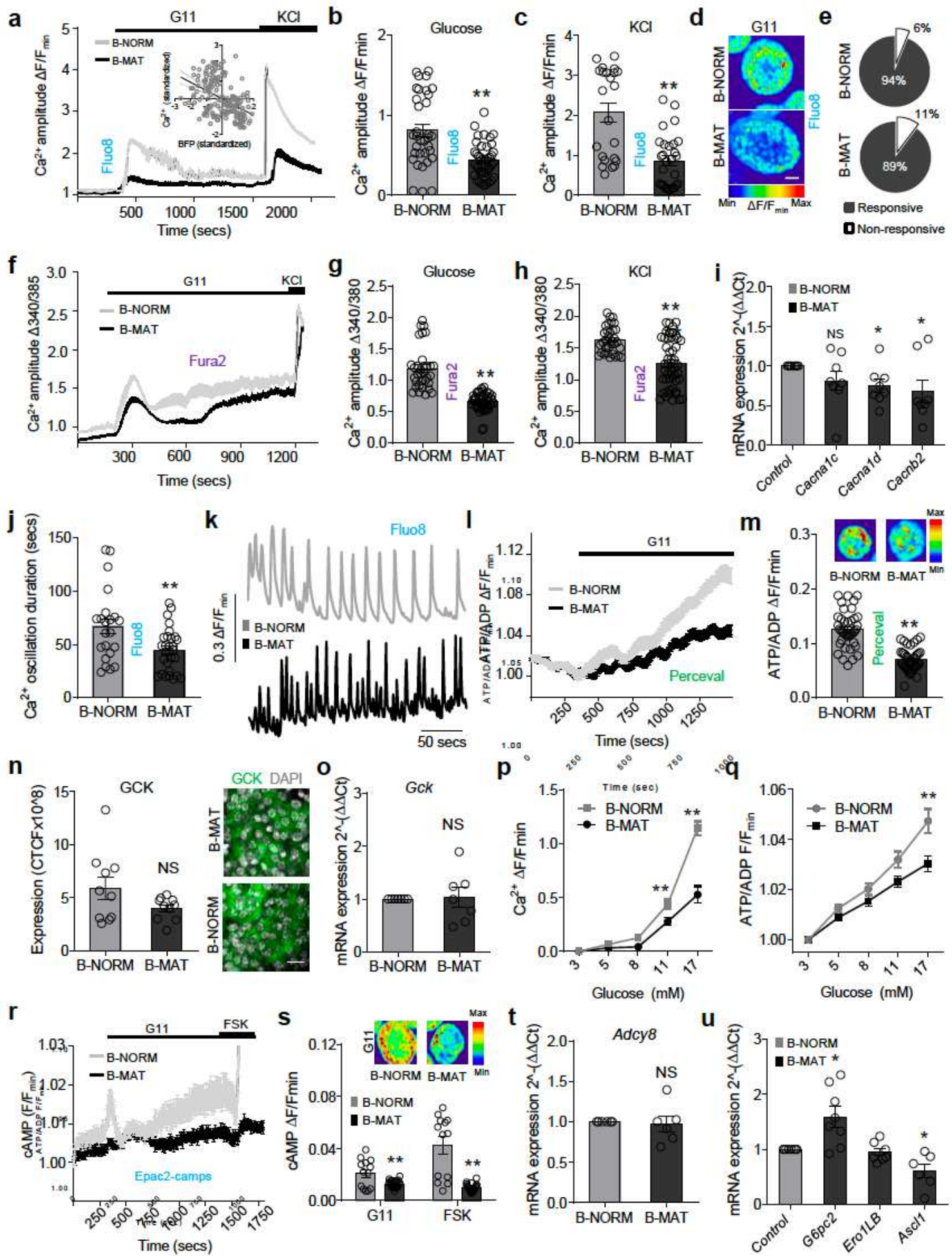

\section{Figure 3}

Differences in $\beta$-cell maturity contribute to islet signalling. a-c Ca2+ fluxes (a) in response to glucose (b) or glucose $+\mathrm{KCl}(\mathrm{c})$ are significantly impaired in B-MAT islets. Inset shows inverse linear correlation between $\mathrm{Ca} 2+$ amplitude and BFP expression in individual $\beta$ - cells in Pdx1-BFP islets in response to 17 $\mathrm{mM}$ glucose (G11, $11 \mathrm{mM}$ glucose; $\mathrm{KCl}, 10 \mathrm{mM}$ ) (B-NORM/B-MAT: $\mathrm{n}=34-43$ islets/4-5 animals; unpaired t-test) (Pdx1-BFP; $n=6$ islets $/ 3$ animals; $R 2=0.21, P<0.0001)$. $d$ Representative images showing loss of 
glucose-stimulated Ca2+ rises in B-MAT but not B-NORM islets (scale bar $=40 \mu \mathrm{m}$ ). e No differences in the proportion (\%) of glucose-responsive $\beta$-cells are detected in B-MAT islets ( $n=34-43$ islets $/ 4-5$ animals; unpaired t-test). $\mathrm{f}-\mathrm{h}$ As for (a-c), but instead using the ratiometric $\mathrm{Ca} 2+$ indicator Fura2 to account for any effects on basal Ca2+ levels. ( $n=33-50$ islets/4 animals; unpaired t-test). i Expression of genes encoding the VDCC subunits CACNA1D and CACNB2 is reduced in B-MAT islets ( $n=8-10$ animals; paired t-test). $\mathrm{j}, \mathrm{k}$ B-MAT islets show a reduction in $\mathrm{Ca} 2+$ pulse duration, as shown by summary bar graph ( $\mathrm{j}$ ) and representative traces $(k)(n=8-15$ islets/4 animals; unpaired t-test). I, $m$ ATP/ADP ratios $(I)$ recorded using the recombinant probe Perceval are 50\% reduced in B-MAT islets. Representative images $(\mathrm{m})$ of glucose-stimulated ATP/ADP rises are displayed above the corresponding bar ( $n=40$ islets/ 4 animals; unpaired t-test). $n$, o Glucokinase (GCK) protein expression ( $n$ ) tends to be reduced in B-MAT islets ( $n=10$ islets/2 animals; paired t-test), although Gck mRNA levels are normal (o) ( $n=7$ animals; paired t-test) (scale bar $=15 \mu \mathrm{m}) . \mathrm{p}, \mathrm{q} \mathrm{Ca} 2+(\mathrm{p})$ and ATP/ADP $(q)$ responses to increasing glucose concentration are decreased in B-MAT islets (Ca2+: $\mathrm{n}=11-24$ islets $/ 5$ animals; two-way ANOVA $\mathrm{F}=20.36, \mathrm{DF}=4$ ) (ATP/ADP: $n=37-38$ islets/5 animals, two-way ANOVA; $F=6.10, D F=4)$. $r$, s Mean traces $(r)$ and bar graph (s) showing that cAMP levels in response to glucose and forskolin (FSK, $100 \mu \mathrm{M})$ are reduced in $\mathrm{B}$ MAT islets. Representative images of glucose-stimulated cAMP rises are displayed above the corresponding bar ( $n=13-24$ islets; unpaired t-test). $t$ Expression of Adcy 8 remains unchanged in B-MAT islets ( $\mathrm{n}=6$ animals; paired t-test). $\mathrm{u}$ The Pdx 1 target genes $\mathrm{G} 6 \mathrm{pc} 2$ and Ascl1 are up- and down-regulated, respectively, in B-MAT islets (expression of Ero1LB is unchanged) ( $n=6-8$ animals; paired t-test). Bar graphs and traces show the mean \pm SEM. ${ }^{*} \mathrm{P}<0.05,{ }^{*} \mathrm{P}<0.01$ and NS, non-significant. CTCF-corrected total cell fluorescence. 
a
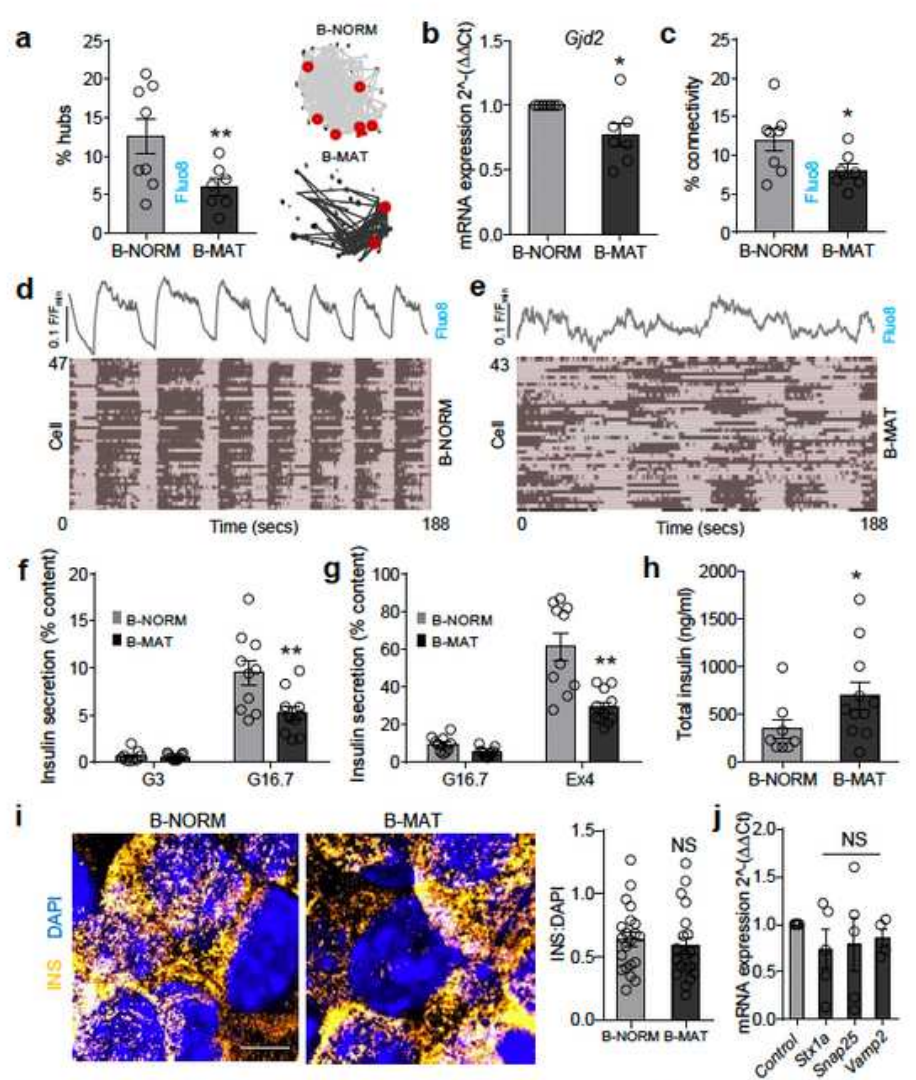

k
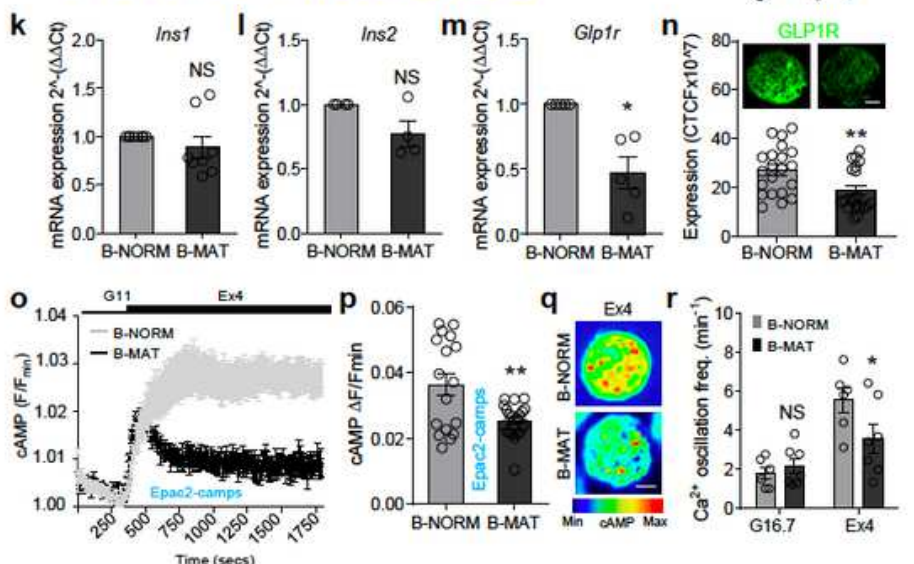

s
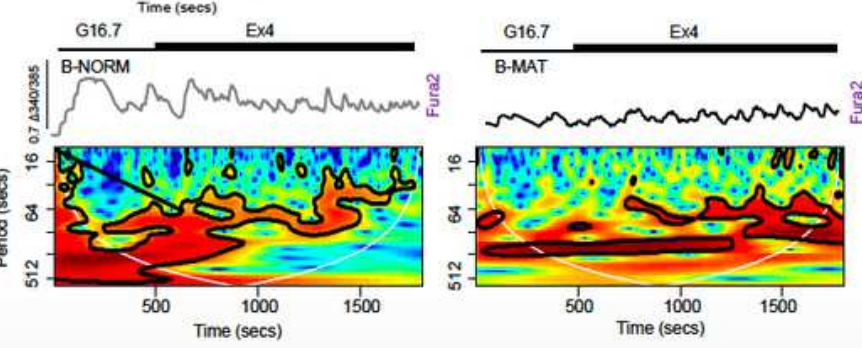

\section{Figure 4}

Both immature and mature $\beta$-cells are required for islet dynamics and insulin secretion. a-c Hub cell proportion (circled in red) (a) ( $\mathrm{n}=7-8$ islets/3 animals; unpaired t-test), mRNA for Gjd2 (b) ( $\mathrm{n}=7$ animals; paired t-test) and coordinated $\beta$-cell- $\beta$-cell activity (connectivity) (c) ( $n=7-8$ islets/3 animals; unpaired ttest) are all decreased in B-MAT islets. $d$, e Raster plots showing $\beta$-cell activity profiles across the population, which is coordinated in B-NORM islets (d), but more stochastic in B-MAT islets (e). f-h Loss of 
immature $\beta$-cells leadsto reductions in glucose $(\mathrm{f})$ - and Exendin-4 $(\mathrm{g})$-stimulated insulin secretion $(\mathrm{n}=10$ 11 replicates $/ 4$ animals; two-way ANOVA) $(G 16.7: F=7.89, D F=1)(E x 4: F=13.40, D F=1)$,despite an increase in insulin content $(\mathrm{h})$ (\% insulin content $=$ secreted insulin $/$ total insulin)( $\mathrm{n}=$ 8-10 replicates $/ 4$ animals; unpaired t-test). Note that all samples were run together, butdue to the relative magnitude of the Exendin- 4 response, the results are displayed separatelywith the same high glucose state (G3, $3 \mathrm{mM}$ glucose; G16.7, 16.7 mM glucose; Ex4, 20 nMExendin-4). i Representative super-resolution images and summary bar graph showingabsence of changes in insulin granule density at the membrane (normalized to DAPI) in B-MAT islets (scale bar $=6 \mu \mathrm{m})(\mathrm{n}=12$ islets $/ 6$ animals; unpaired t-test). $\mathrm{j}$ No differences inexpression of Stx1a, Snap25 and Vamp2 are detected in B-MAT islets ( $n=5-6$ animals; pairedt-test). $k$, I Ins1 ( $k$ ) and Ins2 (I) mRNA levels are unchanged in B-MAT islets ( $n=4-8$ animals;paired t-test). $m, n$ GLP1R mRNA (m) ( $n=5$ animals, paired t-test) and protein $(n)(n=20-21$ islets/4 animals, unpaired t-test) expression are markedly reduced in B-MAT islets(representative images shown above bar graph, scale bar $=25 \mu \mathrm{m}$ ). o-q Maximal Exendin-4-stimulated cAMP rises are blunted in B-MAT islets, shown by mean traces $(0)$, summary bargraph $(p)$ and representative images (scale bar $=25 \mu \mathrm{m})(\mathrm{q})(\mathrm{n}=17-22$ islets $/ 2$ animals; unpaired t-test) (G11, 11 mM glucose; Ex4, 20 nM Exendin-4). r, s Exendin-4 increases Ca2+spiking frequency in B-NORM islets which is blunted in B-MAT islets ( $r$ ), confirmed usingwavelet analysis of the dominant frequencies ( $\mathrm{s}$ ) (mean wave shown) ( $\mathrm{n}=6-7$ islets/3 animals,two-way ANOVA) $(F=4.40, D F=1)(G 16.7,16.7 \mathrm{mM}$ glucose; Ex4, $20 \mathrm{nM}$ Exendin-4). Bargraphs and traces show the mean \pm SEM. ${ }^{*} P<0.05,{ }^{\star *} \mathrm{P}<0.01$ and NS, non-significant. 
FIGURE 5
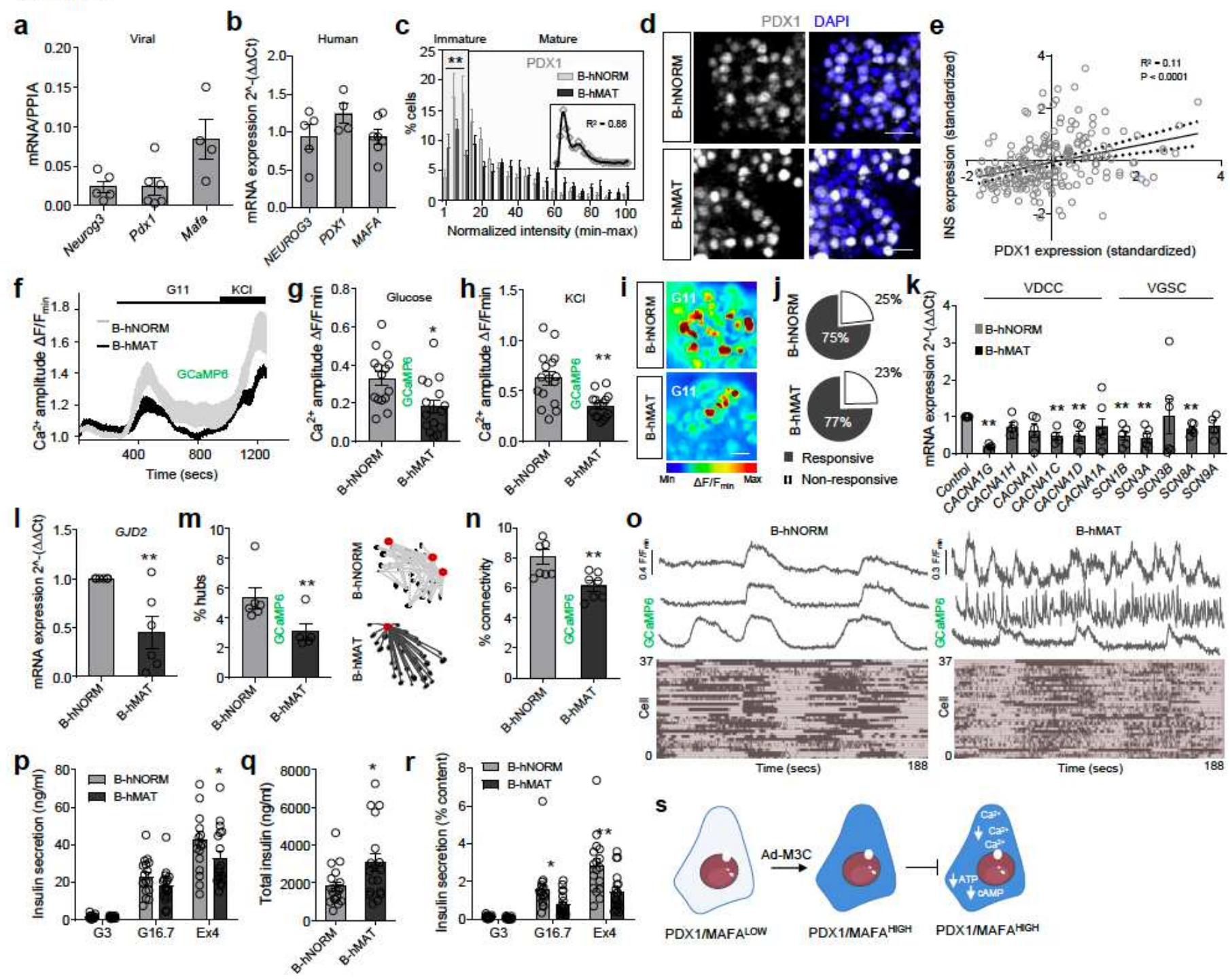

\section{Figure 5}

Differences in $\beta$-cell maturity contribute to human islet function. $a, b$ Ad-M3C increases exogenous Neurog3, Pdx1 and MafA expression (a), while no differences are detected in native NEUROG3, PDX1 and MAFA expression (b) ( $n=4-8$ donors). c, Ad-M3C increases the proportion of cells expressing high PDX1 levels (B-hMAT) (inset is the nonnormalized B-hNORM distribution fitted with a polynomial) $(n=13$ islets/4 donors; two-way ANOVA) ( $F=4.14, D F=20)$. $d$ Representative images showing loss of PDX1LOW cells in BhMAT islets (detected using a PDX1 antibody with reactivity against mouse and human protein) (scale bar $=42.5 \mu \mathrm{m}$ ). e PDX1 and INS1 are positively correlated in individual cells from B-hNORM islets $(\mathrm{n}=220$ cells). $\mathrm{f}-\mathrm{h}$ Ca2+ traces $(\mathrm{f})$ showing decreased responsiveness to glucose $(\mathrm{g})$ and $\mathrm{KCl}(\mathrm{h})$ in $\mathrm{B}$ hMAT islets ( $\mathrm{n}=16$ islets/3 donors; unpaired t-test). $\mathrm{i}, \mathrm{j}$ as for $(\mathrm{f}-\mathrm{h})$, but representative images (scale bar = $25 \mu \mathrm{m}$ ) showing loss of glucose-stimulated $\mathrm{Ca} 2+$ rises in B-hMAT but not B-hNORM islets (i), despite no differences in the proportion of responsive cells $(j)$ ( $n=16$ islets 3 donors; unpaired t-test). $k$ The VDCC and $\mathrm{Na}+$ channel subunits CACNA1G, CACNA1C, CACNA1D, SCN1B, SCN3A and SCN8A are all downregulated in B-hMAT islets ( $n=4-6$ donors; paired t-test). I-o GJD2 expression (I) is decreased in B- 
hMAT islets ( $\mathrm{n}=6$ donors; paired t-test), which is associated with a decrease in the number of hubs (circled in red) ( $\mathrm{m}$ ) and coordinated $\beta$-cell- $\beta$-cell activity (connectivity) ( $\mathrm{n}$ and o) (representative traces are from 'connected' cells) ( $n=7-8$ islets $/ 3$ donors unpaired t-test). $p$-r Non-normalized Insulin secretion is similar in B-hMAT and B-hNORM islets (p), although B-hMAT islets only release a fraction of their total insulin ( $q$ and $r$ ) (\% insulin content $=$ secreted insulin / total insulin) $(n=17-18$ replicates $/ 5$ donors; unpaired t-test and two-way ANOVA). s Schematic showing proposed changes occurring in $\beta$-cells in BhMAT islets. Bar graphs and traces show the mean $\pm S E M .{ }^{*} P<0.05,{ }^{*} \mathrm{P}<0.01$ and NS, non-significant. GCaMP6-genetically-encoded Ca2+ indicator; VDCC-voltage-dependent Ca2+ channels; VGSC-voltagegated $\mathrm{Na}+$ channels; GJD2-Gap junction delta-2 protein encoding Connexin-36. 

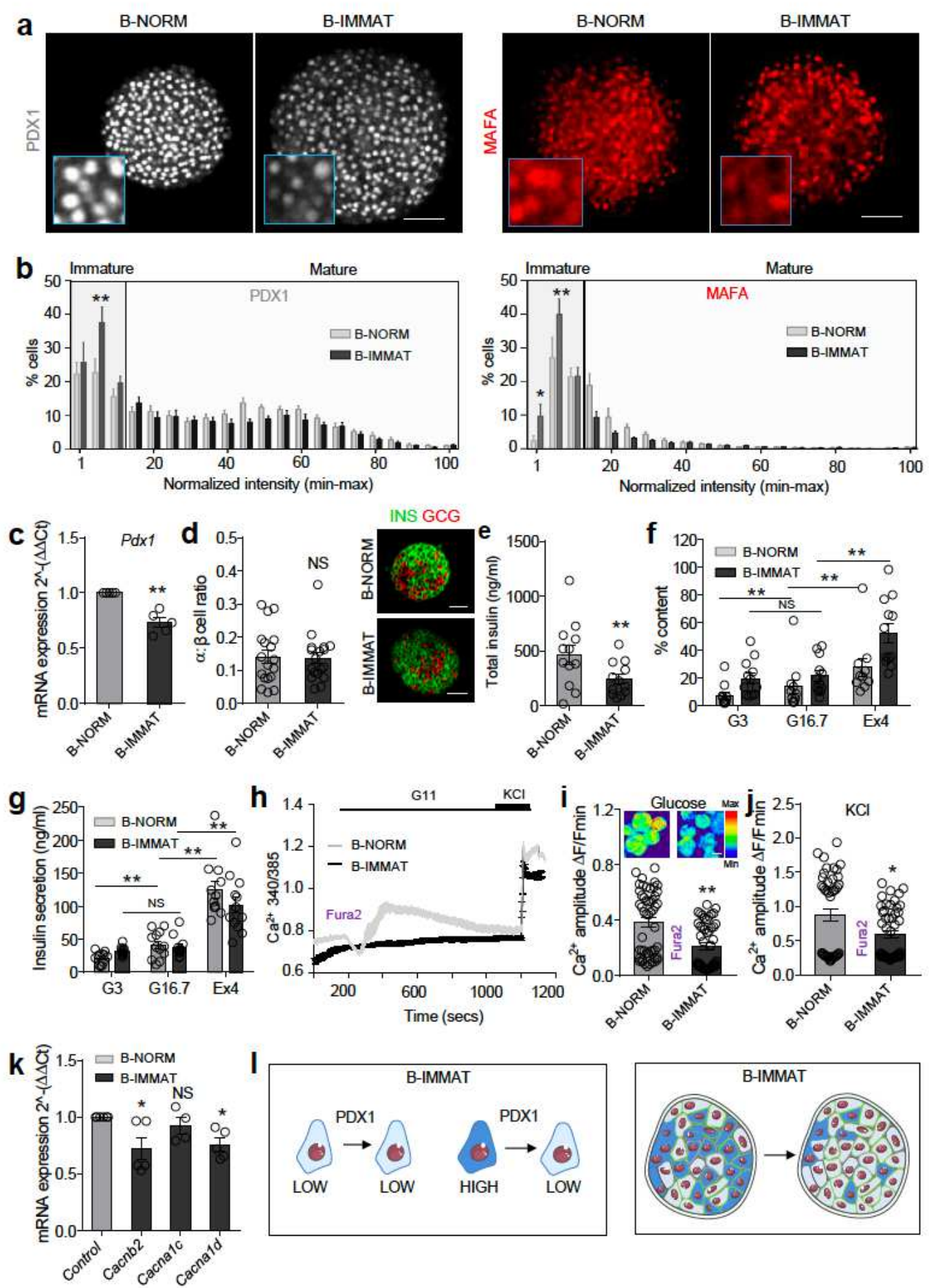

\section{Figure 6}

A proportional increase in immature $\beta$-cells impairs islet function. a shPdx 1 increases the proportion of $\beta$ cells in the islet with low levels of PDX1 and MAFA ( $\beta$-cell immature; B-IMMAT) (scale bar $=60 \mu \mathrm{m}) . \mathrm{b}$ Quantification of PDX1 and MAFA expression intensity shows an increase in $\beta$-cells occupying the bottom 15 percentile in B-IMMAT islets ( $\mathrm{n}=13-14$ islets/3 animals; two-way ANOVA) (PDX1: $\mathrm{F}=2.38$, DF = 20) (MAFA: $F=3 \cdot 20$, DF $=20$ ). c RT-qPCR showing a decrease in Pdx1 expression levels in B-IMMAT 
islets ( $n=5$; paired t-test). $d$ Induction of homogenous $\beta$-cell immaturity does not alter the $\alpha$ - to $\beta$-cell ratio (scale bar $=42.5 \mu \mathrm{m})(\mathrm{n}=18$ islets/ 2-3 animals; unpaired t-test). e-g B-IMMAT islets display decreased insulin content (e), increased basal insulin release and absence of significant glucose-stimulated insulin secretion ( $\mathrm{f}$ and $\mathrm{g}$ ) ( $\mathrm{n}=$ 10-12 replicates/4 animals; t-test and oneway ANOVA) (G3, 3 mM glucose; G16.7, 16.7 mM glucose; Ex4, 20 nM Exendin-4). h-j Ca2+traces (h) and bar graphs (i and j) showing impaired responses to glucose and glucose $+\mathrm{KCl}$ in B-IMMAT islets $(n=49-51$ islets $/ 4-5$ animals; unpaired t-test $)$ (representative images shown above bar graph, scale bar $=75 \mu \mathrm{m}$ ). $\mathrm{k}$ mRNA for the L-type VDCC subunits Cacnb2 and Cacna1d are significantly downregulated in B-IMMAT islets ( $n=5-6$; paired t-test). I

Schematic showing the proposed changes in B-IMMAT islets. Bar graphs and traces show the mean \pm SEM. ${ }^{*}<<0.05,{ }^{*} \mathrm{P}<0.01$ and NS, non-significant.
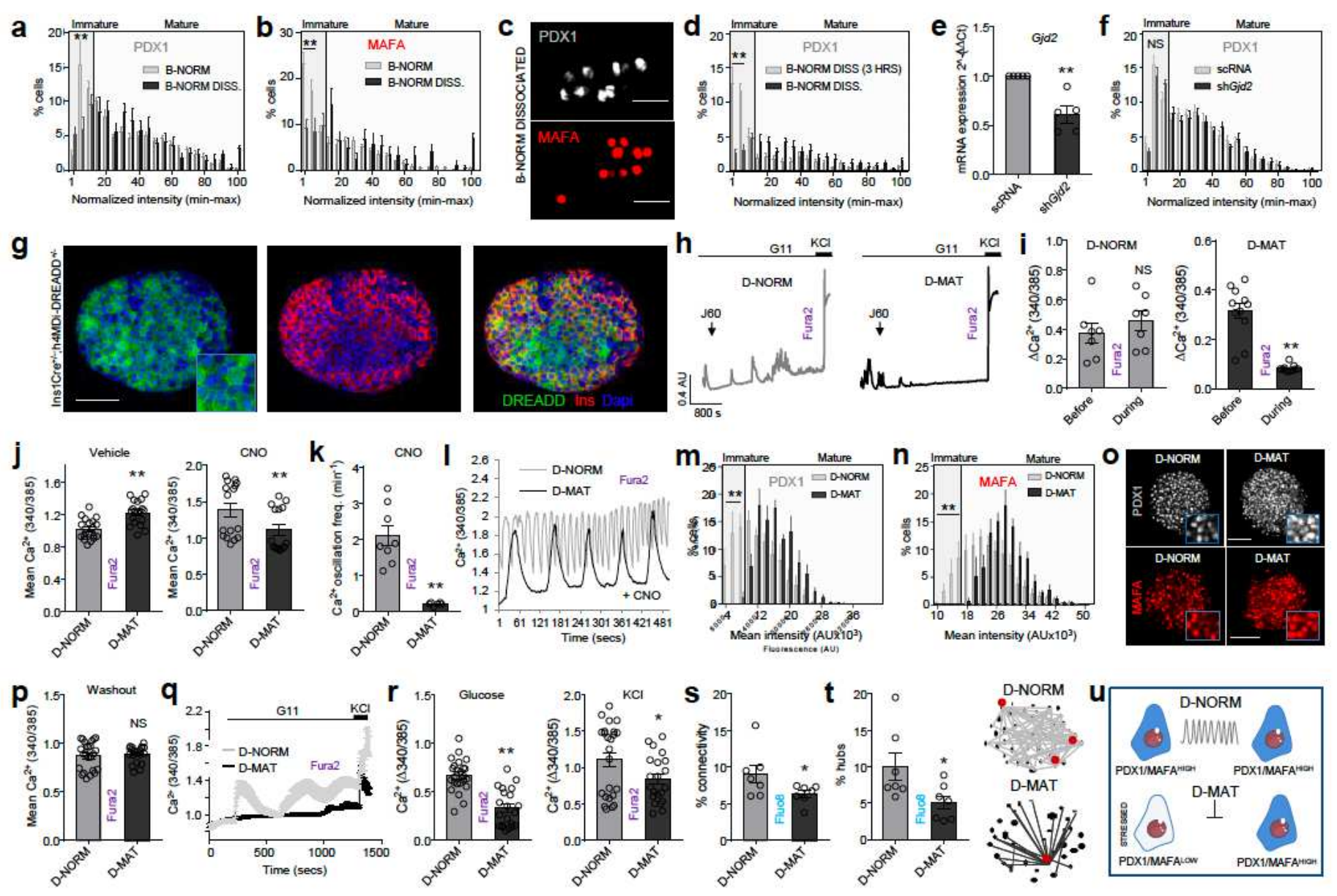

\section{Figure 7}

Differences in $\beta$-cell maturity are encoded by islet signaling patterns. $a$, $b$ Dissociation of islets into single $\beta$-cells (B-NORM DISS.) leads to loss of cells occupying the bottom 15 percentile for PDX1 (a) and MAFA (b) expression (B-NORM data from Fig. $1 \mathrm{~b}$ and $\mathrm{c}$ are superimposed for comparison purposes) $(\mathrm{n}=6-11$ islets $/ 4$ animals; two-way ANOVA) (PDX1: $F=7.23, D F=19)$ (MAFA: $F=4.69, D F=20)$ (scale bar $=42.5$ $\mu \mathrm{m})$. c Representative images showing a decrease in the proportion of PDX1/MAFALOW $\beta$-cells following dissociation of islets, as indicated by increased PDX1/MAFA fluorescence intensity throughout the $\beta$-cell 
population. $d$ Immature $\beta$-cells (PDX1LOW) are still present 3 hours following dissociation of islets into single cells ( $n=80$ islets $/ 10$ coverslips; two-way ANOVA) (PDX1: $F=9.54, D F=40)($ MAFA: $F=5.22, D F=$ 20). e Gjd2 expression is decreased in islets treated with shGjd2 versus scRNA controls ( $n=5$ animals; paired t-test). $f$ Relatively immature $\beta$-cells (PDX1LOW) are still present in scRNA- and shGjd2-treated islets $(\mathrm{n}=8-9$ islets $/ 2-3$ animals; two-way ANOVA) $(F=12.85, \mathrm{DF}=20) . \mathrm{g}$ The inhibitory DREADDs, h4MDi, are conditionally expressed in the membrane of $\beta$-cells following Cre-mediated recombination (DMAT) ( $n=3$ islets) (scale bar $=85 \mu \mathrm{m})$. h, i Representative Ca2+ traces $(\mathrm{h})$ and analysis (i) showing complete silencing of $\beta$-cell activity in D-MAT but not D-NORM (control) islets following application of the designer ligand $\mathrm{J} 60$ ( $n=7-11$ islets/3 animals; unpaired t-test). j, Clozapine-N-oxide (CNO) decreases intracellular $\mathrm{Ca} 2+$ levels in D-MAT islets following 3 hours incubation compared to vehicle control (DMSO) ( $n=16$ islets/5 animals; Mann-Whitney $U$ test). $k$, I CNO decreases Ca2+ oscillation frequency ( $k$ ) in D-MAT islets following 3 hours incubation, also shown by representative traces $(I)(n=6-8$ islets $/ 2$ animals; unpaired t-test). $m, n$ Incubation of D-MAT islets with CNO for 48 hours induces loss of $\beta$-cells occupying the bottom 15 percentile for PDX1 $(m)$ and MAFA $(n)$ expression $(n=8-9$ islets/3-4 animals; two-way ANOVA) (PDX1: $F=5.34, \mathrm{DF}=20)(\mathrm{MAFA}: \mathrm{F}=4.63, \mathrm{DF}=20)$. o Representative images showing loss of PDX1/MAFALOW cells in in D-MAT islets (scale bar $=60 \mu \mathrm{m}$ ). p Intracellular Ca2+ levels are restored in 48 hours CNO-treated islets following a 2 hour washout period $(n=21-24$ islets $/ 3$ animals; unpaired t-test). q-r Ca2+ traces (q) showing defective responses to $11 \mathrm{mM}$ glucose (G11) and $\mathrm{KCl}(10$ $\mathrm{mM})(\mathrm{r})$ in D-MAT islets, even following removal of CNO for 2 hours $(\mathrm{n}=21-24$ islets $/ 3$ animals; unpaired t-test). s, t D-MAT islets display more stochastic $\mathrm{Ca} 2+$ responses (s)(decreased connectivity), which is associated with loss of hubs (circled in red) ( $\mathrm{t}$ ) ( $\mathrm{n}=7$ islets/4 animals; unpaired $\mathrm{t}$-test). $\mathrm{u}$ Schematic showing effects of altering $\mathrm{Ca} 2+$ signalingpatterns on immature and mature $\beta$-cells. Bar graphs and traces show the mean \pm SEM. ${ }^{*} P<0.05,{ }^{*} \times P<0.01$ and NS, non-significant. 
a

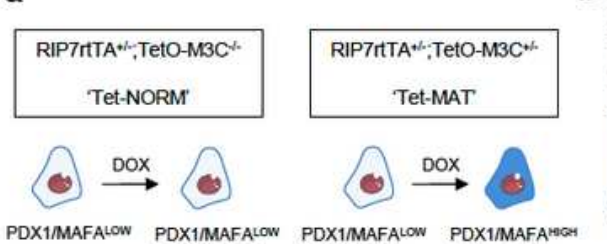

b

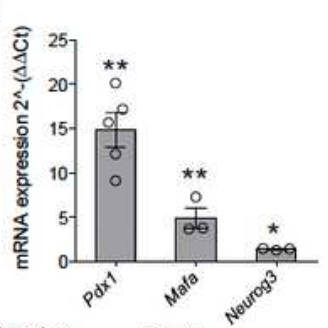

C
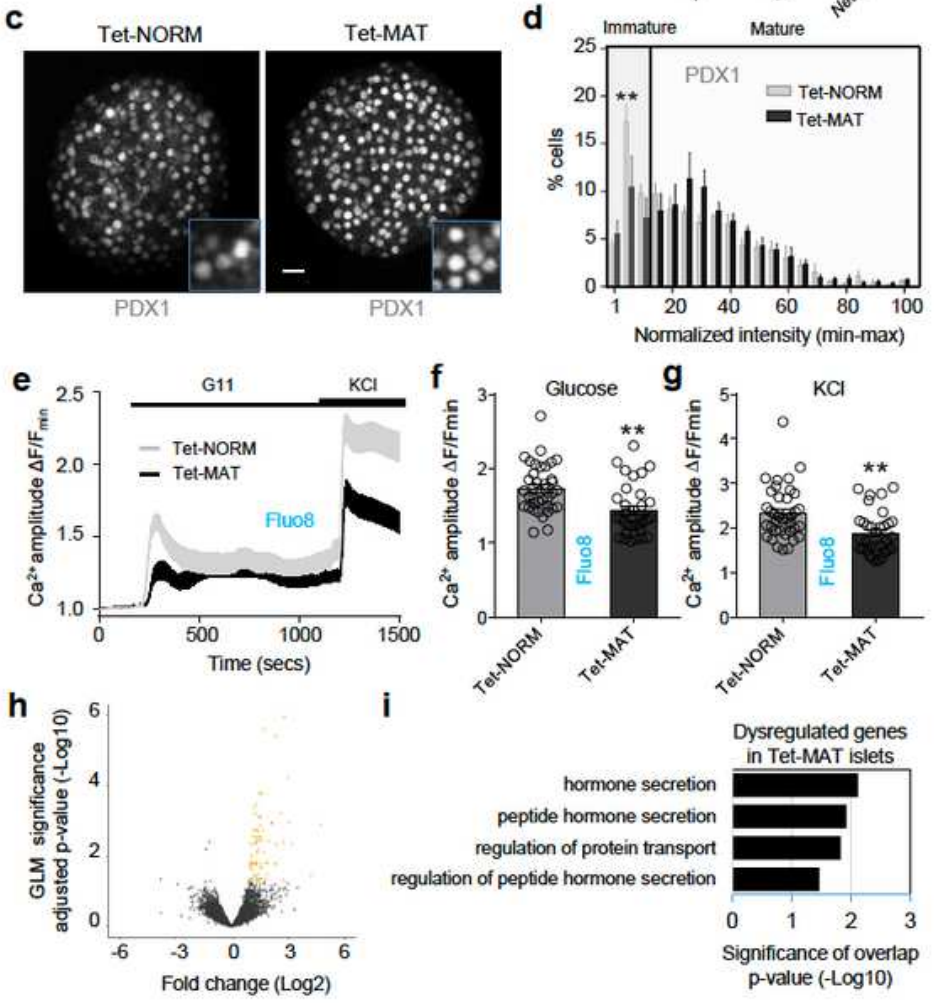

i
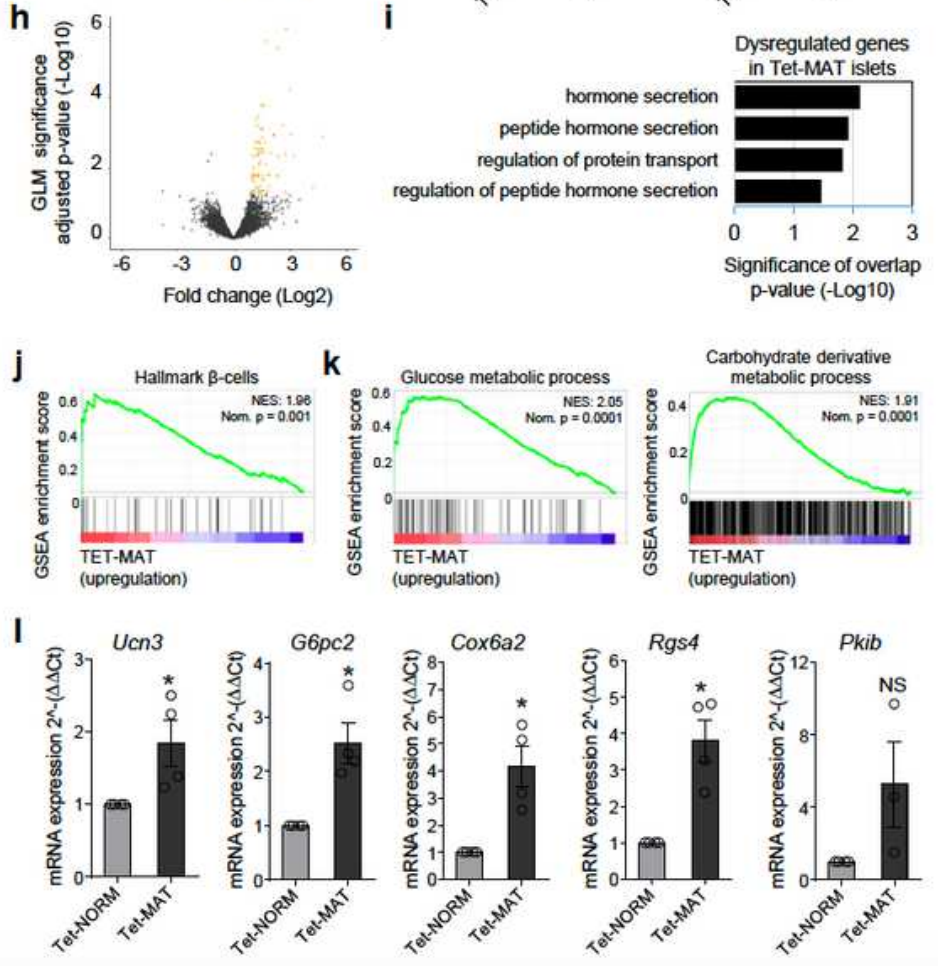

\section{Figure 8}

Differences in $\beta$-cell maturity influence islet gene expression. a Recombination of RIP7rtTA and TetO/M3C mice allows doxycycline-inducible changes in $\beta$-cell maturity in Tet-MAT but not Tet-NORM (control) islets. b Pdx1, Mafa and Neurog3 expression increases following incubation of Tet-MAT islets with 100 $\mathrm{ng} / \mathrm{ml}$ doxycycline for 48 hours ( $\mathrm{n}=3-5$ animals; paired t-test). c, $\mathrm{d}$ A significant decrease in the number of relatively immature $\beta$-cells (PDX1LOW) is seen in doxycycline-treated Tet-MAT islets, as shown by 
representative images (c), as well as the loss of cells in the lowest fluorescence intensity bins (d) (twoway ANOVA; $n=6$ islets $/ 3$ animals) (scale bar $=20 \mu \mathrm{m})(F=41368, D F=20)$. e-g Mean traces $(e)$ and bargraphs ( $\mathrm{f}$ and $\mathrm{g}$ ) showing impaired glucose- and $\mathrm{KCl}$-stimulated $\mathrm{Ca} 2+$ rises in Tet-MAT but not TetNORM islets ( $n=33-37$ islets/ 4 animals; unpaired t-test). $\mathrm{h}$ Volcano plot of differential gene expression between Tet-NORM and Tet-MAT islets. Fold-change (Log2, $x$-axis) gene expression is plotted against adjusted $p$-value for differential gene expression (normalized by GLM, -Log10, $y$-axis). Colored dots represent Ensembl genes that are differentially regulated at an adjusted $p$-value $<0.05$ ( $n=5$ animals). $i$ Gene ontology analysis of differentially regulated genes in Tet-MAT islets. A set of 83 genes were functionally annotated using DAVID (adjusted $p$-value of < 0.05). j Gene set enrichment analysis (GSEA) suggests that genes belonging to the gene set "hallmark $\beta$-cells" are upregulated in Tet-MAT islets. Normalized enrichment score (NES) and nominal p-value is presented in the top left corner of the graph. $k$ GSEA analysis shows enrichment of genes belonging to glucose and carbohydrate derivative metabolic processes amongst the upregulated genes in Tet-MAT islets. I RT-qPCR analyses confirming upregulation of Ucn3, G6pc2, Cox6a2 and Rgs4 but not Pkib in Tet-MAT islets ( $n=3-4$ animals; paired t-tes). Bar graphs and traces show the mean \pm SEM. ${ }^{*} P<0.05,{ }^{*} P<0.01$ and NS, non-significant. 
a

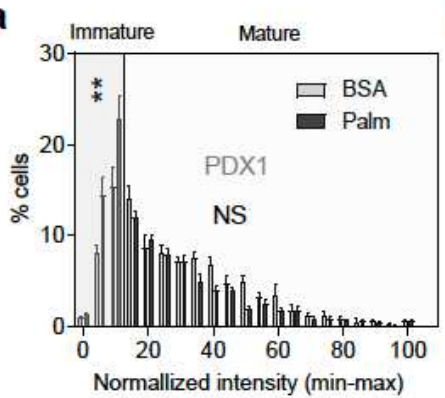

b

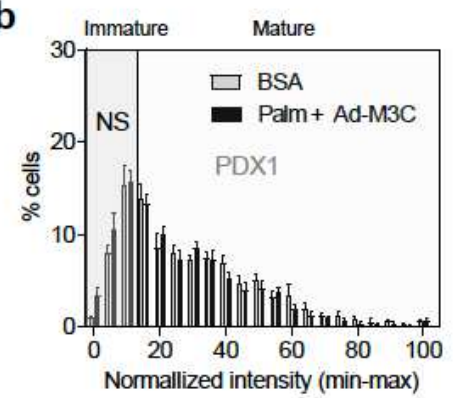

C
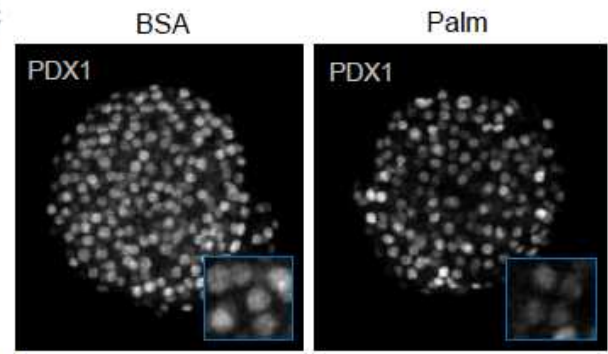

Palm + Ad-M3C
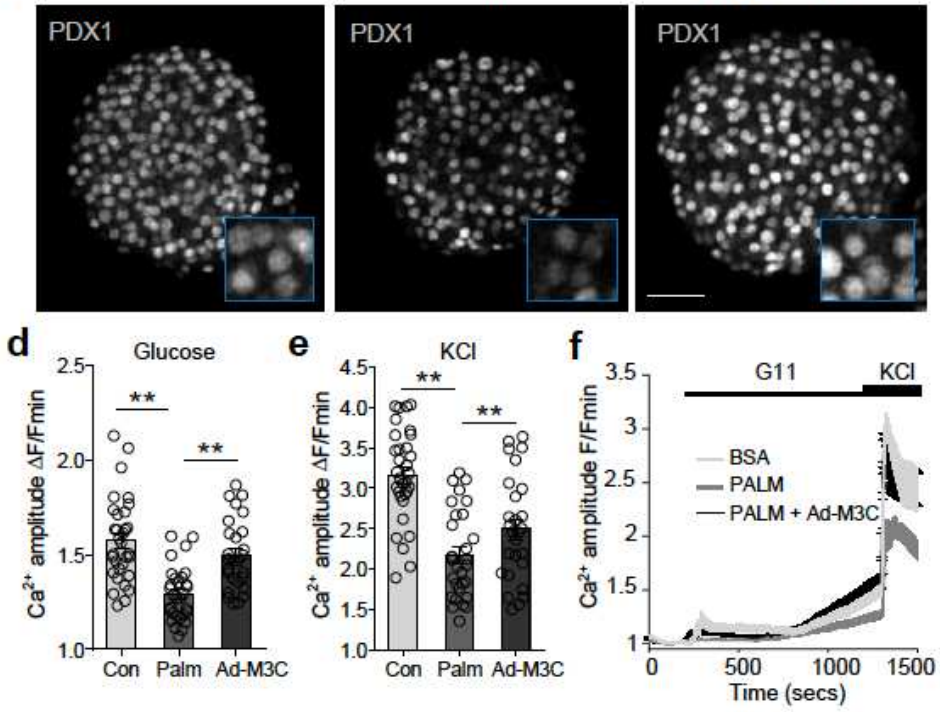

g
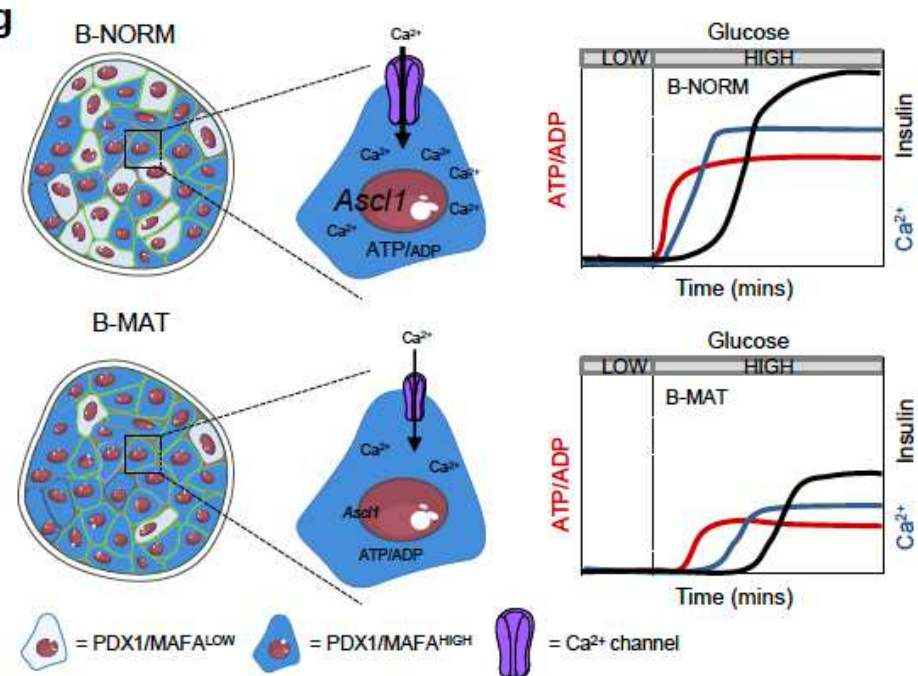

$=\mathrm{Ca}^{2+}$ channel

\section{Figure 9}

Maintaining immature-mature $\beta$-cell balance protects against islet failure. a-c A significant decrease in the proportion of PDX1HIGH $\beta$-cells is detected in palmitate-treated islets (a), and this can be reversed using Ad-M3C (b), as shown by representative images (c) ( $n=7$ islets/ 4 animals; two-way ANOVA) (Palm: $\mathrm{F}=4.28, \mathrm{DF}=20)($ Palm + Ad-M3C: $\mathrm{F}=0.90, \mathrm{DF}=20)(\mathrm{BSA}$, bovine serum albumin; Palm, $0.5 \mathrm{mM}$ palmitate for 48 hours; Ad-M3C, CMV-NEUROG3/PDX1/MAFA/mCherry) (scale bar $=42.5 \mu \mathrm{m}$ ). Note that 
the same BSA-only (control) PDX1 fluorescence intensity distribution is shown in both graphs (a) and (b) to allow cross-comparison (the experiments were performed in parallel). d-f $\mathrm{Ca} 2+$ responses to glucose (d)and $\mathrm{KCl}(\mathrm{e})$ are blunted in palmitate-treated, but not palmitate + Ad-M3C-treated islets(one-way ANOVA; $\mathrm{n}=27-32$ islets $/ 4$ animals $(\mathrm{G} 11: \mathrm{F}=18.80, \mathrm{DF}=2)(\mathrm{KCl}: \mathrm{F}=23.13, \mathrm{DF}=2)$, as shown by mean traces $(\mathrm{f}) \cdot \mathrm{g}$ Schematic showing that a decrease in the proportion ofPDX1LOW/MAFALOW $\beta$-cells leads to altered islet $\mathrm{Ca} 2+$ fluxes, decreased expression of $\mathrm{Ca} 2+$-dependent genes such as Ascl1, and broader changes to $\beta$ cell function including impairedATP/ADP and insulin responses to glucose. Bar graphs and traces show the mean $\pm S E M .{ }^{*} P<0.05,{ }^{*} P<0.01$ and NS, non-significant.

\section{Supplementary Files}

This is a list of supplementary files associated with this preprint. Click to download.

- Nasteskaetal2020NatCommuntransferSIrevision3final.pdf

- RepSum.pdf 